\title{
Geochemical anomaly separation by statistical and fractal methods in the Sehezar Valley of Tonekabon - Northern Iran
}

\author{
Meysam Yazdania ${ }^{2}$ Firouz Alinia ${ }^{a^{*}}$
}

a. School of Mining and Metallurgy Engineering, AmirKabir University of Technology, Tehran, Iran.

\section{Abstract}

Sehezar area is located in southern Tonokabon in Mazandaran province, north of Iran, near the Tarom - Hashdtjin belt. The existence of granitoid masses in the region can be important in terms of the potential of mineralization. Geochemical anomaly separation from the background is one of the important steps in mineral exploration. In the past decades, geochemical anomalies have been identified by means of various methods. Some of these separation methods include: statistical analysis methods (like univariate, bivariate, multivariate statistics), spatial statistical methods and fractal and multi-fractal methods. To identify the anomalous area, 71 stream sediment samples were collected from the area and analyzed by the ICP-MS method, and then interpreted. Initially, data were normalized and afterwards, univariate analysis (threshold limit and screening (P.N) methods) was used, in which results of the probable and definite anomaly of the threshold method were confirmed by the P.N screening method. Finally, the maps of the anomal zones were drawn. Then, bivariate analysis (Pearson correlation coefficients) and multivariate analysis on normal data

\footnotetext{
* Corresponding author at: School of Mining and Metallurgy Engineering, AmirKabir University of Technology, Tehran, Iran. +98 912 1036419, E-mail address: aliniaf@aut.ac.ir meysamyazdani@aut.ac.ir.
} 
were performed on SPSS software, in which factor analysis and cluster analysis were used for multivariate analysis. As a result of using the factor analysis method, six factors were identified and factor maps were drawn by the Surfer software. Also, by using cluster analysis, the variables were divided into two groups. In order for a better separation of the geochemical anomaly from the background, in addition to the threshold method, the Concentration - Area fractal method was used. Here, the fractal geometry using full-logarithmic graphs of the Concentration - Area obtained is capable of separating the stairs of different sections (background, threshold, and anomaly) with respect to the angle coefficient of the Concentration - Area plot. Then, in conclusion, results of these methods were compared and investigated, and finally, the anomalies area maps of the $\mathrm{Au}, \mathrm{Ag}, \mathrm{Cu}, \mathrm{Fe}, \mathrm{W}$ elements were drawn by Concentration - Area fractal and threshold methods and anomalous zones were introduced.

Keywords: Sehezar, Geochemical anomaly separation, Threshold, Factor analysis, Cluster analysis, Concentration - Area fractal. 


\section{Introduction}

Sehezar area is located in southern Tonokabon in Mazandaran province, between $36^{\circ}$ 27 'and $36^{\circ} 35^{\prime}$ latitude North and $50^{\circ} 45^{\prime}$ 'and $50^{\circ} 55^{\prime}$ longitude East. In the study area, the most important intrusive body related to Sehezar is granite mass.

So far in this the region, many studies have not been carried out. The studies that were conducted include: prospecting and Lithogeochemical survey and stream sediment geochemical by Madankav Company in 1998, and a semi-detailed exploration in the Arud area of Sehezar Valley by Kavoshgaran Company in 2014. Also, Rezvani and Ghorbani in their master's thesis studied the lithogeochemical and stream sediment geochemical of Sehezar valley granite. In previous works, a strong anomaly of the iron type of magnetite was observed.

Identifying different elements anomalies from the background in geochemical exploration is the most important section. For anomaly separation in geochemical exploration, various statistical methods were used (Cheng et al., 1994). That involves the use of probability plot and univariate and multivariate analysis methods (Grigorian and Ziaii, 1997). Methods of multifractal IDW and concentration - Area fractal (Cheng, 1999; Cheng and Grunsky 2000; Lima et al., 2003) and concentration- perimeter (Cheng et al., 1996) and concentration - distance (Li et al., 2003) are relatively new methods that are being used in mineral exploration.

Mandelbrot (1983), with the writing and presentation of a valuable book, officially introduced fractal geometry to the world as a new branch from the knowledge of geometry. Continuous being different dimensions and self-similarity of shapes are the base of this geometry. This theory was used in various fields of earth sciences and mineral resources studies since the 1980s (Turcotte, 1986; Agterberg et al., 1996). 
Studies conducted by Cheng et al. (1994) showed fractal correlation between concentration and the focus of elements and geometric characteristics of their geochemical dispersion. Several methods of fractal were used for geochemical exploration and the detection of anomalies, that is, including the methods of concentration - area (Cheng et al., 1994), power spectrum - area (Cheng, 1999), concentration - distance (Li et al., 2003) and concentration - number (Hassanpour and Afzal, 2013). Spatial distribution of most of the elements in the geochemical geological environment is the result of geological processes such as volcanism or intrusive body, sedimentary processes, tectonics, alterations and mineralization processes. These processes have self-similarity properties; therefore, they can be considered fractal or multifractal (Afzal et al. 2016).

The results of the traditional methods based on classical statistics have shortcomings, such as the requirement to follow normal distribution, delete some data as outliers, lack of attention to the distribution of data and lack of attention to the anomalies geometry (Davis, 2002). The basis of classical statistical methods are the calculation of statistical parameters related to the entire region, in which the separation of communities are done by using various parameters and the value of about average (Hassani pak and Sharafodin, 2011).

The concentration - area fractal method in geochemical exploration is for the separation of anomalous communities from background, which were provided for the first time in 1994 by Cheng et al. based on the fractal theory of geochemical distributions in nature (Cheng et al., 1994). The logarithmic plot of concentration against the cumulative area at some point's breaks or in other words, it gives the change of steep slope, which represent the change from background to the different 
degrees of anomalies and consequently, changes in geological condition, especially mineralization (Agterberg et al., 1996). The concentration - area fractal method is based on the amount of area that each particular concentration occupies in the study area. With an increase in the amount of element concentration, the amount of occupied area is reduced. By drawing the area, changes in concentration of the logarithmic plot can calculate dimensions of each community just through the slope of the fitted line. Breakpoints (change the slope of the fitted line) in this plot represent changes of one population to another population, so that in addition to separating the background, it can separate anomalies with varying degrees of an element and even in some cases, major and minor mineralization related to an element (Li, et. al., 2003). Changes of a population to another population represent the geological, geochemical and mineralogical conditions. This unique ability is due to the fractal nature of the distribution of elements in nature, which results in the need to remove the outlier value, and because of the fractal nature of the data, the data will automatically be neutral (Agterberg, et. al., 1996; Goncalves, et al., 2001). Due to many reasons including the consideration of spatial distribution of data and anomalies geometry and the use of all data without modification, fractal methods have had many applications in surface geological and geochemical studies (Davis, 2002). Overall, geochemical data have multifractal behavior that indicate geochemical changes, alteration, mineralization and subsequently the enrichment process of one element (Lima et al., 2003).

The first method in statistical investigations is univariate statistical studies. Due to the the relative simplicity of univariate analysis, these methods often used shallowness, especially in the studies that generally considered the multivariate methods (Hassani pak and Sharafodin, 2011). There are various statistical methods to determine the 
threshold limit and anomaly values, and the final anomalies will be chosen by comparing the results of each method (Hassani pak and Sharafodin, 2011). These methods include:
A. Threshold limit method of $\bar{x}+t s$
B. P. $N^{1}$ method
C. Gap statistical method

Principal Components Analysis is from multivariate statistical methods based on eigenvalues, in which by using eigenvalues and eigenvectors, directions with the highest variability are detected. Then by defining the new variables (Principal Component) that are linear combinations of the initial variables, the dimensions of initial variables are reduced and the role of each of these variables is determined in the variability. In other words, this method is a way to find a linear combination of correlated initial variables, which constitute a new coordinate axes and its aims are to justify a large part of the variability between observations, that appear to form $\mathrm{N}$ points in the space of P dimensions (Howarth \& Sinding-Larson, 1983).

The purpose of this study was to identify regions of anomalous elements by using univariate analysis (threshold limit and PN methods), bivariate analysis (correlation coefficient), multivariate analysis (cluster analysis and factor analysis) and concentration - area fractal methods, based on the data obtained from stream sediments in the study area and by using Arc Gis, Excel, SPSS, Matlab, and Surfer Softwares.

\footnotetext{
${ }^{1}$ Probability Number
} 


\section{Geological setting of study area}

The geological structures in the surrounding outcrop range are mainly comprised of Paleozoic to Cenozoic rock units. The oldest outcropped rocks in the region are the equivalent constructive of Kahar and Lalun that represent the continental margin sediments, and after that is the volcanic complex with Silurian age that represents the failure stages and perfect opening of the primary platform. The presence of Carboniferous carbonate sediments and Permian and Triassic clastic carbonate represent a shallow marine environment and continental conditions. Middle and upper Jurassic carbonate sediments were lack of Continuity with Cretaceous sediments, in which volcanic rocks and upper Cretaceous limestone introduced the part of the sequence of shell environments of the continental margin. After that the Tertiary intrusive activities were observed to form the Granitoid intrusive body. Fig. 1 is the geology and stream map of the study area. . In Fig. 2, the location of the studied area is presented in the worldview satellite image. In Fig. 3, the location of the studied area is presented in the major structural zones map of Iran.

\section{Material and methods}

In this study, the evaluated data corresponding to 71 stream sediment samples were taken at Sehezar Valley of Tonekabon, and measured in the laboratory by the Thermo Electron X-series inductively coupled plasma mass spectrometer (ICP-MS).

At first the statistical parameters were calculated by SPSS 22 software. The most important issue in the analysis of geochemical data is to determine the threshold limit of each element and separation of anomaly from background in the region, and cannot identify anomalous areas just by using the traditional methods and geological information accurately. However, due to this fact, the methods of univariate analysis, 
bivariate analysis, multivariate analysis and the concentration - area fractal method were used to identify the areas of high potential.

\section{Results and Discussion}

\subsection{Univariate analysis}

\subsubsection{Threshold limit method}

At first, data was normalized and the Kolmogorov - Smirnov non-parametric test also helps to accurately determine the normality of the population. In the KolmogorovSmirnov non-parametric test, if the value of Asymp. Sig. (2-tailed) specified in the table was above 0.05 , it indicates that the population distribution follows from a normal distribution (StatSoft, 2007). The results of this test for normalized data for some elements in Table 2 show that the data were normalized well. Histograms and Q-Q and P-P plots of some elements before normalization and after normalization are presented in the Appendix that shows the data are normalized (Fig. A. 1 to Fig. A. 30).

The application of classical statistics is based on the assumption of independence of samples and normality of their distribution. Certain conversions usually were used for normal of values from univariate geochemical data set (Carranza, 2009).

The threshold method was used for drawing the map, which is one way to understand the relationship between data and checked information in an exploration project. For drawing the map of elements anomaly, their threshold must first be obtained, in which the background and standard deviation value should be specified for determining by the $\bar{x}+t s$ method.

The most common statistical method to determine the value of the threshold is putting it equal to its average or median (or their logarithmic) plus one, two or three times the 
standard deviation. In this study, the threshold limit value was considered as the mean value plus the standard deviation. To distinguish between possible anomalies and glitch anomalies (high-intensity anomalies), the threshold value plus the standard deviation of each variable was used.

Thus, for each element five quite distinct groups were identified. After the statistical processes and obtaining the relevant parameters, the samples known as anomaly were identified in this manner, and the results are shown in Table 1 . The yellow cells indicate possible anomalies and red cells indicate the high-intensity anomaly of elements. Symbolic and distribution maps of anomalies from $\mathrm{Au}, \mathrm{Ag}, \mathrm{Cu}, \mathrm{Fe}$ and $\mathrm{W}$ elements are shown in Fig. 19 to Fig. 32, and other elements have weak anomalies or do not have any anomaly.

\subsubsection{P.N method}

The logic of the P.N. method for detection of anomalous values is based on two principles: one is the increase in variable value and another is the increase in its relative frequency. Thus, the intensity of each anomaly is dependant on two factors (Hassani pak and Sharafodin, 2011):

1- With the possibility of the emergence of a sample at the desired value $(P)$, the smaller the possibility, the anomaly intensity will be more in its reagent sample.

2- With the number of samples taken $(\mathrm{N})$, the smaller the value, the stronger the anomaly intensity.

So the multiplication of two factors, namely $\mathrm{P} \times \mathrm{N}$, can be used as a criterion for selection of the anomaly. Obviously, the smaller this value is than unity, the anomalies have more intensity, because in normality mode, multiplying the number of samples 
with an assumed grade at a probability of its grade occurrence will be unit. The P value for each element in each sample is equal to the probability of occurrence of the greater or equal value of the investigated variable in the intended sample.

In this study, the code of this method was coded in MATLAB software (Fig. 4) and then for the study the data were applied. The results of samples were as anomalies shown in Table 1, the yellow cells indicating the probable anomalies with the P.N value between 1 to 0.1 and the red cells indicating a high-intensity anomaly with the P.N value less than 0.1 . The majority of probable and high-intensity anomalies from the threshold limit method were confirmed by the anomalies of this method, as shown in Table 1.

\subsection{Bivariate analysis}

\subsubsection{Calculate and interpret the correlation coefficient between the elements}

There are several methods for the calculation of correlation coefficients, the most common being Pearson and Spearman's rank methods. The Pearson method was used to determine the correlation coefficient in this study.

According to the results of Pearson's correlation coefficient, the most logical of coefficients can be stated as below (Table A. 1):

$\checkmark \mathrm{Cr}, \mathrm{Co}, \mathrm{Ni}, \mathrm{Ti}, \mathrm{Sc}$ and $\mathrm{V}$ had a positive correlation, and an increase in each of these elements lead to an increase in other elements.

$\checkmark$ Elements Al, Ba, Be, Y and Th showed a good positive correlation with other elements. In most cases, these correlations were related to lithological properties of rocks and did not result in specific mineralization, but these elements should be further investigated. 
$\checkmark$ Strong positive correlations were observed between the Fe and the elements of V, Ti, La, Co, Ce and Cr. Fe also indicated the weak positive correlation with most other elements.

$\checkmark$ Au had weak positive correlation with other elements and its highest correlation was observed with the elements of $\mathrm{Ba}, \mathrm{Y}, \mathrm{Mg}, \mathrm{Fe}$ and $\mathrm{Zn}$.

$\checkmark \mathrm{Cu}$ had a strong positive correlation with $\mathrm{Ni}, \mathrm{Co}, \mathrm{Cr}, \mathrm{Y}$ and $\mathrm{Zr}$ and also a strong negative correlation with $\mathrm{Ag}, \mathrm{Bi}$ and $\mathrm{Sr}$.

$\checkmark \mathrm{Pb}$ and $\mathrm{Zn}$ together had a good positive correlation with $\mathrm{Y}, \mathrm{Zr}, \mathrm{Cu}$ and $\mathrm{W}$ and also a negative correlation with $\mathrm{Sr}$ and $\mathrm{Bi}$.

$\checkmark$ W had a weak positive correlation with other elements and only a strong positive correlation with $\mathrm{Pb}$ and a medium positive correlation with $\mathrm{Zn}$ and Mo.

\subsection{Multivariate analysis}

\subsubsection{Cluster analysis}

The cluster analysis method is a multivariate analysis method, and the variables are classified in a certain category based on their correlation. Since every given group of elements show a similar behavior to a set of environmental conditions, understanding the relation and mutual genetic correlation between the various elements can be used to accurately identify the changes in geochemical environments. The genetic accumulation of some elements may be used as a direct guide to commentary of deposit kind the possible exist in region.

Cluster analysis methods were established based on the relative detection of homogeneous groups from variables or samples based on selected characteristics and by using an appropriate algorithm. In this method, each variable or sample is located 
in a separate cluster and then by combining clusters it is finally connected to a single cluster (Coakes and Steed, 2009).

The result of cluster analysis of the Sehezar region was provided as a tree plot in Fig. 5. Accordingly, the tree plot can achieve the results below:

According to this classification, the variables were categorized into two groups. The first group was associated with the mineralization and includes two subgroups (subgroups I and II) and the second group was associated with the series of sedimentary rocks and was divided into two subgroups (subgroups III and IV). The variables were located in the four subgroups with good correlation as below:

$\checkmark$ The first subgroup: includes elements of Fe, V, Ti, Ce, La, Cr, Co, P, Zr, Cu, Ni, $\mathrm{Y}, \mathrm{Be}, \mathrm{Al}, \mathrm{K}, \mathrm{Na}, \mathrm{Sc}, \mathrm{Mn}$, and $\mathrm{Au}$.

$\checkmark$ The second subgroup: includes elements of $\mathrm{Pb}, \mathrm{Zn}, \mathrm{Cd}$ and As.

$\checkmark$ The third subgroup: includes elements of $\mathrm{Bi}, \mathrm{Sr}, \mathrm{Ag}, \mathrm{S}$, and Mo.

$\checkmark$ The fourth subgroup: includes elements of $\mathrm{Mg}$ and $\mathrm{Ca}$.

In this area, the rocks had an outcrop variety of sedimentary (chemical, clastic and evaporative), volcanic and acidic plutonic and metamorphic rocks and there were more than one rock kind in the drainage basin of more samples. This heterogeneity of upstream rocks caused heterogeneity in cluster analysis, and in some clusters the heterogeneous elements were located together. Accordingly, this can be explained briefly below:

$\checkmark$ The first subgroup had 10 subcategories. The first subcategories include elements of $\mathrm{V}, \mathrm{Ti}$ and Fe that have a strong correlation with each other. The correlation of elements $\mathrm{V}, \mathrm{Ti}$ and $\mathrm{Fe}$ in the first subcategory were often 
associated with mafic minerals at the intrusive body, so these correlations were approved by Pearson's correlation table.

$\checkmark$ The second subgroup was divided into three subcategories, at first the subcategory of the elements of $\mathrm{Pb}$ and $\mathrm{Zn}$ were side by side with a strong correlation.

$\checkmark$ The third subgroup was divided into three subcategories. The third subcategory includes elements of S and Mo that were side by side with a strong correlation and then it was connected to the first and second subcategories.

$\checkmark$ The fourth subgroup includes a subcategory. The fourth subgroup includes alkaline earth elements that are often associated with a series of sedimentary rocks.

Overall, from this cluster analysis it be understood that the lithological elements were at the second group, which had a different association with mineral elements. The first group had a good relationship with mineralization and mineral paragenesis was interesting.

\subsubsection{Factor analysis}

The factor analysis method is another way to reduce the volume of data and determine the relationship between different groups of variables (StatSoft, 2007). The purpose of factor analysis is to identify the main controller variables from the variable with less significance. Thus, it is possible to explain maximum variability between data and the relative contribution of each factors variable is identified in justification with the minimum number of factors variables (Carranza, 2009).

At first, the suitability of the data for performing these calculations should be evaluated. For this purpose, we use $\mathrm{KMO}$ and Bartlett's tests. The closer the $\mathrm{KMO}$ value is to one, 
it further confirms the factor analysis (Coakes and Steed, 2009). For the values of about 0.9 of this parameter, factor analysis is very suitable. For the values of about 0.8 factor analysis is suitable, about 0.7 is balancing, about 0.6 is average, about 0.5 is poor, and less than that is unsuitable. Finally, the optimal factors number is determined according to the fraction of the variance of each factor to cumulative variance (Carranza, 2009).

The KMO value for the data of this study was 0.784 , which indicated that factor analysis results were balancing (Table 3 ). The reason for the low $\mathrm{KMO}$ value could be due to the low number of data.

The scree plot (Fig. 6) shows calculated eigenvalues which were sorted in terms of importance from the largest to smallest value (Coakes and Steed, 2009). This plot is used to determine the optimal number of factors. According to this plot, from factor 6 onwards changes of eigenvalue were low. So 6 components have the most influence in determining the variance value (StatSoft, 2007).

Eigenvalues, variance percent and variance's cumulative percentage corresponding to the parameters were calculated and then values greater than 1 ( 6 values) have been extracted and rotated (Coakes and Steed, 2009). Based on these results, the largest eigenvalues (variances) are related to the first, second and third components, their variability percentages are 30.307, 18.822 and 14.846, respectively. These 6 factors allocated to themselves totaling $84.032 \%$ of the variance (StatSoft, 2007).

As these results suggest, the sum of eigenvalues percentage of all variables based on the PCA will be $100 \%$ if all the variables are included in the calculations. However, the purpose here is to reduce the dimensions of the variables, so after loading calculations 
in the initial state and then in the rotation mode with the Varimax function, number 6 factors were determined which the total covers approximately $84.032 \%$ of the overall variance. The 6 factors are identified and aligned in the Rotated Component Matrix Table (StatSoft, 2007) (Table 4).

Finally, after conducting factor analysis, the 6 factors were introduced in accordance with Table 4, which is as follows.

- Factor 1: Includes elements of Ni, Y, Cr, Ce, Co, Fe, La, Na, Ti, V, Ag and P, and the covering variance of this factor is $30.307 \%$ and its highest correlation is with $\mathrm{Cu}$ from factor 2.

- Factor 2: Includes elements of $\mathrm{Pb}, \mathrm{Zn}, \mathrm{Zr}, \mathrm{As}, \mathrm{Bi}, \mathrm{Cd}, \mathrm{Cu}$ and $\mathrm{Sr}$, in which the highest correlation is with Ni from factor 1 and its covering variance is $18.822 \%$.

- Factor 3: Includes elements of $\mathrm{Al}, \mathrm{Sc}, \mathrm{Ca}, \mathrm{Mn}$ and $\mathrm{K}$, the covering variance of this factor is $14.846 \%$.

- Factor 4: This factor with $8.084 \%$ covering variance includes elements of S and Mo, and its highest correlation is with Ag from factor 1 and As from factor 2.

- Factor 5: Includes elements of Be and Mg, and its highest correlation is with La and $\mathrm{Na}$ from factor 1 , with a covering variance of $7.37 \%$.

- Factor 6: includes element of Au, and its highest correlation is with factor 1 , with a covering variance of $4.602 \%$.

According to the cluster and factor analysis results in Table 4 and correlation coefficient results, we find that these two methods are almost overlapping. As in the correlation coefficients table, there are strong correlations between the Fe and the elements of $\mathrm{V}$, Ti, La, Co, Ce and Cr. Here, these elements are also located in a factor (factor 1). 
In general, for factor analysis, factors are to be sorted based on the amount of share of variance, which is allocated to themselves, and the variance amount also depends on expanding its constituent factors on the range (lithology or mineralization).

According to the results of this analysis and cluster analysis we noticed many similarities between these two analyses. Factors 3, 4 and 5 have often been associated with lithological agents and were participated in Petrogenesis processes of the region. The first factor was associated with the intrusive body of the region and the third and fifth factors were associated with clastic sedimentary rocks and Precambrian tuff equivalent with Kahar formation. Due to the variety of rock units (sedimentary, igneous and metamorphic), more accurate interpretations are with error. In factors 1, 2 and 6, the presence of mineral elements, which can be associated with mineralization agents are important and will be considered in the field control phase. These groups include mineral elements and can show Paragenesis of mineralization in the region.

Distribution maps of factors using Surfer software and Kriging interpolation were plotted (Fig .7 to Fig. 12). According to the maps of factors 1, 2 and 6, that correspond to mineralization in this region, the Arud region is the focus of these factors more than other regions.

\subsection{Concentration - Area fractal method}

One of the fractal's new methods for separation of anomaly from background is the Concentration - Area fractal method, which is one of the strongest methods with a high safety factor. The Concentration - Area fractal method in geochemical exploration for the separation of anomaly communities from background is based on the fractal behavior of geochemical distributions in nature. 
In choosing a certain way from among the various methods available to detect geochemical anomalies, it should be noted that none of the available methods to detect and identify anomalies are independent of Geological Sciences, and for any interpretation of the results obtained, they should to be consistent with geological information. The Concentration - Area fractal method is based on the amount of area that each particular grade is occupied in the study area. The more the grade of the element is increased, the amount of its occupied area should be decreased. One of the most common methods for displaying grade distribution of an element in an area is mapping the grade distribution contour map of the corresponding element in the study area. If the grade value of each contour equal to $v$ is considered, we can provide a power equation as below for materials to focus on fractal properties.

$$
A(\geq V) \infty V^{-\alpha}
$$

$\mathrm{A}(\mathrm{V})$ is enclosed cumulative area by grade contour lines, in which their corresponding grade is greater than or equal to $v$. The $\alpha$ amount in fact represents the fractal dimension related to V's different domains. By drawing the area changes against grade at the logarithmic plot can calculate the dimension of each community through the steep slope of its fitted lines. Breakpoints (change in slope of the fitted line) in this plot represent changes from one community to another community, so that in addition to the separate background, they can separate anomalies with a varying degree of an element and even in some cases major and minor mineralization related to it from each other. Changes from one community to another community represents the geological, geochemical and mineralogical conditions. This unique ability is because of the nature of the fractal elements distribution in nature (Heidari et al.; 2013 Afzal et al. 2012). 
The first task at this step was conducted in the ArcView GIS Software, and geochemical grades between points sampled were interpolation, using Kriging for mapping the grade contour lines, and the grade contour lines map was obtained and then the area between the lines was determined. For drawing the concentration - area plots of data, be sure that first the results of estimating the network for classification are based on grade (from greater to least grade, preferably). To this end, the grade changes range of each category, average of its grade and the number of cells in this grade range are located in a statistical estimation of the community of existing data which were calculated and the necessary data for drawing the logarithmic plot of grade against the area logarithm were provided.

In order to determine the fractal dimension for each community, the scatter plot of area basins of each section was drawn based on its corresponding grade in the logarithmic scale. A power relationship is established between the grade and the areas of the basins. Thus, different communities are separated by using it.

\subsubsection{Gold concentration - area logarithmic plot}

Fig. 13 shows the $(C-A) \log -\log$ plot of $A u$ in the study area. As you can see, this plot consists of 3 lines with different slopes and amount of occupied area decreases with the increase in the element grade. Each line represents a different geochemical community. The line equations of $(C-A) \log -\log$ plot were obtained in the Excel software setting, and then the fractal dimension of each community was determined. As we can see, the fractal dimension of the first community is $\alpha=0.009$ and the fractal dimension of the second and third communities are $\alpha=1.713$ and $\alpha=10.58$, respectively. Since the fractal dimension of the three communities are very different, as a result there are three geochemical communities. The first line represents the 
background community and its intersection point with the second line is the threshold and the subsequent values are the anomaly community. Au's anomalous threshold is 38.8 ppb. Also, the fractal dimensions of the second and third communities are very different, that is indicating two completely different geochemical communities, and the intersection point of these two lines represents the high-intensity anomaly, for which Au's high-intensity anomaly is $479.1 \mathrm{ppb}$.

\subsubsection{Silver concentration - area logarithmic plot}

Fig. 14 shows the $(C-A) \log -\log$ plot of $A g$ in the study area. As you can see, this plot consists of 4 lines with different slopes and the amount of occupied area decreases with an increase in the element grade. Each line represents a different geochemical community. The lines equations of (C - A) log-log plot were obtained in the Excel software setting, and then the fractal dimension of each community was determined. As we can see, the fractal dimension of the first community is $\alpha=0.143$ and the fractal dimension of the second and third communities are $\alpha=7.617$ and $\alpha=4.468$ respectively, and since the slope of these two lines are close together and their fractal dimensions are slightly different, it seems that these two lines represent a community, and the fractal dimension of the next society is $\alpha=22.71$, that represents the anomalous community. As a result, there are three geochemical communities. The first line represents the background community and its intersection point with the second line is the threshold and the subsequent values are the anomaly community. Ag's anomalous threshold is $0.57 \mathrm{ppm}$. Also, the fractal dimensions of the second and third communities are very different, which indicates two completely different geochemical communities, and the intersection point of these two lines represents the high-intensity anomaly, for which Ag's high-intensity anomaly is $2.36 \mathrm{ppm}$. 


\subsubsection{Copper concentration - area logarithmic plot}

Fig. 15 shows the $(C-A) \log -\log$ plot of $\mathrm{Cu}$ in the study area. As you can see, this plot consists of 3 lines with different slopes and the amount of occupied area decreases with an increase in the element grade. Each line represents a different geochemical community. The line equations of the $(\mathrm{C}-\mathrm{A})$ log-log plot were obtained in the Excel software setting, and then the fractal dimension of each community was determined. As we can see, the fractal dimension of the first community is $\alpha=0.812$, the second fractal of the second community is $\alpha=4.986$, and the fractal dimension of the next community is $\alpha=31.81$ which indicates the anomaly community. As a result, there are three geochemical communities and since the fractal dimensions of the first and second communities are very different, the first line represents the background community and its intersection point with the second line is the threshold and the subsequent values are the anomaly community. Cu's anomalous threshold is 19.59 ppm. Also, the fractal dimensions of the second and third communities are very different, that is indicating two completely different geochemical communities, and the intersection point of these two lines represents the high-intensity anomaly, for which Cu's high-intensity anomaly is $31.39 \mathrm{ppm}$.

\subsubsection{Iron concentration - area logarithmic plot}

Fig. 16 shows the $(C-A) \log -\log$ plot of Fe in the study area. As you can see, this plot consists of 3 lines with different slopes and the amount of occupied area decreases with an increase in the element grade. As we can see, the fractal dimension of the first community is $\alpha=0.45$, the second fractal of the second community is $\alpha=3.649$, and the fractal dimension of the next community is $\alpha=9.256$ and this indicates the anomaly community. As a result, there are three geochemical communities and since the fractal 
dimensions of the three communities are very different, the first, second and third lines represent the background, threshold and anomaly communities, respectively, and the intersection point of the first line with the second line is the threshold and the intersection point of the second line with the third line is high-intensity anomaly. Fe's anomalous threshold and its high-intensity anomaly are 30175.31 ppm and 38934.33 ppm, respectively.

\subsubsection{Tungsten concentration - area logarithmic plot}

Fig. 17 shows the $(C-A) \log -\log$ plot of $W$ in the study area. As you can see, this plot consists of 3 lines with different slopes and the amount of occupied area decreases with an increase in the element grade. As we can see, the fractal dimension of the first community is $\alpha=4.049$, the second fractal of the second community is $\alpha=12.08$, and the fractal dimension of the next community is $\alpha=37.32$, which indicates the anomaly community. As a result, there are three geochemical communities and since the fractal dimensions of the three communities are very different, the first, second and third lines represent the background, threshold and anomaly communities respectively, and the intersection point of the first line with the second line is the threshold and the intersection point of the second line with the third line is the high-intensity anomaly. W's anomalous threshold and its high-intensity anomaly are 1.91 ppm and 2.14 ppm, respectively.

After calculating the anomalous threshold and the high-intensity anomaly for the elements, their results are presented with the help of Surfer software and by the Kriging interpolation as the distribution maps of the promising areas (Fig .18 to Fig. 32). 


\section{Conclusions}

The statistical methods used in this project showed relatively similar results. According to the Pearson Correlation Table, the highest correlation coefficients belong to the elements of $\mathrm{Pb}-\mathrm{Zn}$ (0.76), Cr-Co (0.82), Cr-Fe (0.86), Cr-Ti (0.87), Cr-V (0.88), Co-Fe 0.84), Co-Ti (0.85), Co-V (0.87), Ag-Co (-0.71), Cu-Ni (0.78), Cu-Zr (0.79), W-Pb (0.61) and the other numbers that are identified in table. Here, iron also has a positive correlation with gold and copper.

According to cluster analysis classification, the first group was associated with the mineralization and the second group was associated with the series of sedimentary rocks and also in the fourth subgroup, alkaline earth elements are often associated with a series of sedimentary rocks. Here, the three elements of iron, gold and copper are also located in the first group (mineralization).

According to the factor analysis, 6 factors and the factors map plotted in the Surfer software are identified. According to the results of factor analysis and cluster analysis, we noticed many similarities between these two analyses. Factors 3, 4 and 5 have often been associated with lithological agents and were participated in the Petrogenesis processes of the region. In factors 1, 2 and 6, the presence of mineral elements that can be associated with mineralization agents are important and will be considered in the field control phase. These groups include mineral elements and can show Paragenesis of mineralization in the region. According to the maps of factors 1 , 2 and 6, which correspond to mineralization in this region, in the Arud region the focus of these factors is more than other regions. Here, iron is located in the first factor, and gold after factor 6 has the highest correlation with this factor, and also, copper after factor 2 has the highest correlation with the first factor. As a result, we can conclude 
that these three elements (gold, copper and iron) are also related to a particular factor, the first factor.

By applying the concentration-area fractal method in the study area, the anomalous samples were identified and the promising region maps were eventually drawn. Also, nonstructural methods such as classical statistical methods were investigated. Based on the maps of the statistical methods and the fractal method, the focus of the data is more in the area of Arud and near the granitoid mass. The drawing of the corresponding anomaly maps shows that the skarn areas in the vicinity of the Ruteh and Mubarak formations have the highest amount of element anomalies. For this reason, further studies in the Sehezar area can continue in the vicinity of the skarn bodies area.

According to the elements anomalous maps (maps based on fractal and threshold methods and factors maps):

$>A u$ anomalies are located in the granitoid body of the region and in the northern parts of the Arud village, the result of factor analysis also confirms these areas, and $\mathrm{Au}$ is located in the sixth factor, and the sixth factor in these areas (Arud village) is anomalous.

$>\mathrm{Cu}$ anomalies are located between the village of Arud and Ghazi-Mahallah and in the northern parts of the Arud village on the margin of the granitoid body as well as in the western parts of the study area. The result of factor analysis also confirms these areas, and showsqw that $\mathrm{Cu}$ is located in the second factor, and this factor in these areas (in the southern parts of the region and between the village of Arud and Ghazi-Mahallah) is anomalous. 
$\mathrm{Ag}$ anomalies, like Au are located in the granitoid body of the region and in the northern parts of the Arud village, and Ag is located in the first factor, and the first factor in these areas (Arud village) is anomalous.

Fe anomalies are located in the granitoid body and more in the middle parts of the granitoid body, and Fe is located in the first factor, and this factor in the middle parts of the granitoid body is anomalous and confirms these results.

$>\mathrm{W}$ anomalies are located in the southern parts of the study area, between the village of Arud and Ghazi-Mahallah, and more in the southern parts of the Arud village.

The results of geochemical processes confirm the results of lithogeochemical studies with good accuracy. Accordingly, the study area is susceptible to sulfide mineralization similar to vein mineralization and or skarn mineralization for $\mathrm{Au}, \mathrm{Cu}$ and Fe elements.

\section{References}

Afzal, P., Tehrani, M. E., Ghaderi, M., \& Hosseini, M. R. (2016). Delineation of supergene enrichment, hypogene and oxidation zones utilizing staged factor analysis and fractal modeling in Takht-e-Gonbad porphyry deposit, SE Iran. Journal of Geochemical Exploration, 161, 119-127.

Afzal, P., Afshar, Z. Z., Khankandi, F. S., Wetherelt, A., \& Yasrebi, B. A. (2012). Separation of uranium anomalies based on geophysical airborne analysis by using Concentration-Area (CA) Fractal Model, Mahneshan 1: 50000 Sheet, NW IRAN. Journal of Mining and Metallurgy A: Mining, 48(1), 1-11. 
Agterberg, F. P., Cheng, Q., Brown, A., \& Good, D. (1996). Multifractal modeling of fractures in the Lac du Bonnet batholith, Manitoba. Computers \& Geosciences, 22(5), 497-507.

Carranza, E.J.M., (2009), Geochemical anomaly and mineral prospectivity mapping in GIS, Handbook of Exploration and Environmental Geochemistry, Elsevier B.V. Vol. 11.

Cheng, Q., Agterberg, F. P., \& Ballantyne, S. B. (1994). The separation of geochemical anomalies from background by fractal methods. Journal of Geochemical Exploration, 51(2), 109-130.

Cheng, Q. (1999). Spatial and scaling modelling for geochemical anomaly separation. Journal of Geochemical exploration, 65(3), 175-194.

Cheng, Q., Xu, Y., \& Grunsky, E. (2000). Integrated spatial and spectrum method for geochemical anomaly separation. Natural Resources Research, 9(1), 4352.

Cheng, Q., Agterberg, F. P., \& Bonham-Carter, G. F. (1996). A spatial analysis method for geochemical anomaly separation. Journal of Geochemical Exploration, 56(3), 183-195.

Coakes, S. J., \& Steed, L. (2009). SPSS: Analysis without anguish using SPSS version 14.0 for Windows. John Wiley \& Sons, Inc.

Davis, John.C., 2002, Statistics and data analysis in Geology, John Wiley and Sons Inc., NewYork, 638p. 
Ghorbani Samsoori, M., 2014, Lithogeochemistry and stream sediment investigation of granite lower sehhezar valley_toncabone, Master's thesis, Amirkabir University of Technology.

Goncalves, M. A., Mateus, A., \& Oliveira, V. (2001). Geochemical anomaly separation by multifractal modelling. Journal of Geochemical Exploration, 72(2), 91-114.

Grigorian, S. V., \& Ziaii, M. (1997). Computing methods for determination of geochemical haloes background. In International symposium, applied geochemistry in CIS. IMGRE.

Hashempour, M., 2011, prospecting of minerals in the Arud area of Sehezar Valley of Tonekabon; Iran.

Hassanpour, S., \& Afzal, P. (2013). Application of concentration-number (C-N) multifractal modeling for geochemical anomaly separation in Haftcheshmeh porphyry system, NW Iran. Arabian Journal of Geosciences, 6(3), 957-970.

Hassani Pak, A., \& Sharafodin, M. 2001, Exploration data analysis (background \& anomaly separation, Eng. probability \& statistics, ore reserve estimation), University of Tehran Press.

Hassani Pak, A. 2008, Principles of Geochemical Prospecting, University of Tehran Press. 
Heidari, S. M., Ghaderi, M., \& Afzal, P. (2013). Delineating mineralized phases based on lithogeochemical data using multifractal model in Touzlar epithermal Au-Ag (Cu) deposit, NW Iran. Applied geochemistry, 31, 119-132.

Howarth, R. J. \& Sinding-Larson, R., (1983)- In: R. J. Howarth(editor), Statistic and Data Analysis in Geochemical prospecting. Handbook of exploration Geochemistry, vol.2, Elsevier, Amesterdam, pp: 207-28

Li, C., Ma, T., \& Shi, J. (2003). Application of a fractal method relating concentrations and distances for separation of geochemical anomalies from background. Journal of Geochemical Exploration, 77(2), 167-175.

Lima, A., De Vivo, B., Cicchella, D., Cortini, M., \& Albanese, S. (2003). Multifractal IDW interpolation and fractal filtering method in environmental studies: an application on regional stream sediments of (Italy), Campania region. Applied Geochemistry, 18(12), 1853-1865.

Rezvani Manzari, M., 2015, Lithogeochemistry and stream sediment investigation of granite upper sehhezar valley_toncabone, Master's thesis, Amir Kabir University of Technology.

StatSoft, I. (2007). Electronic statistics textbook. Tulsa, OK: StatSoft.

Turcotte, D. L. (1986). A fractal approach to the relationship between ore grade and tonnage. Economic Geology, 81(6), 1528-1532. 


\section{Figure and table captions}

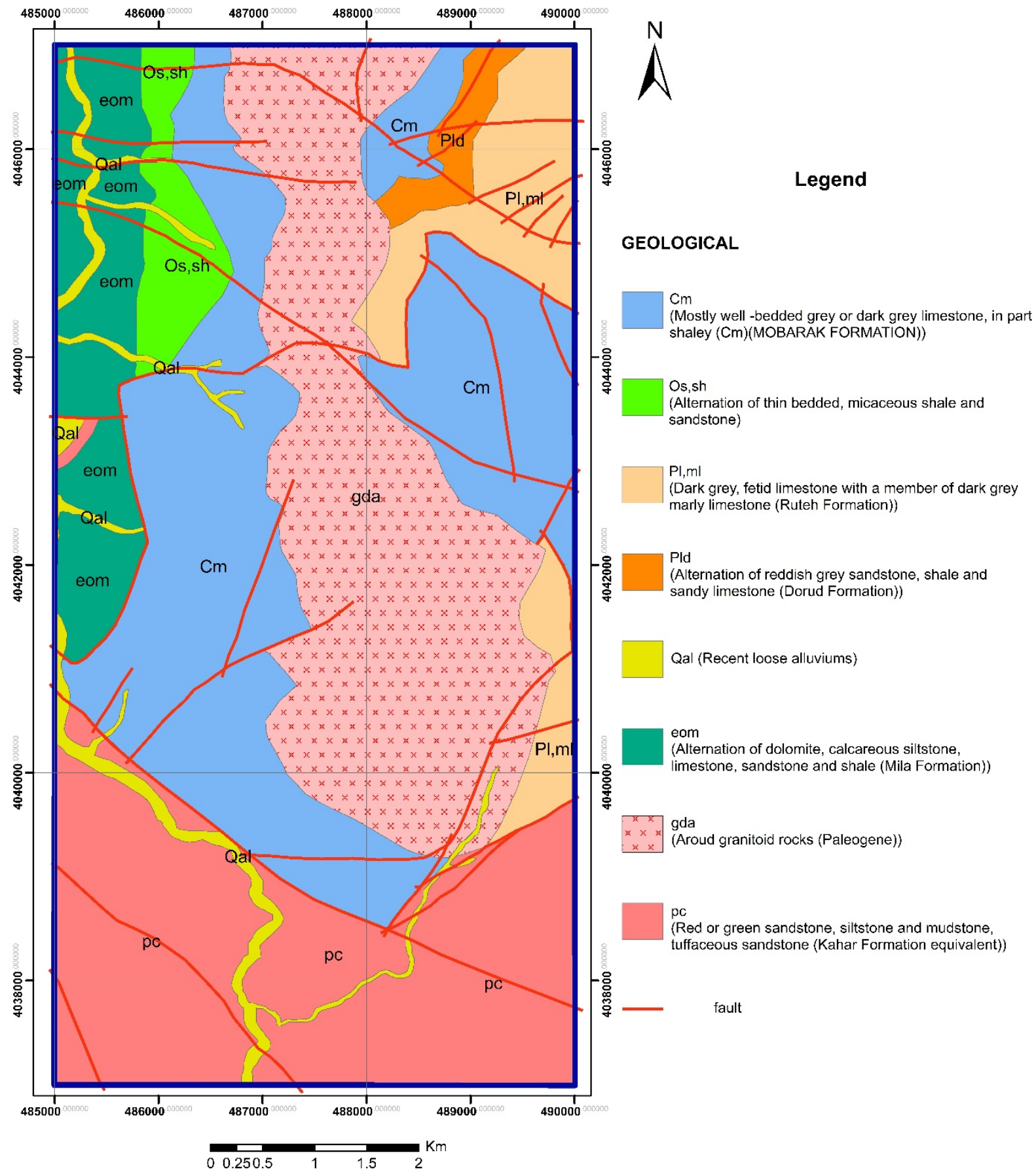

Fig. 1 Geology and stream maps of the Sehezar region. 


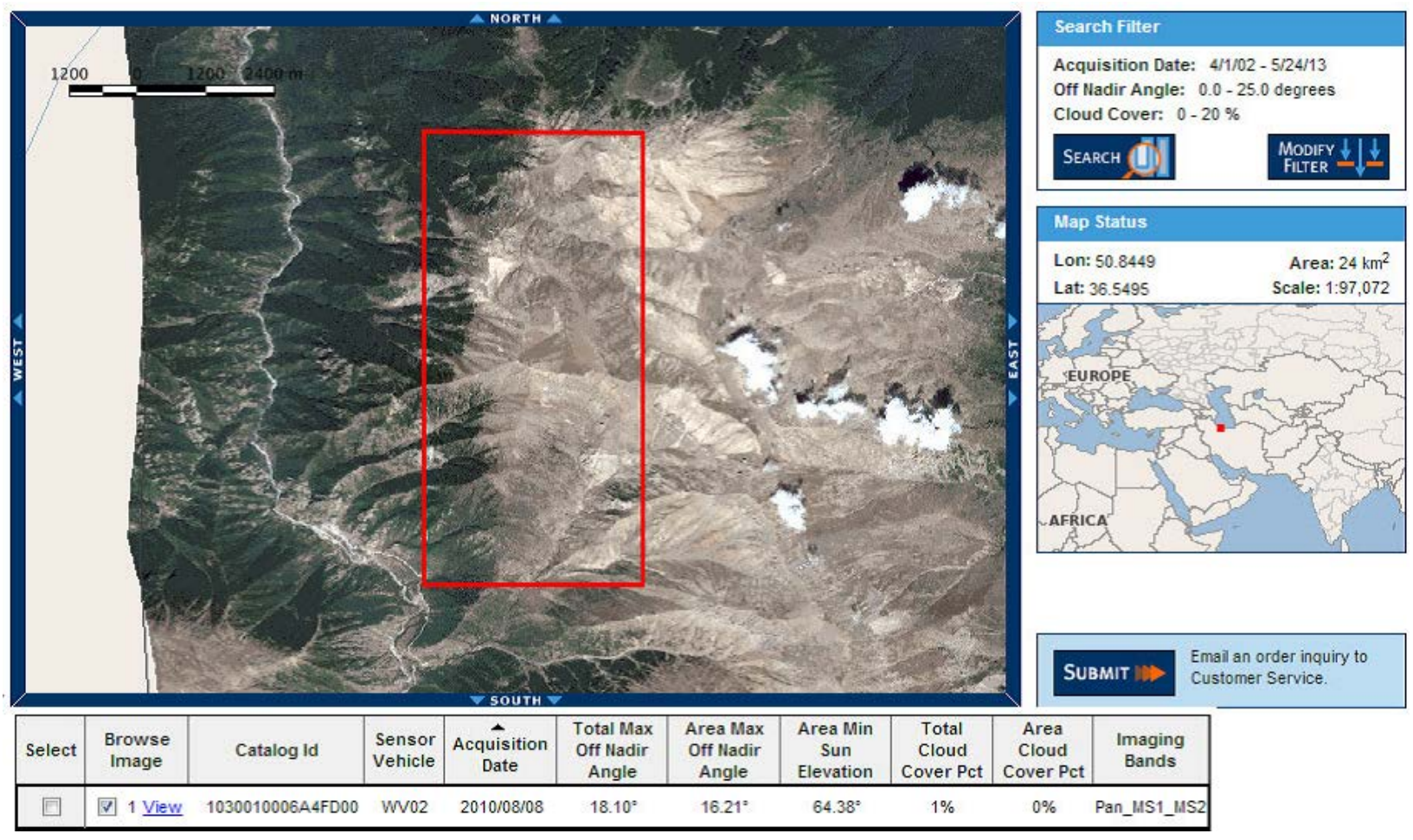

Fig. 2 Location of the studied area in the Worldview image.
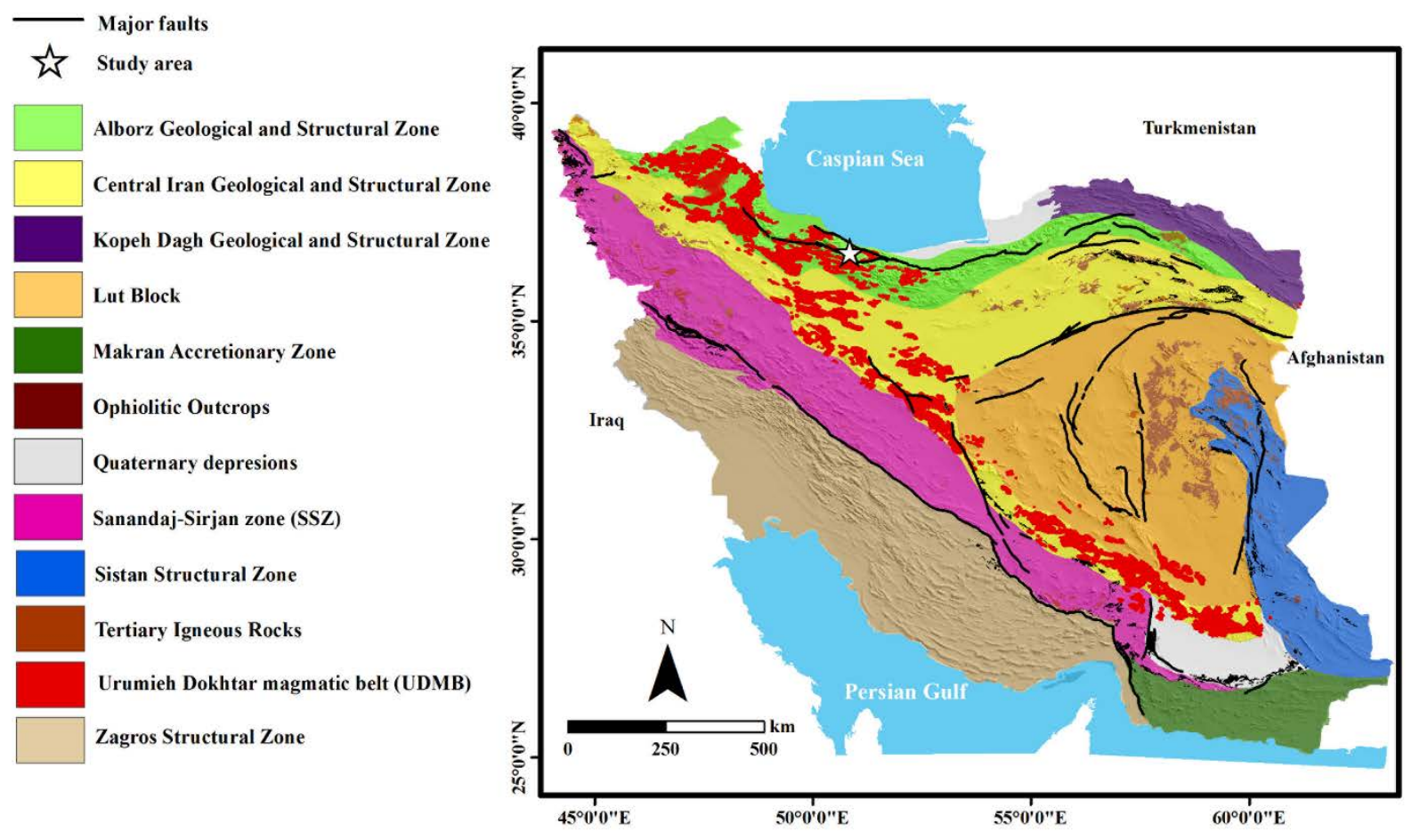

Fig. 3 Major structural zones in Iran (after Alavi, 1994), location of the study area. 


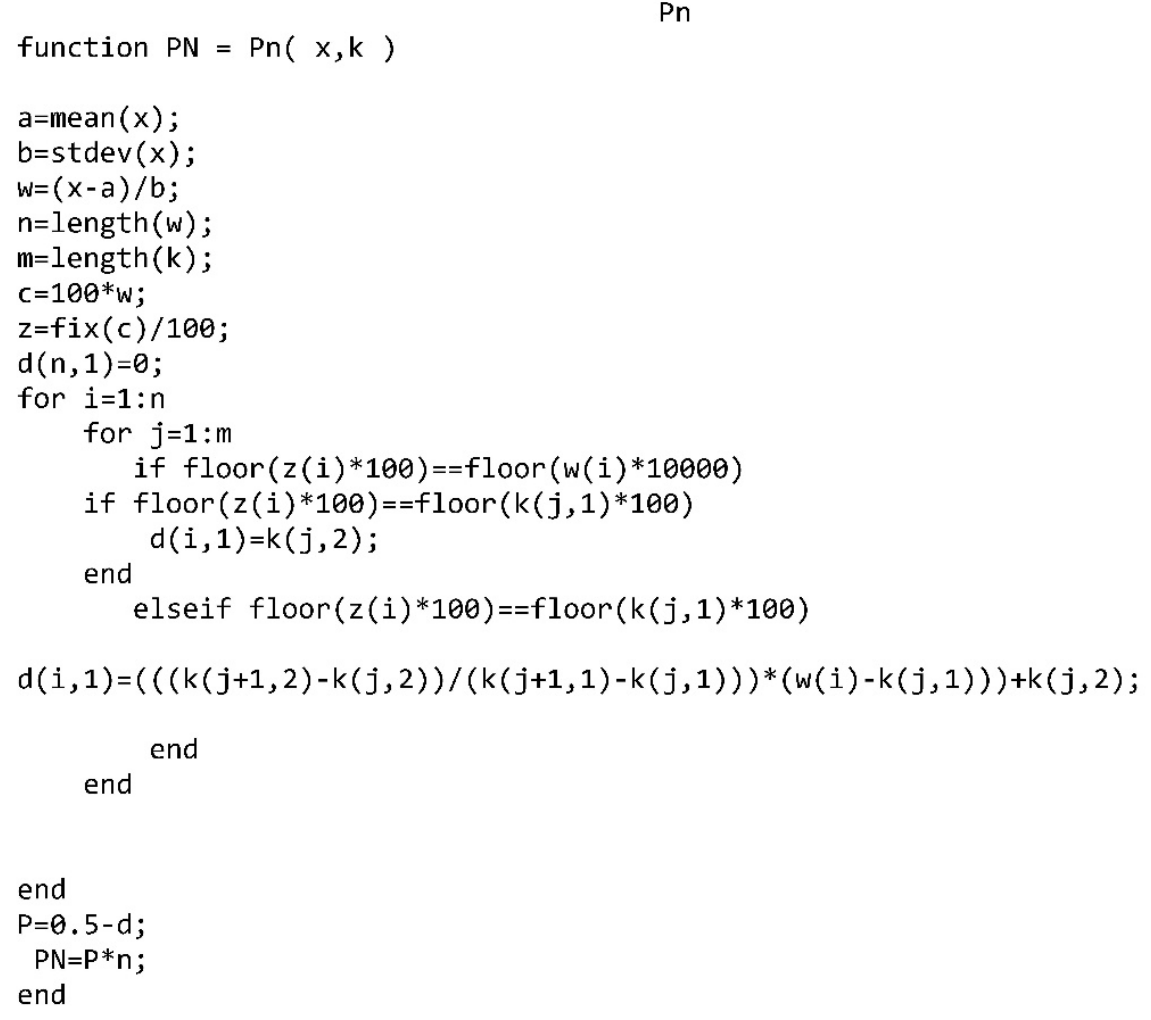

Fig. 4 Part of the P.N method code at the MATLAB software 


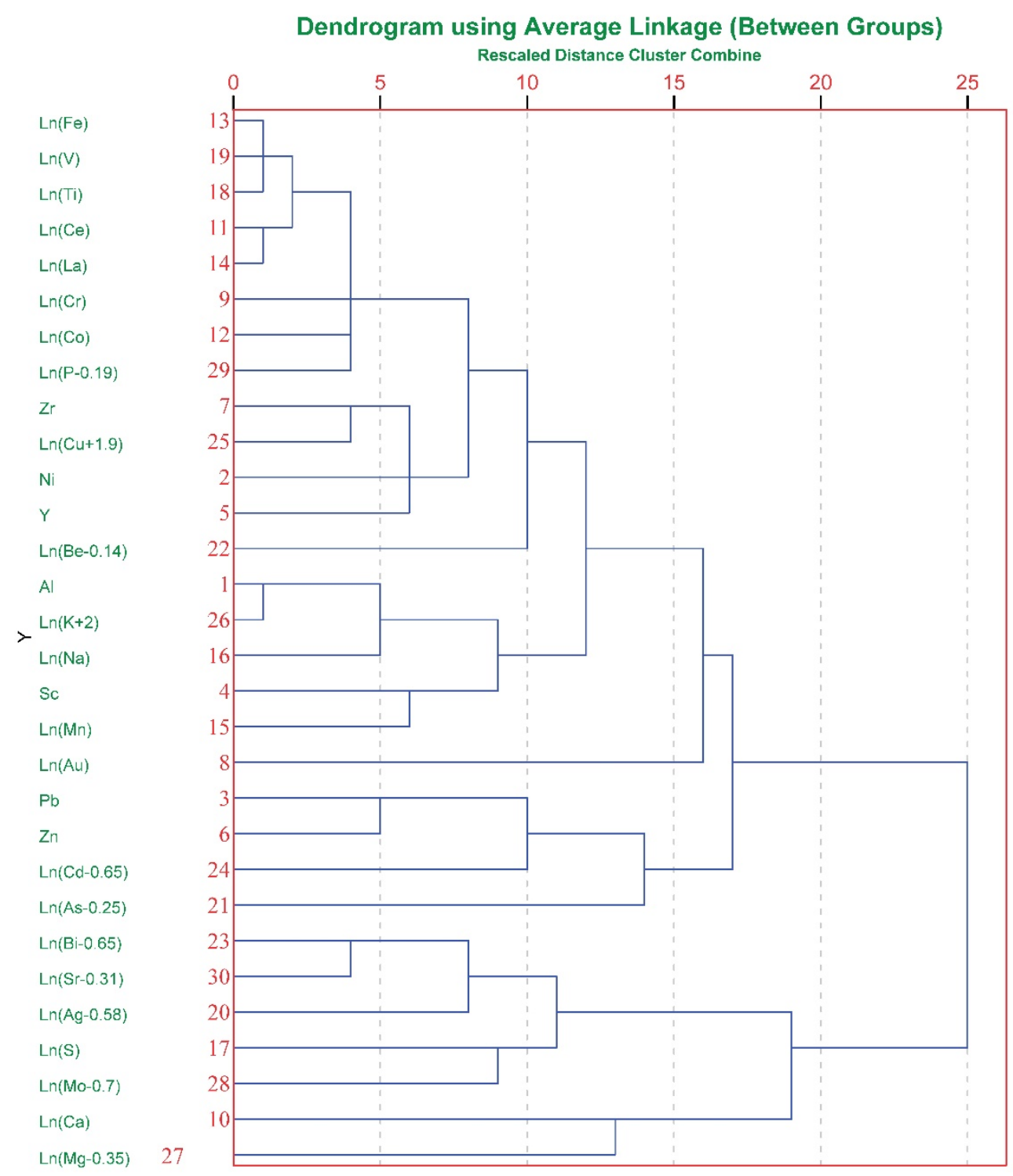

Fig. 5 Dendrogram of the cluster analysis. 


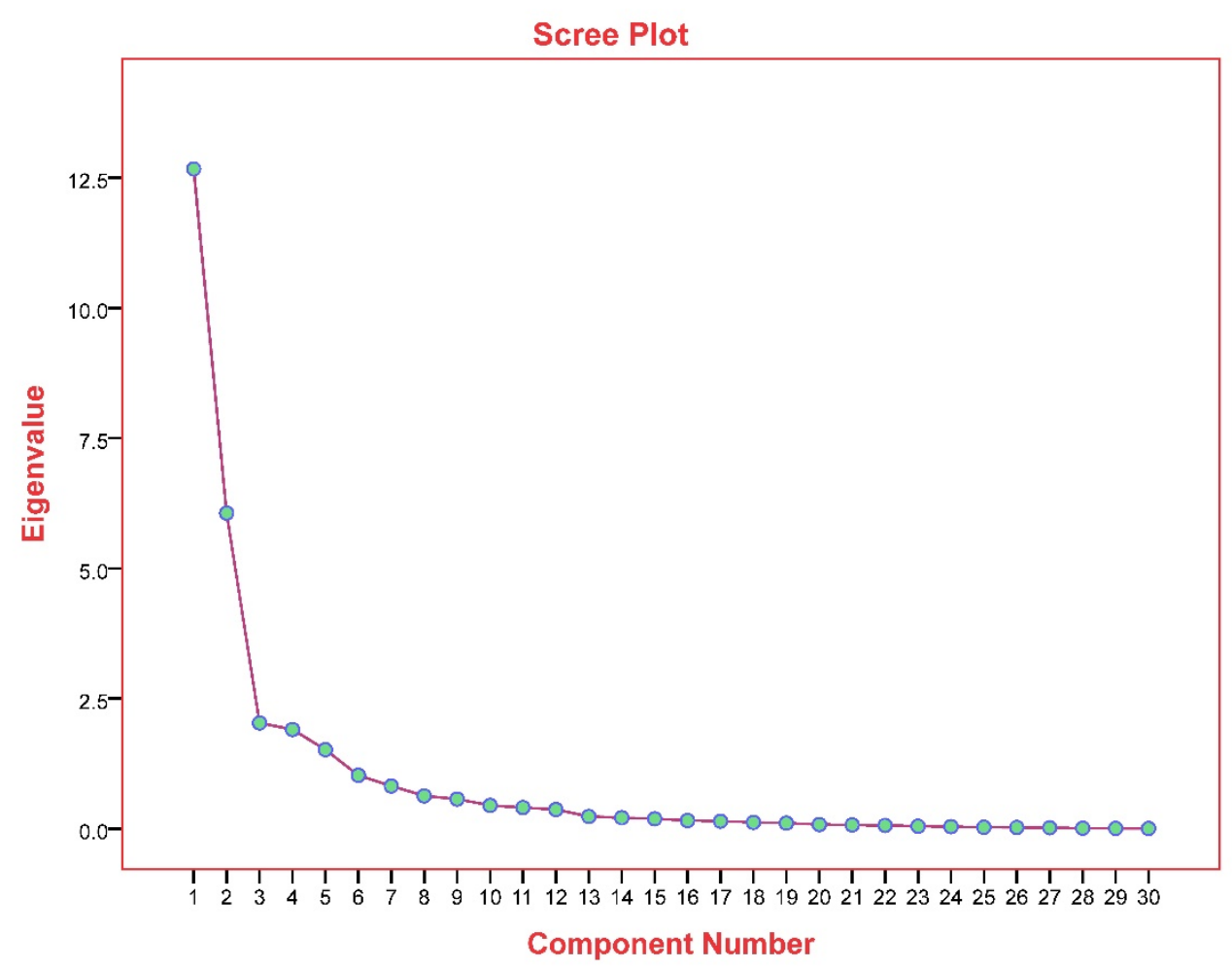

Fig. 6 Scree plot. 


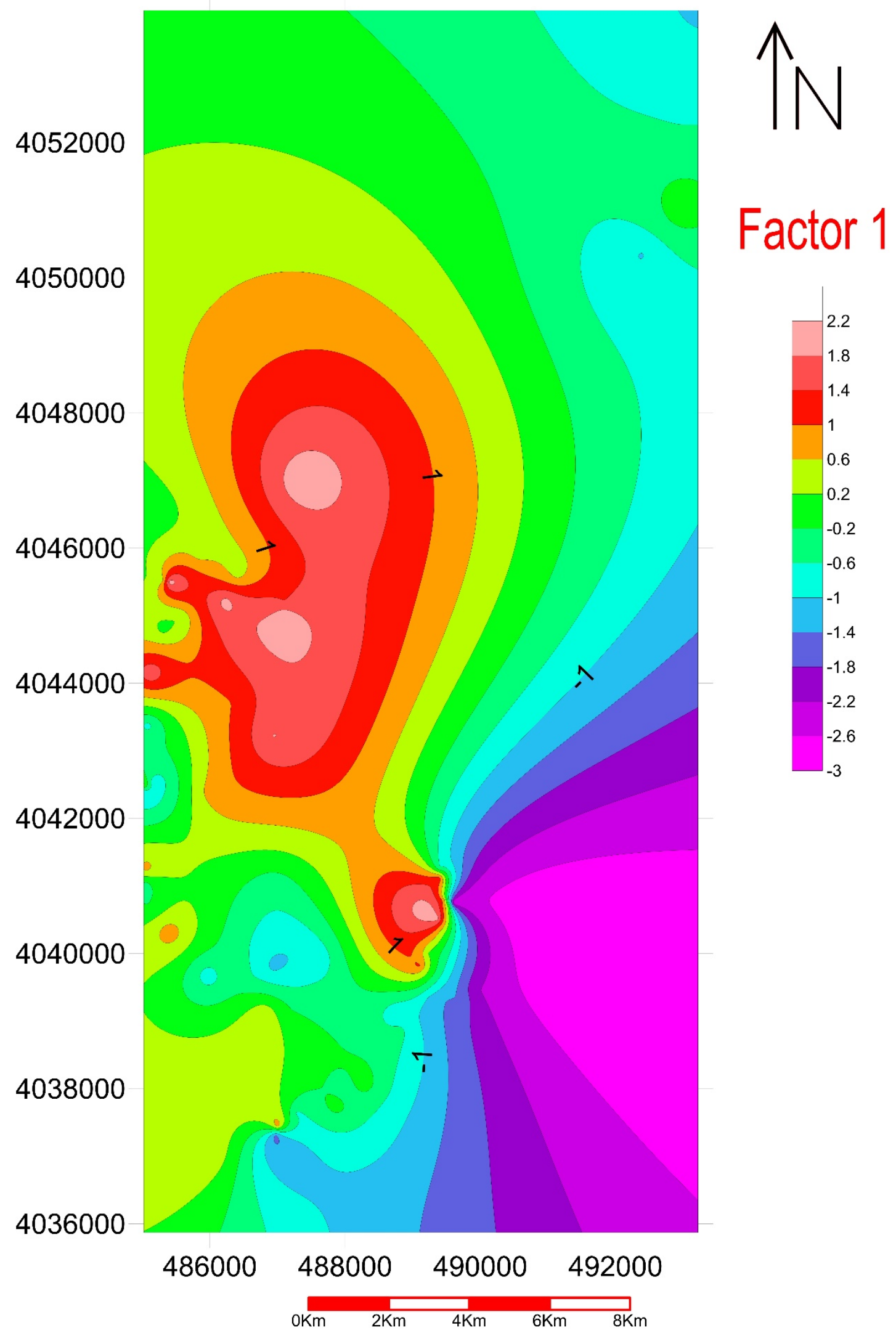

Fig .7 Map of factor 1 


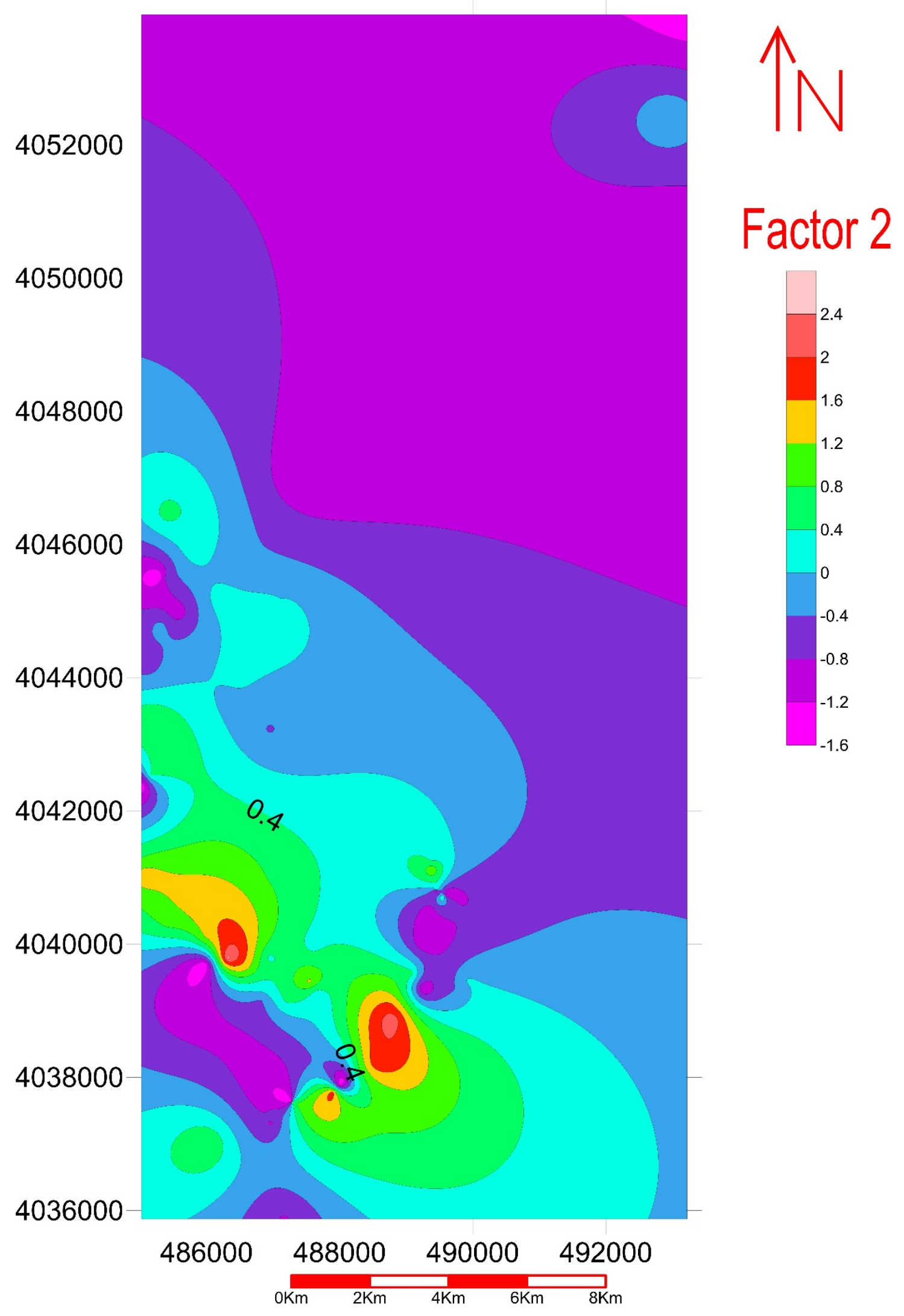

Fig. 8 Map of factor 2 


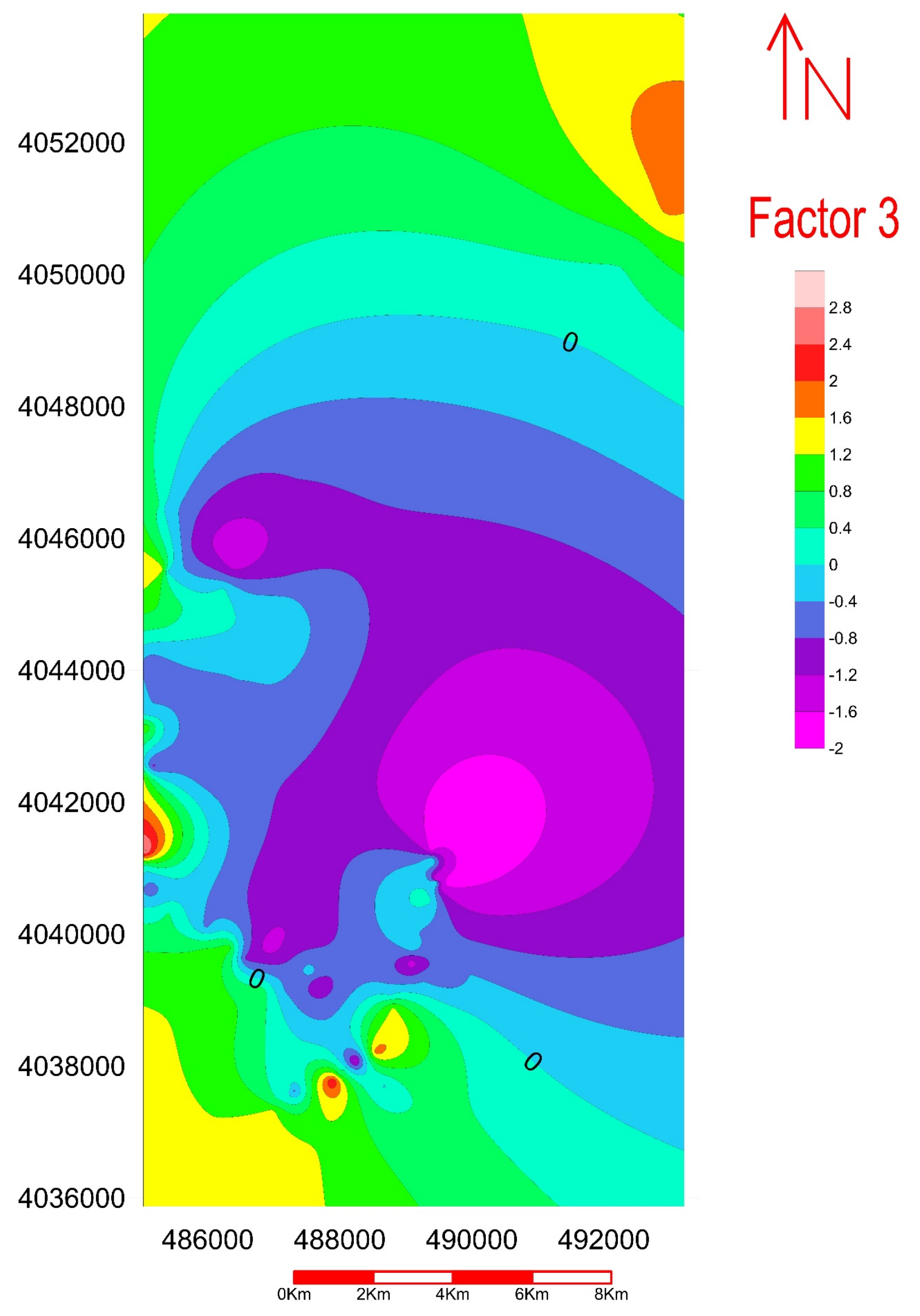

Fig. 9 Map of factor 3 


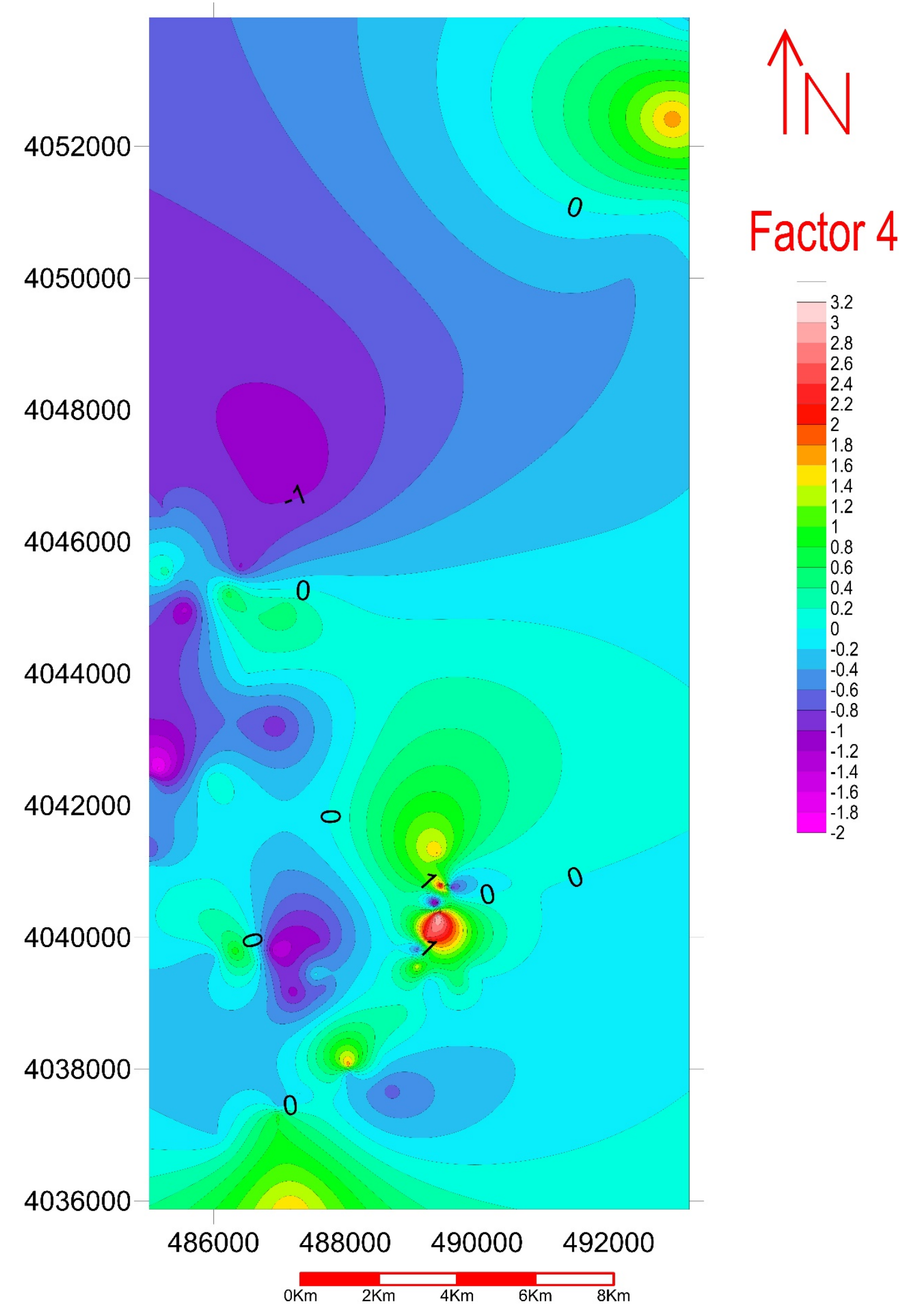

Fig. 10 Map of factor 4 


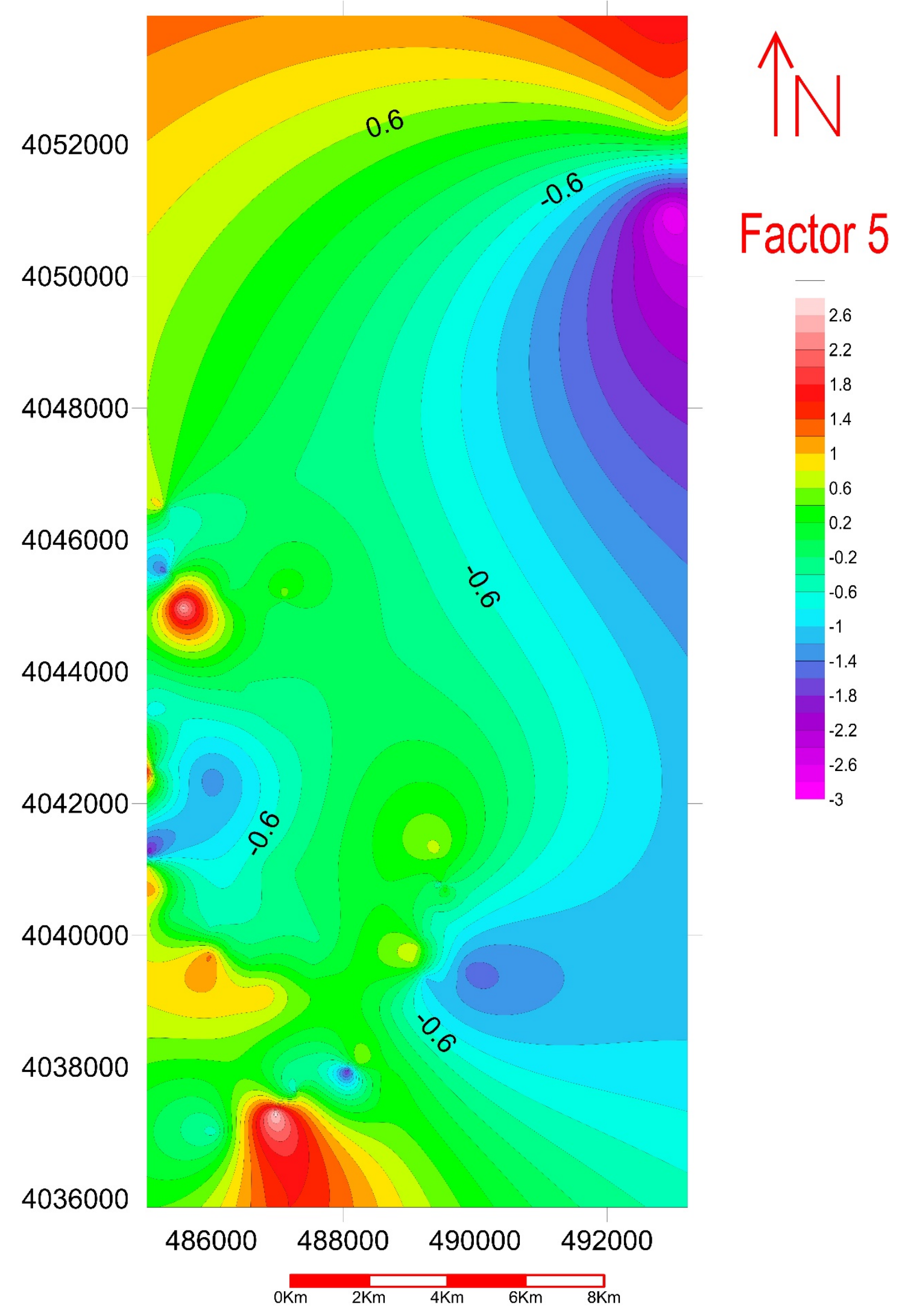

Fig. 11 Map of factor 5 


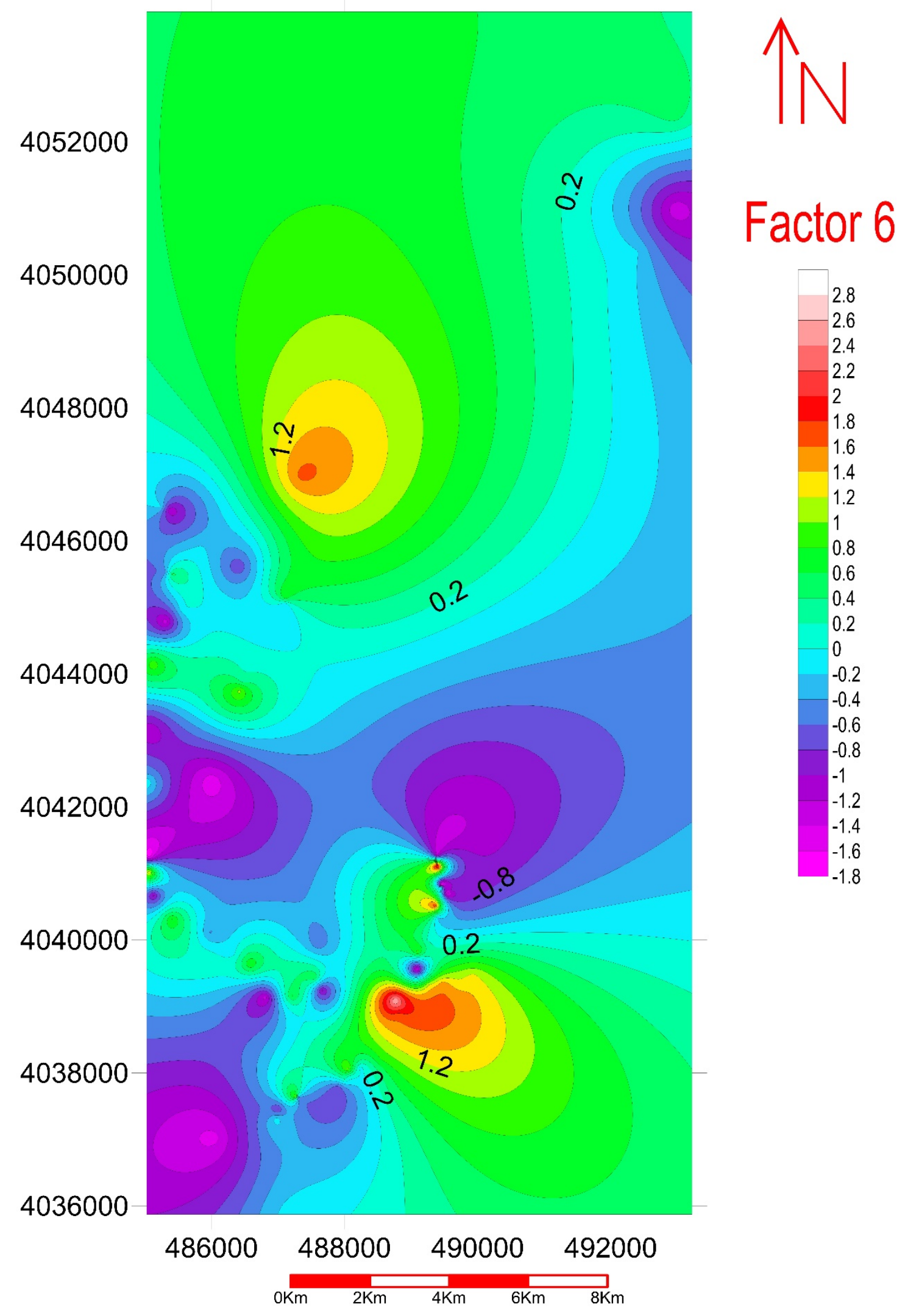

Fig. 12 Map of factor 6 


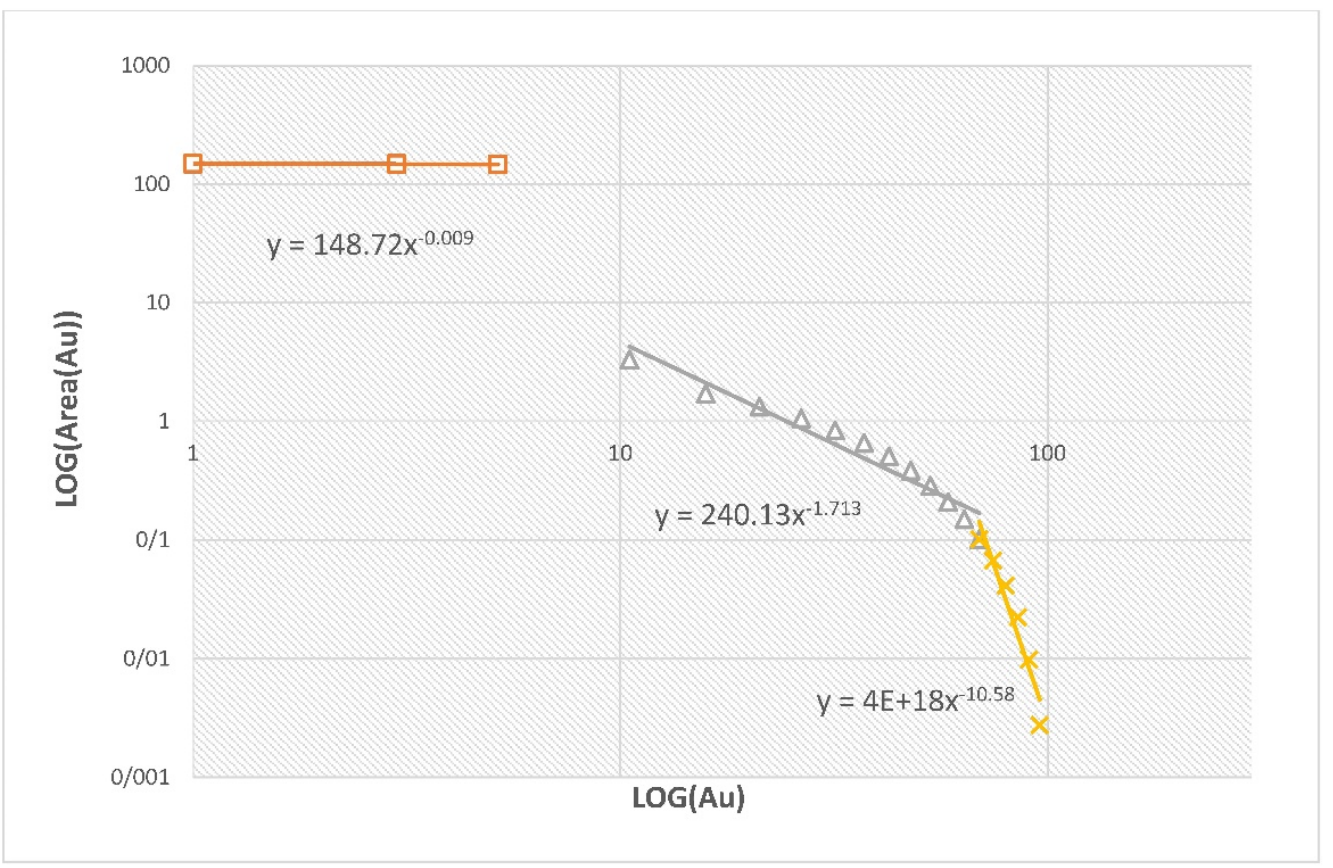

Fig. $13(C-A) \log -\log$ plot for $A u$

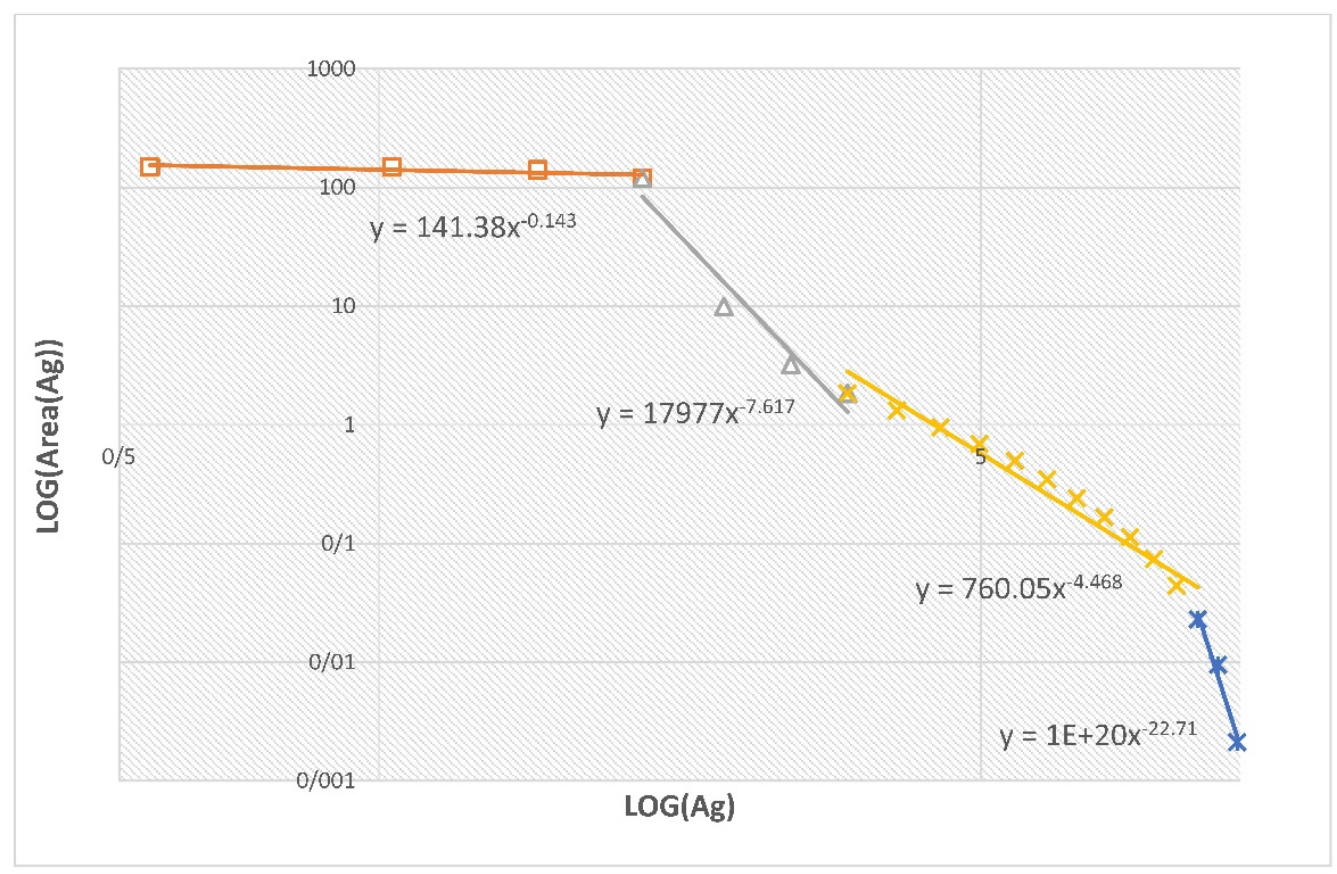

Fig. $14(C-A) \log -\log$ plot for $A g$ 


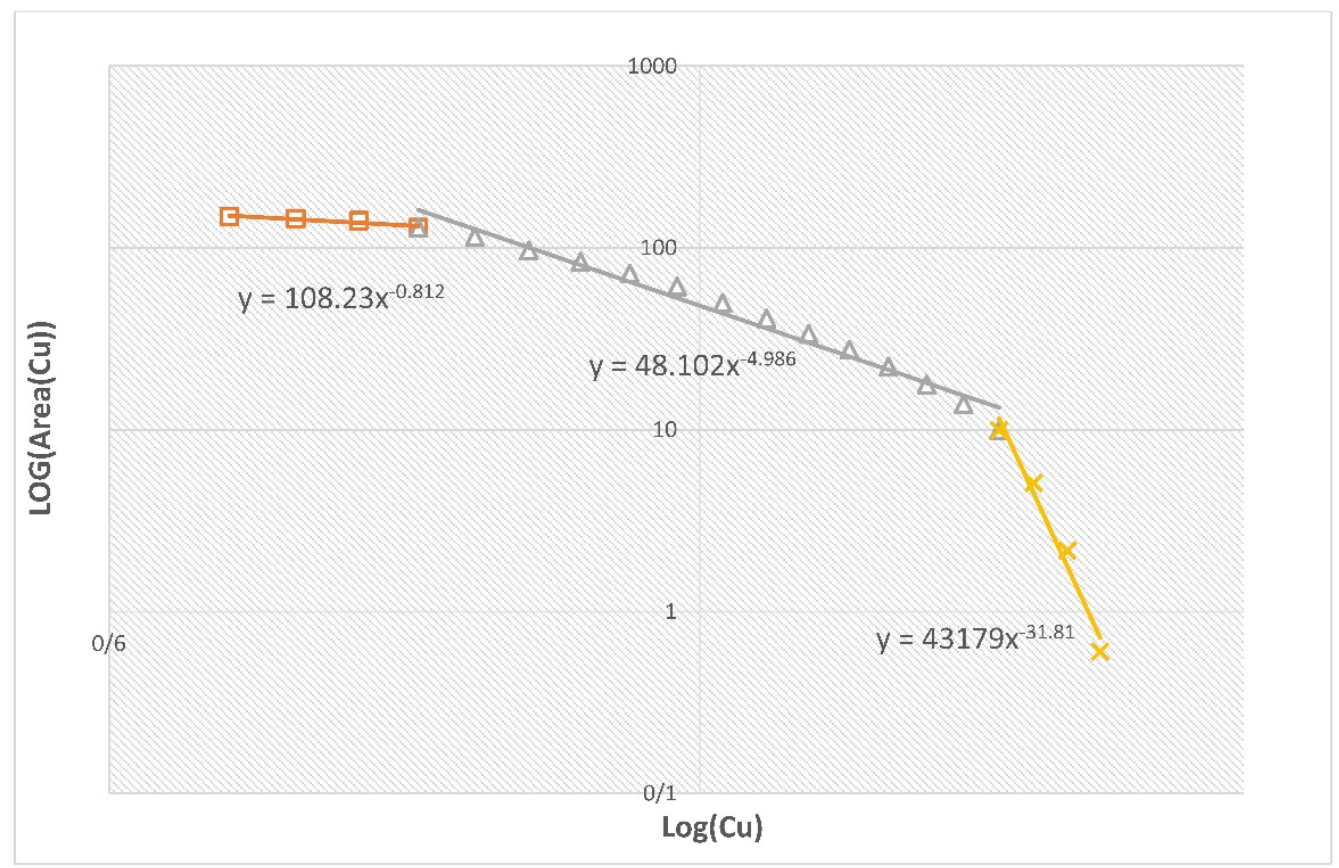

Fig. $15(C-A) \log -\log$ plot for $\mathrm{Cu}$

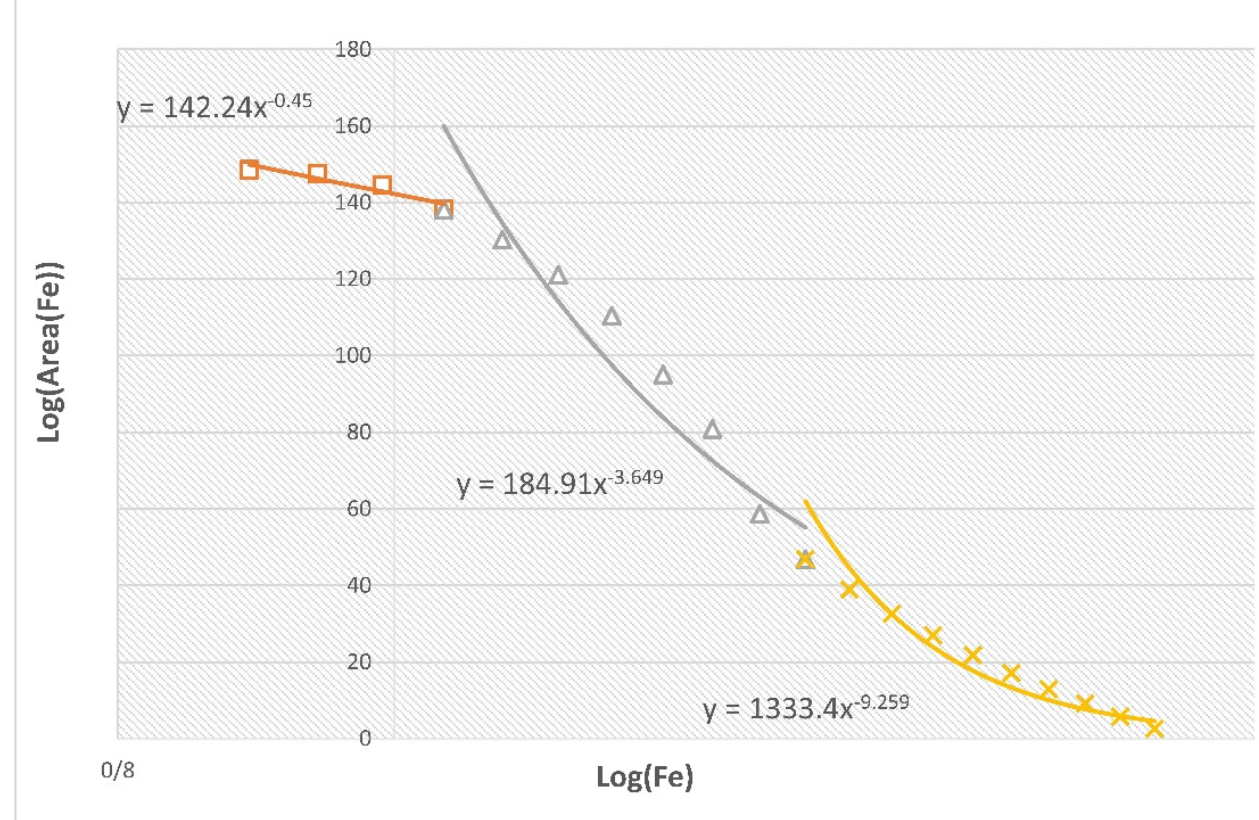

Fig. $16(C-A) \log -\log$ plot for Fe 


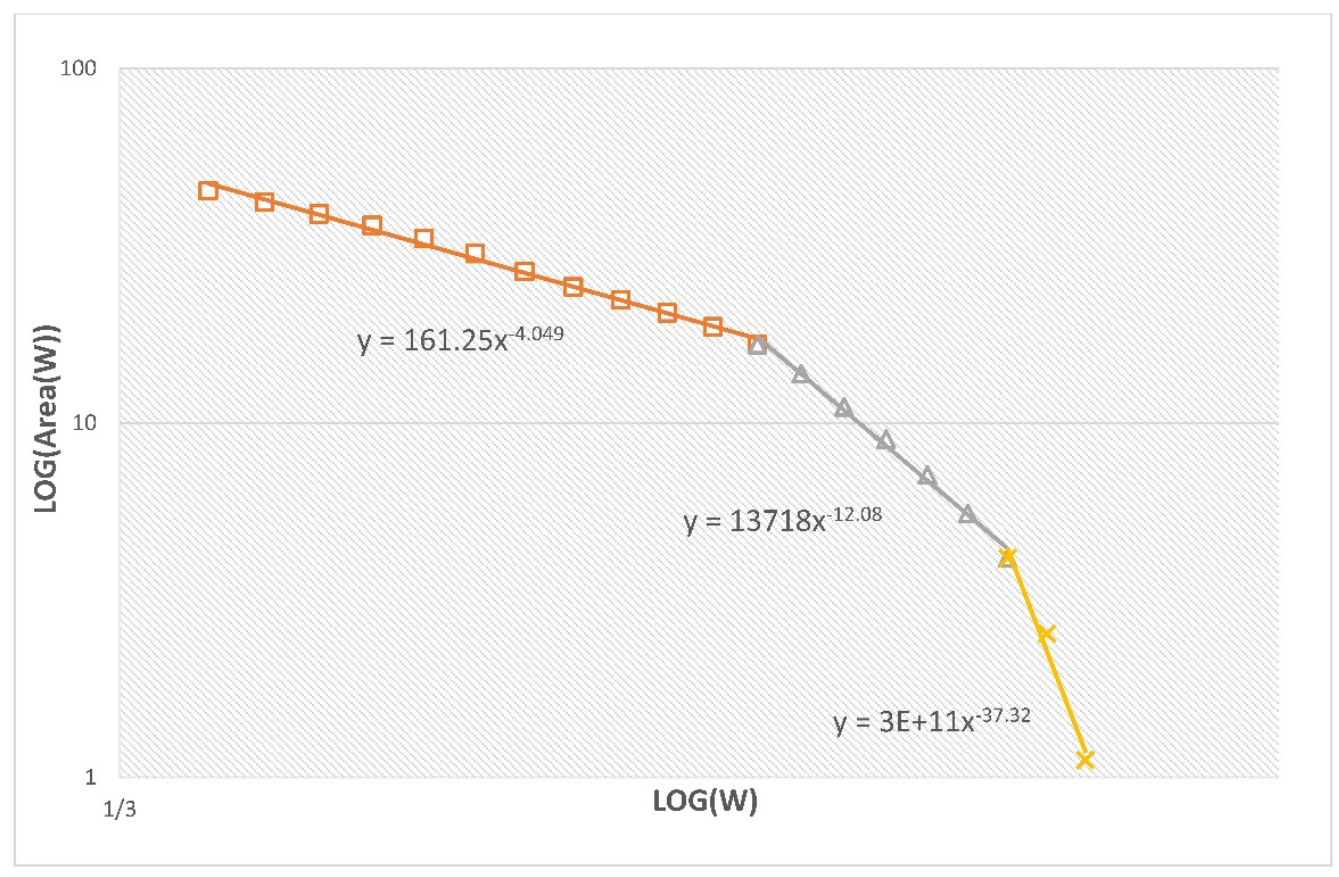

Fig. $17(C-A) \log -\log$ plot for $W$ 


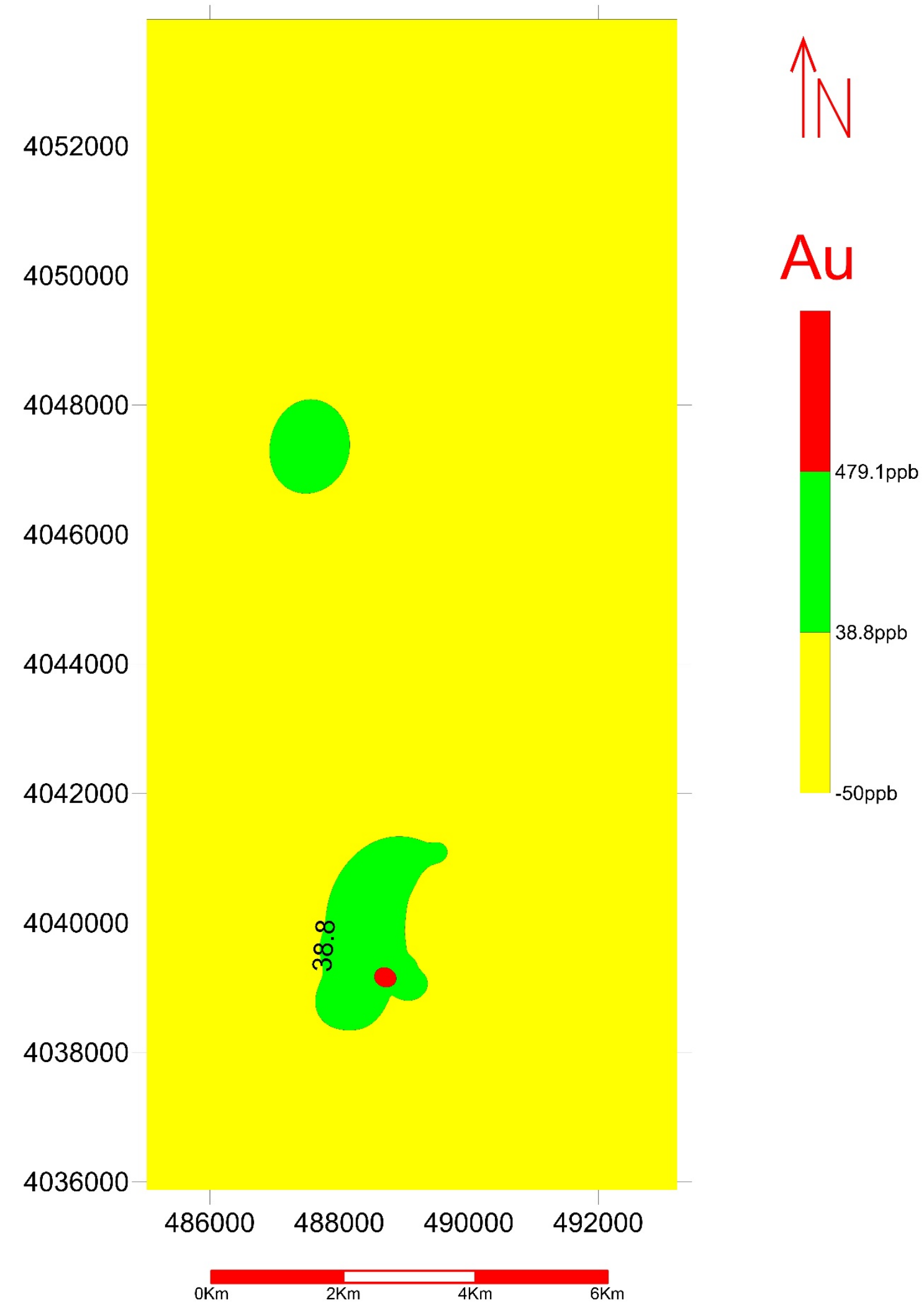

Fig .18 Au geochemical population distribution map based on C-A method. 


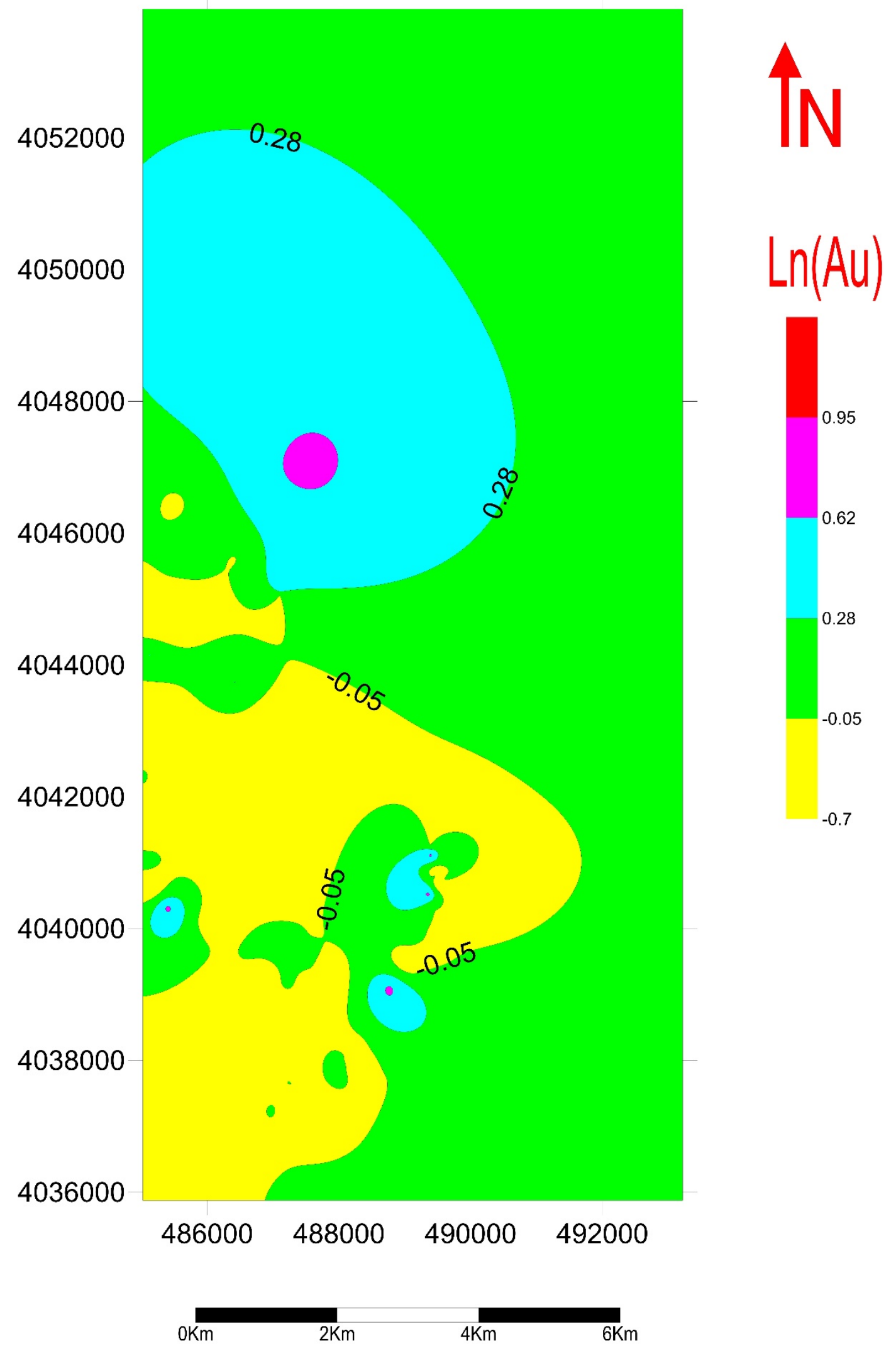

Fig. 19 Au geochemical population distribution map based on threshold method. 


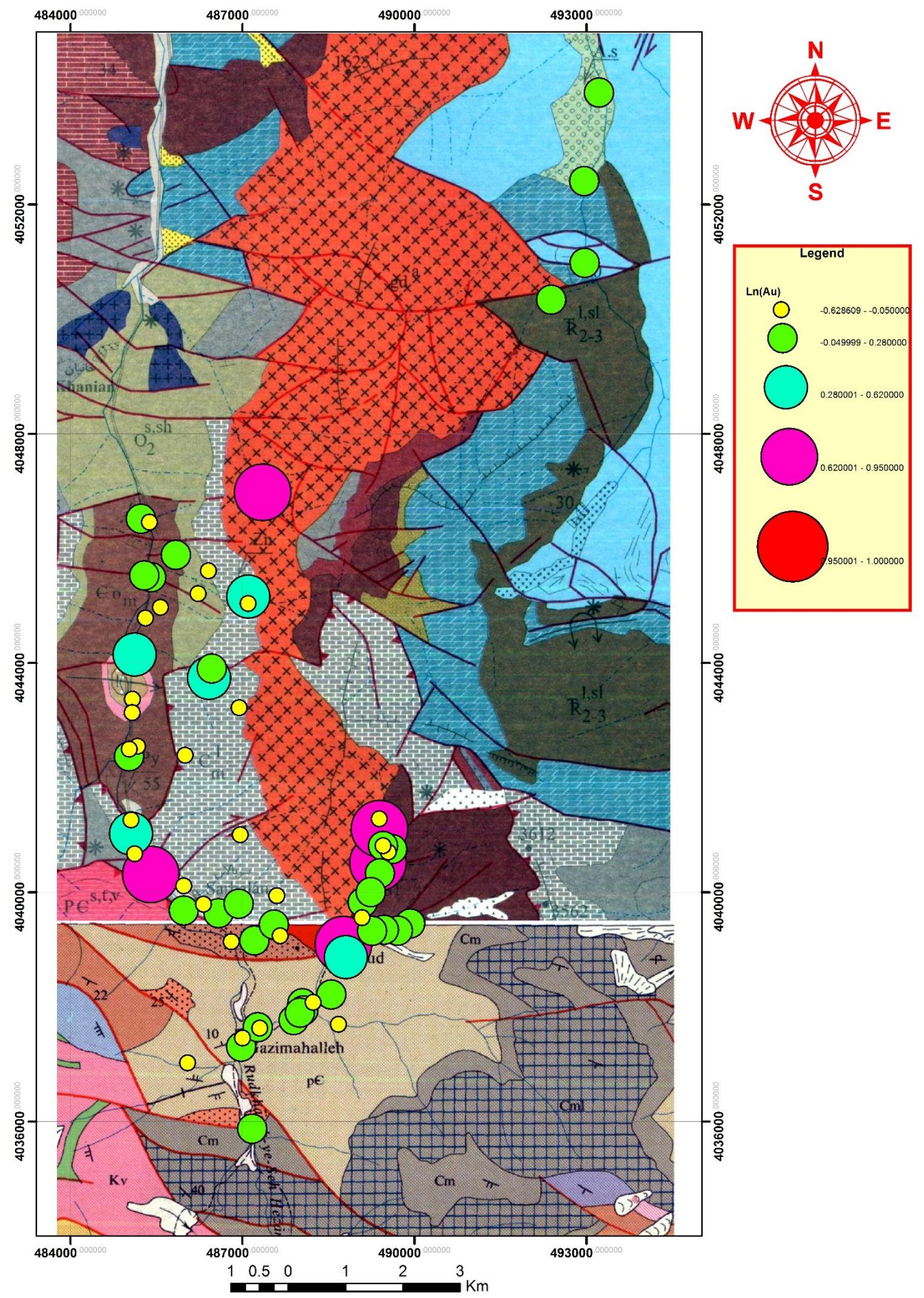

Fig. 20 Au geochemical grade symbolic map based on threshold method. 


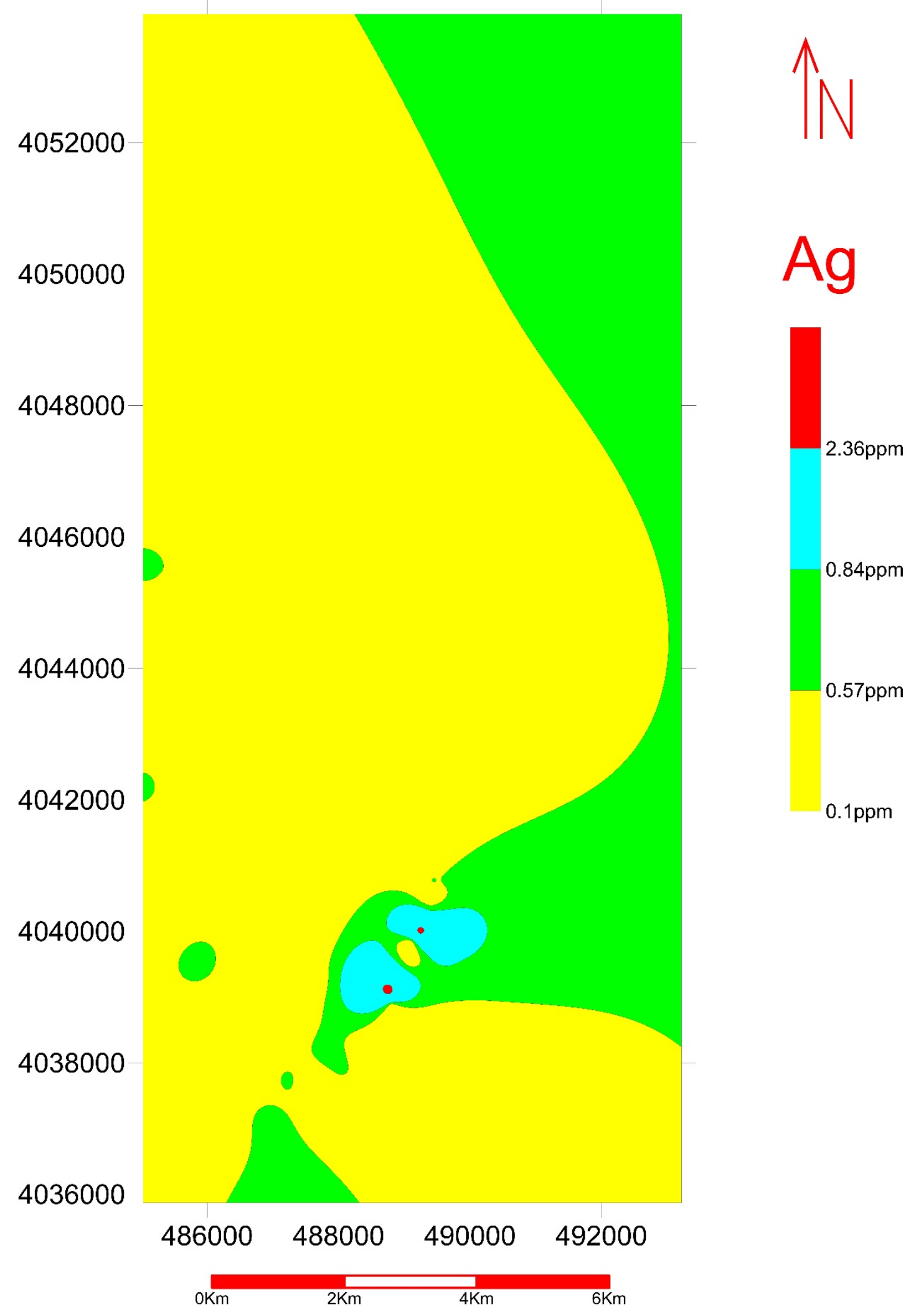

Fig. $21 \mathrm{Ag}$ geochemical population distribution map based on C-A method. 


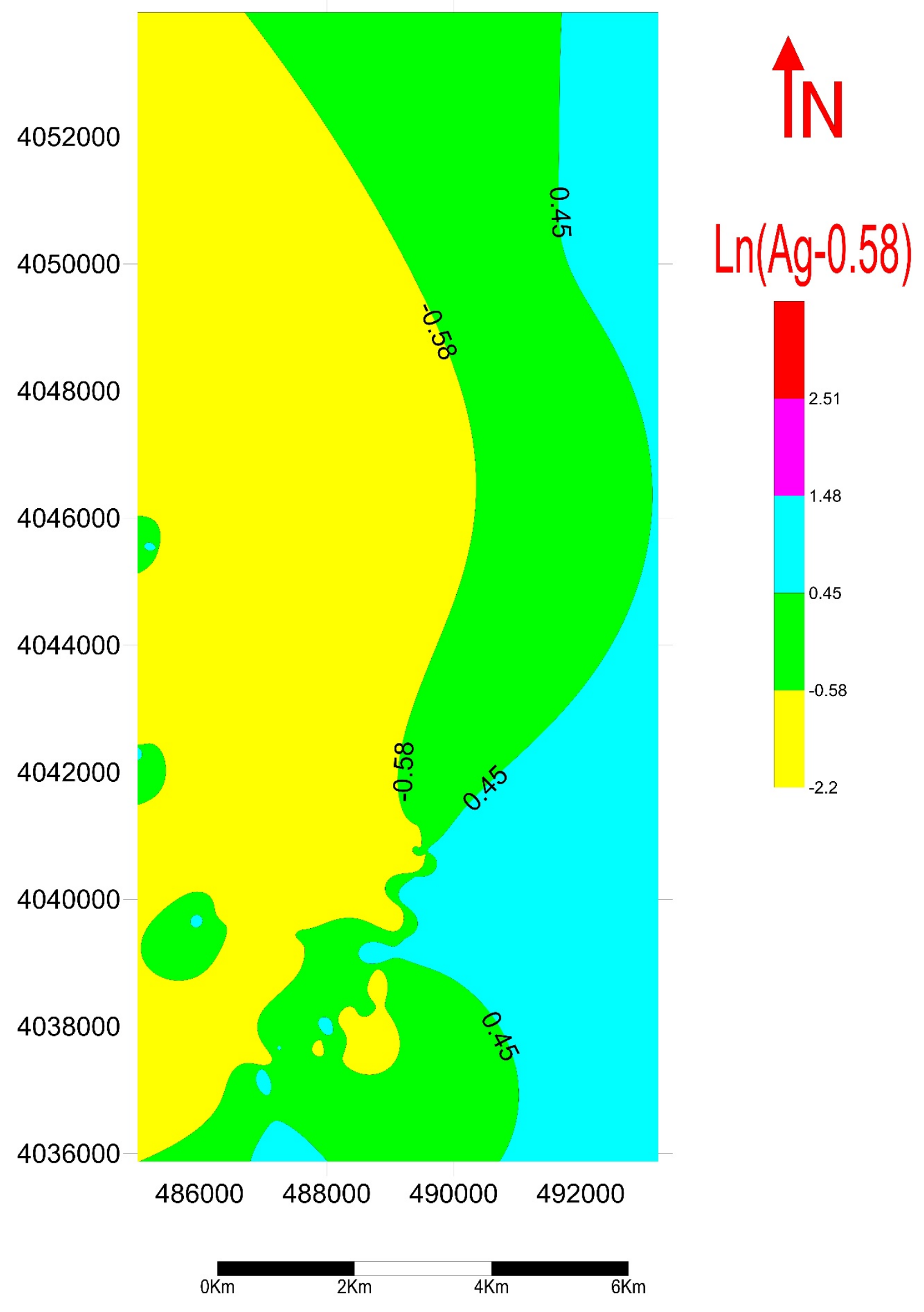

Fig. $22 \mathrm{Ag}$ geochemical population distribution map based on threshold method. 


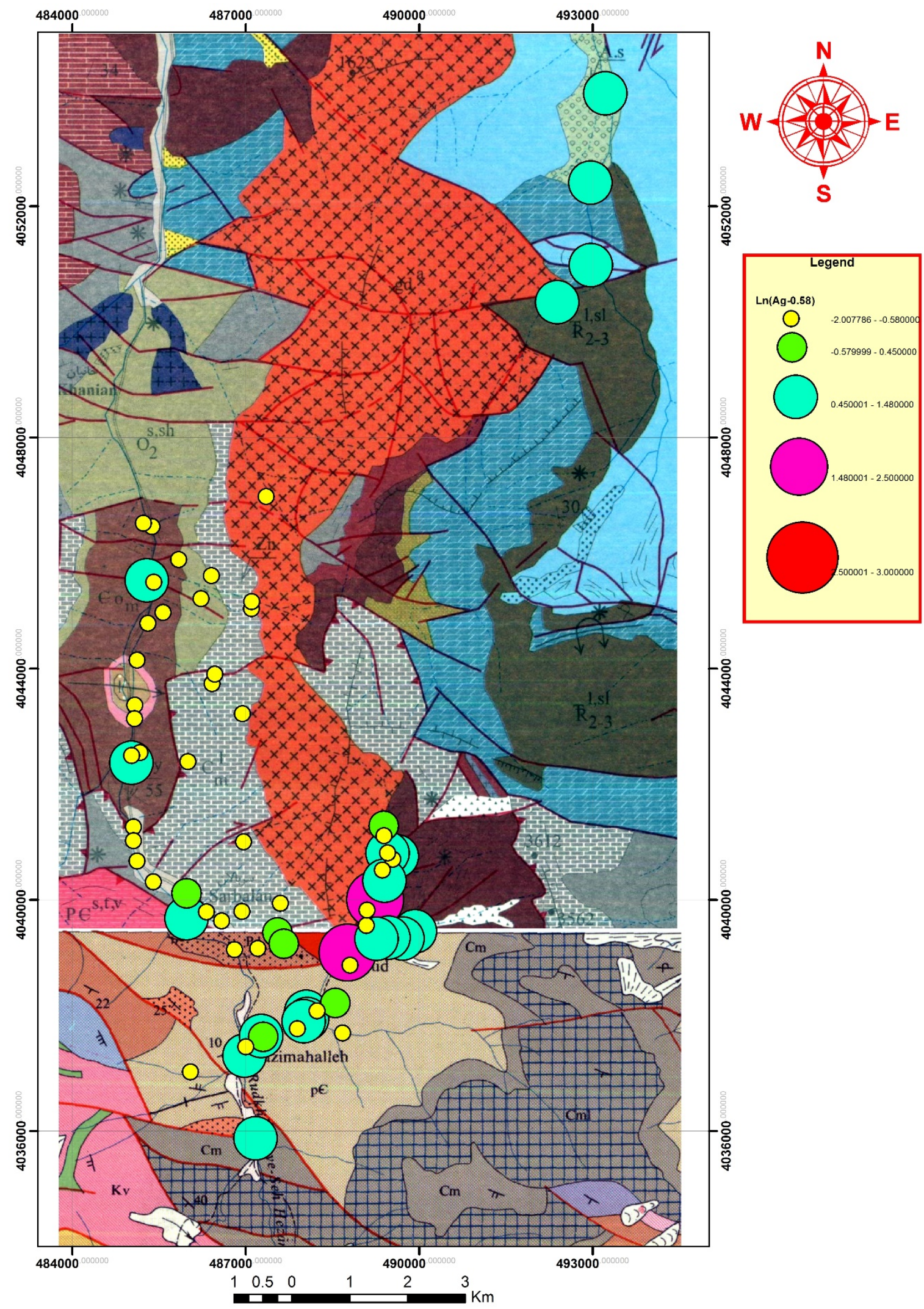

Fig. $23 \mathrm{Ag}$ geochemical grade symbolic map based on threshold method. 


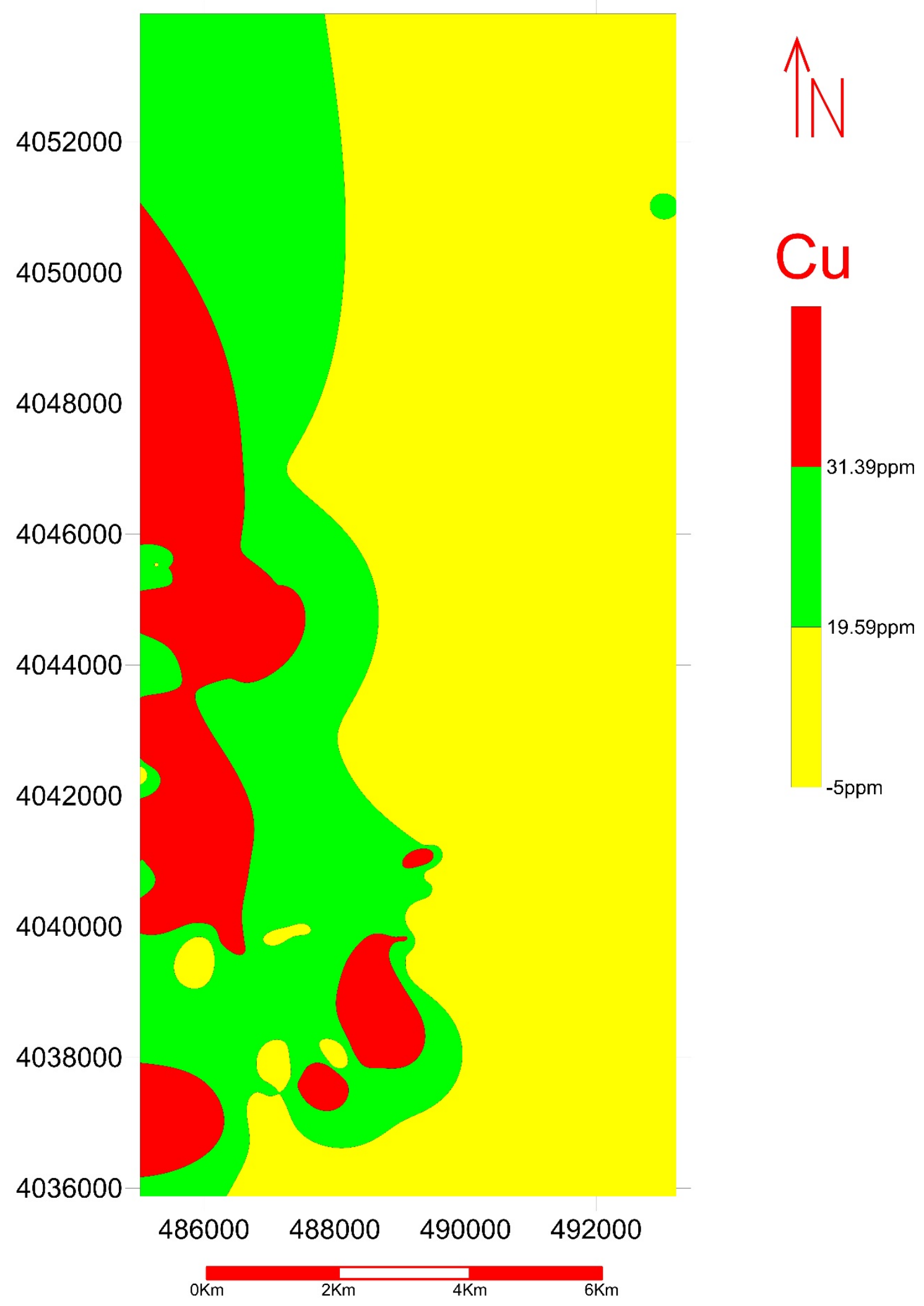

Fig. $24 \mathrm{Cu}$ geochemical population distribution map based on C-A method. 


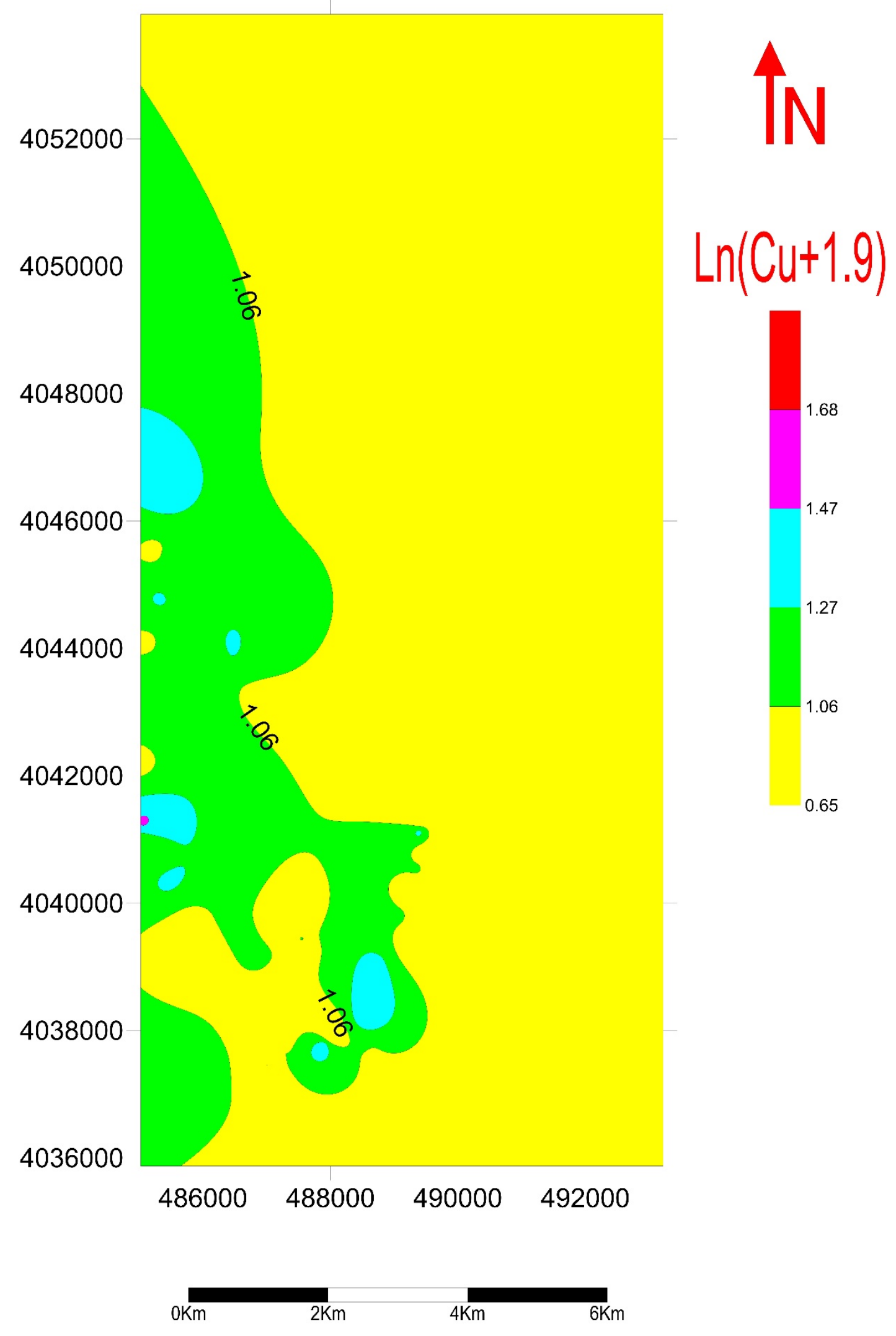

Fig. $25 \mathrm{Cu}$ geochemical population distribution map based on threshold method. 


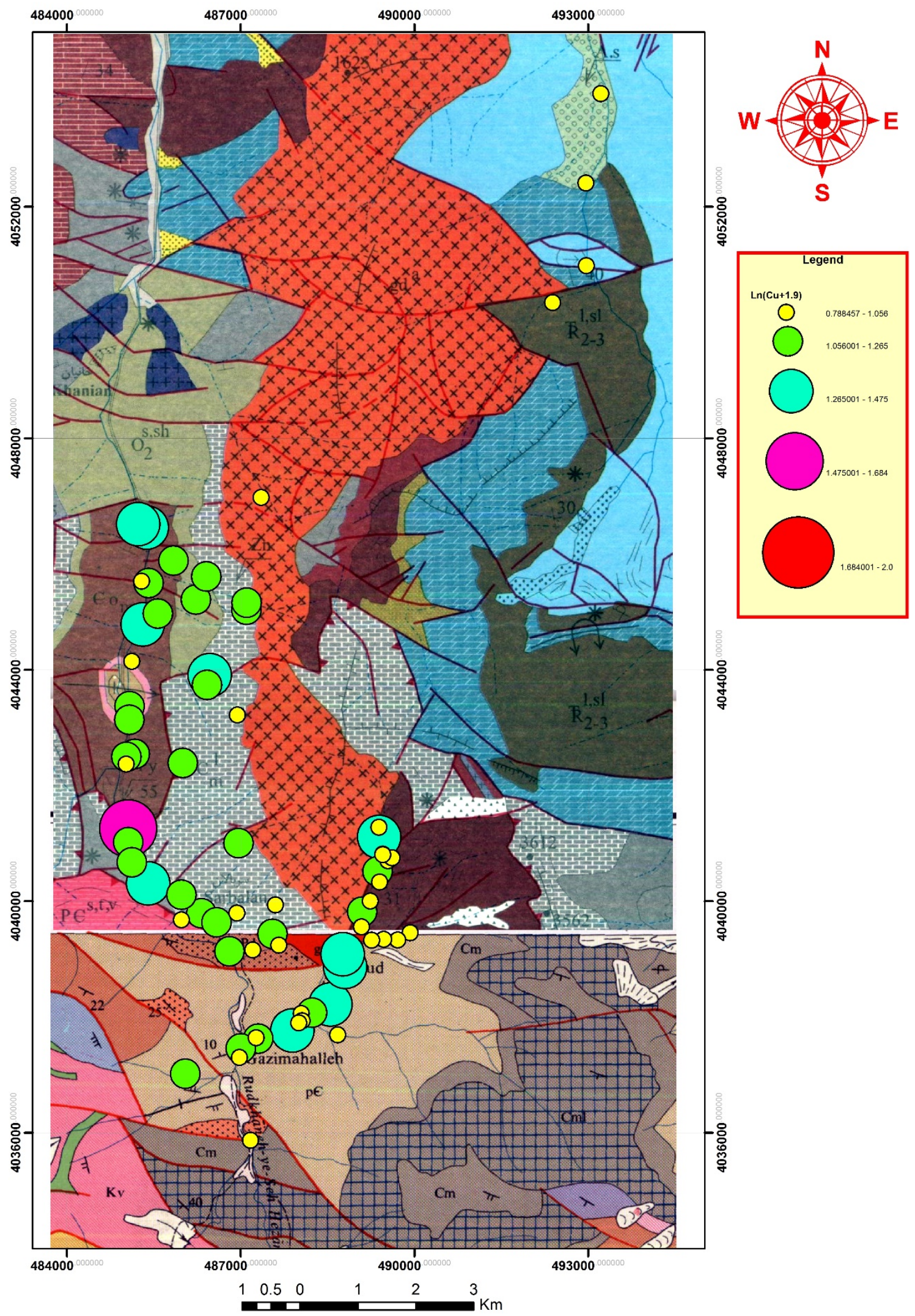

Fig. $26 \mathrm{Cu}$ geochemical grade symbolic map based on threshold method. 


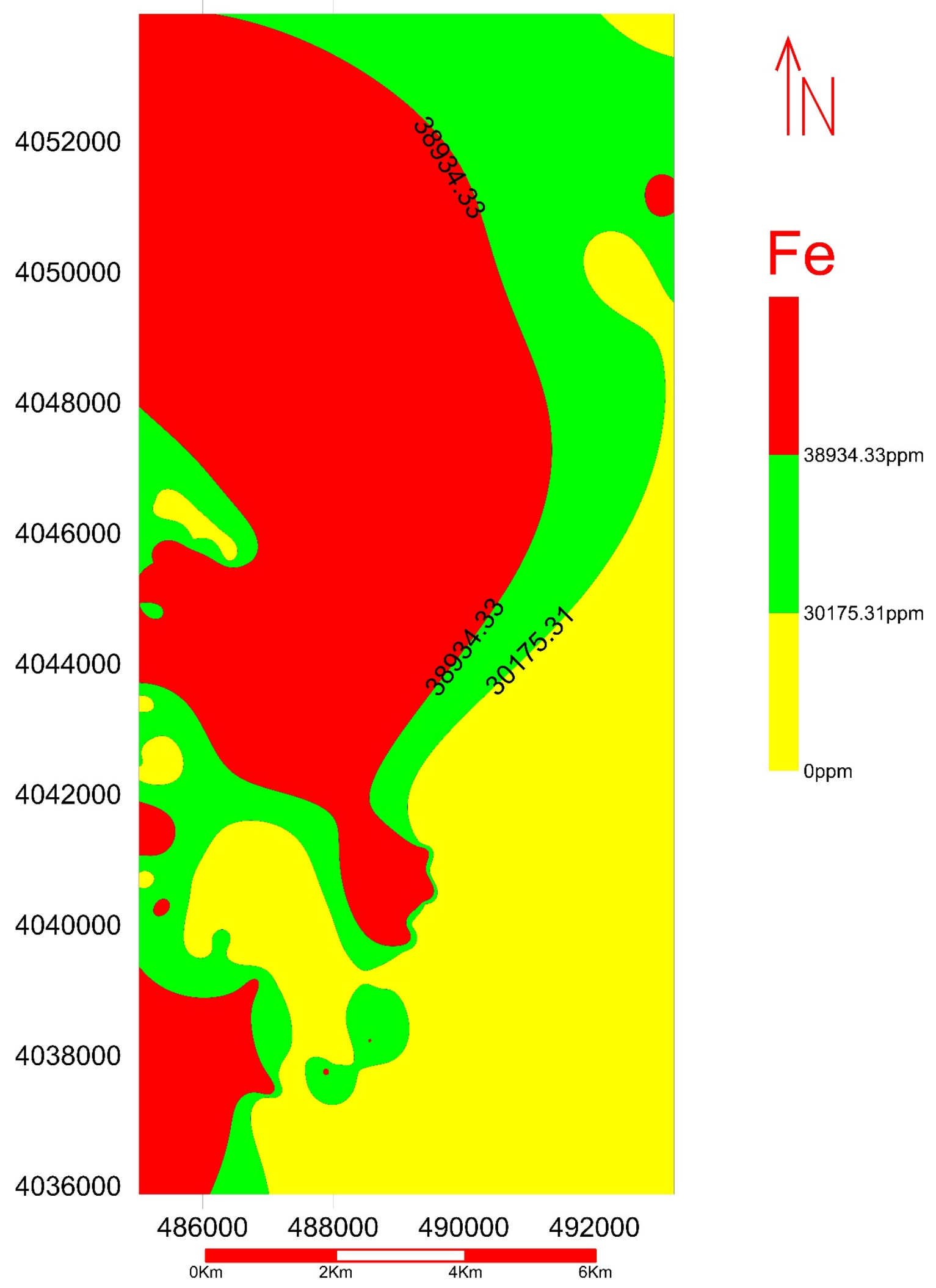

Fig. 27 Fe geochemical population distribution map based on C-A method. 


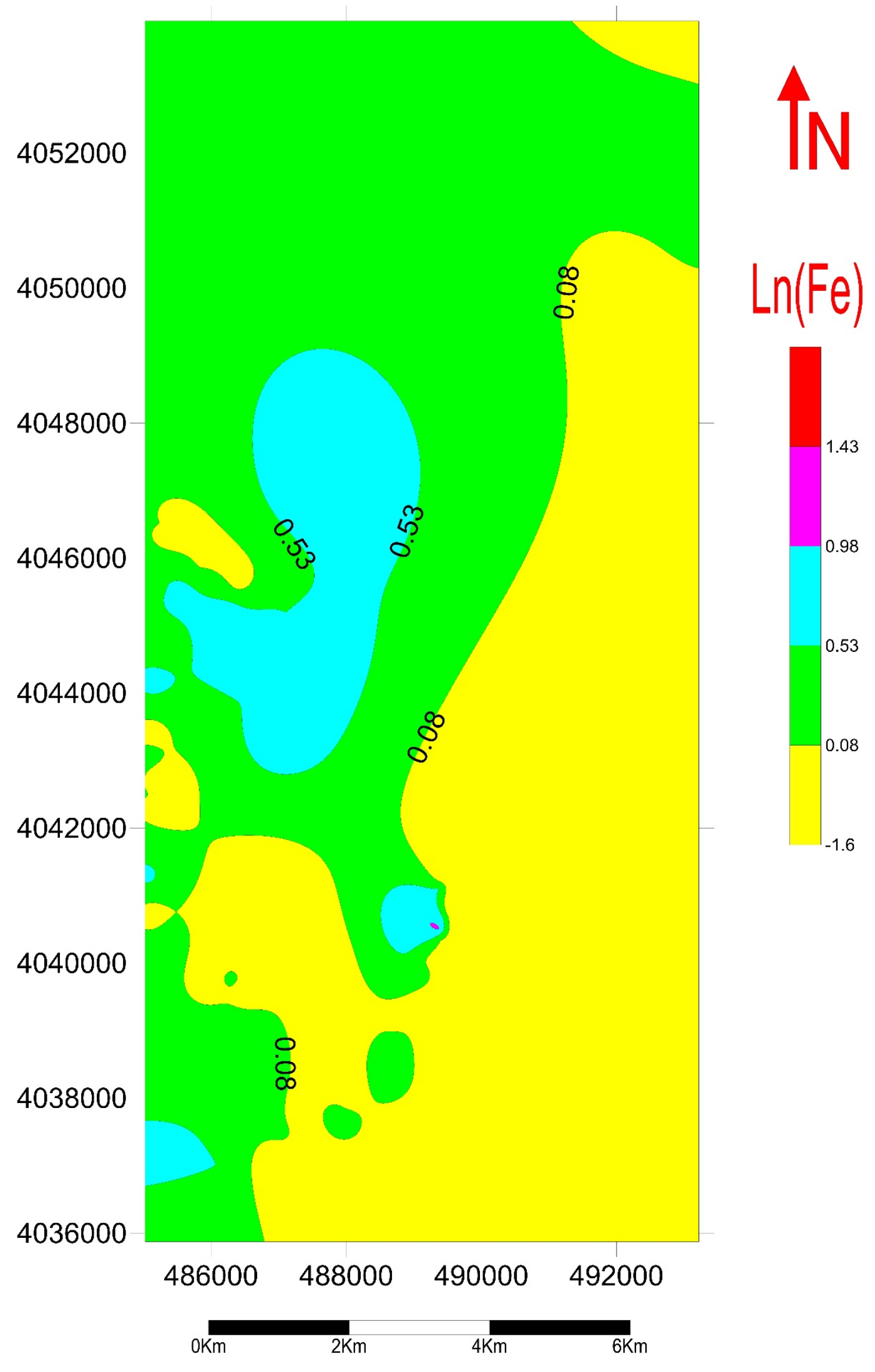

Fig. 28 Fe geochemical population distribution map based on threshold method. 


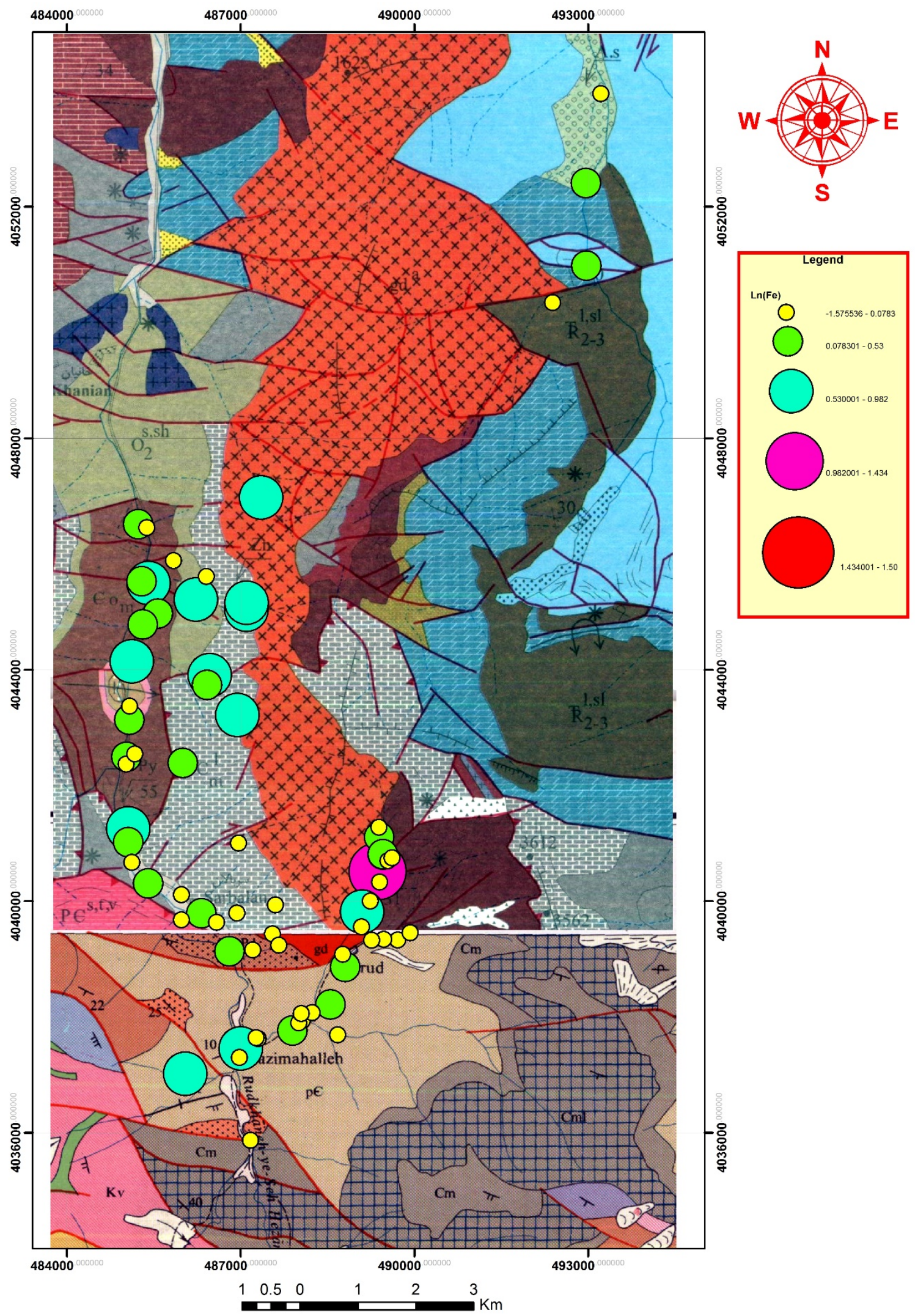

Fig. 29 Fe geochemical grade symbolic map based on threshold method. 


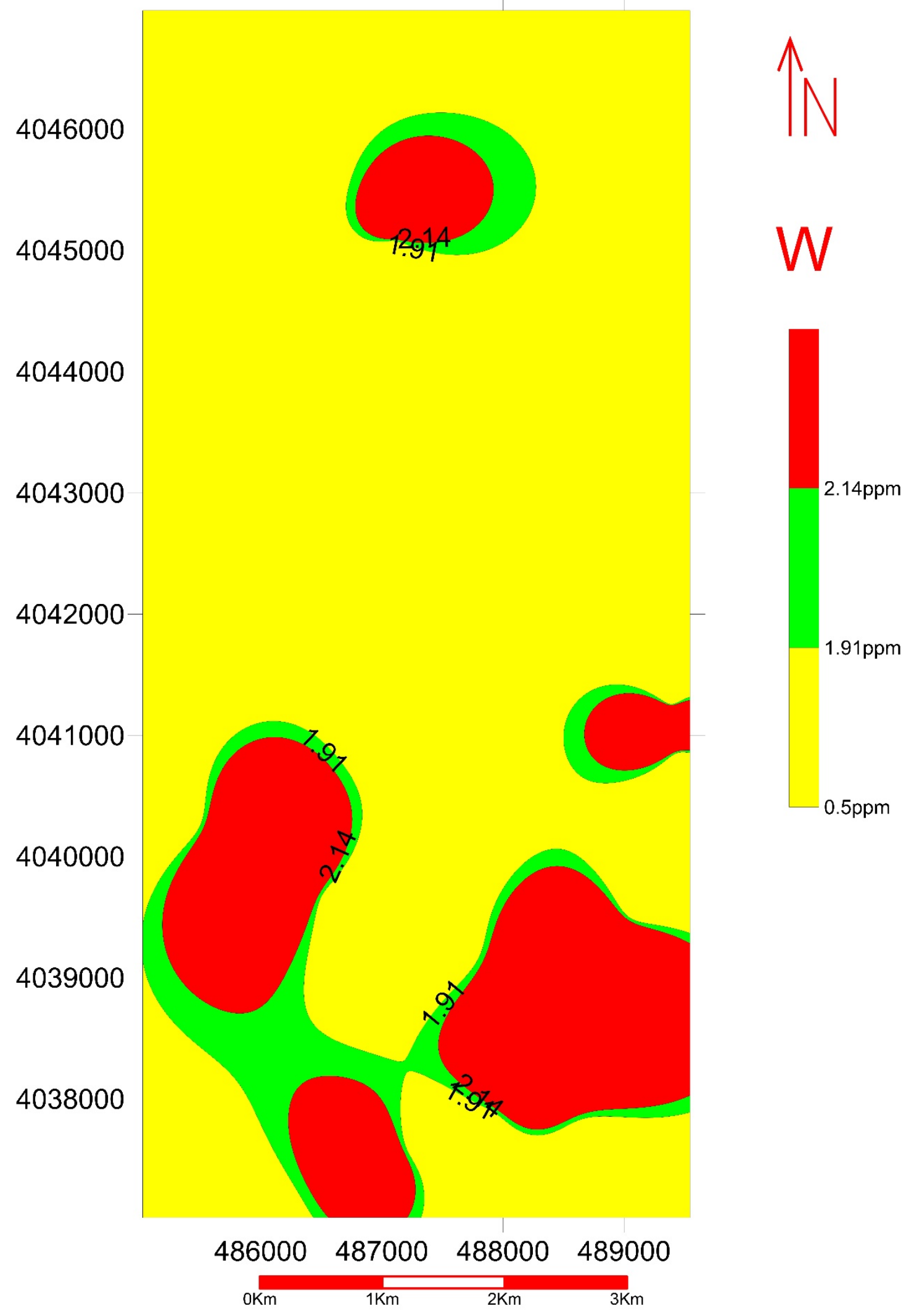

Fig. $30 \mathrm{~W}$ geochemical population distribution map based on C-A method. 


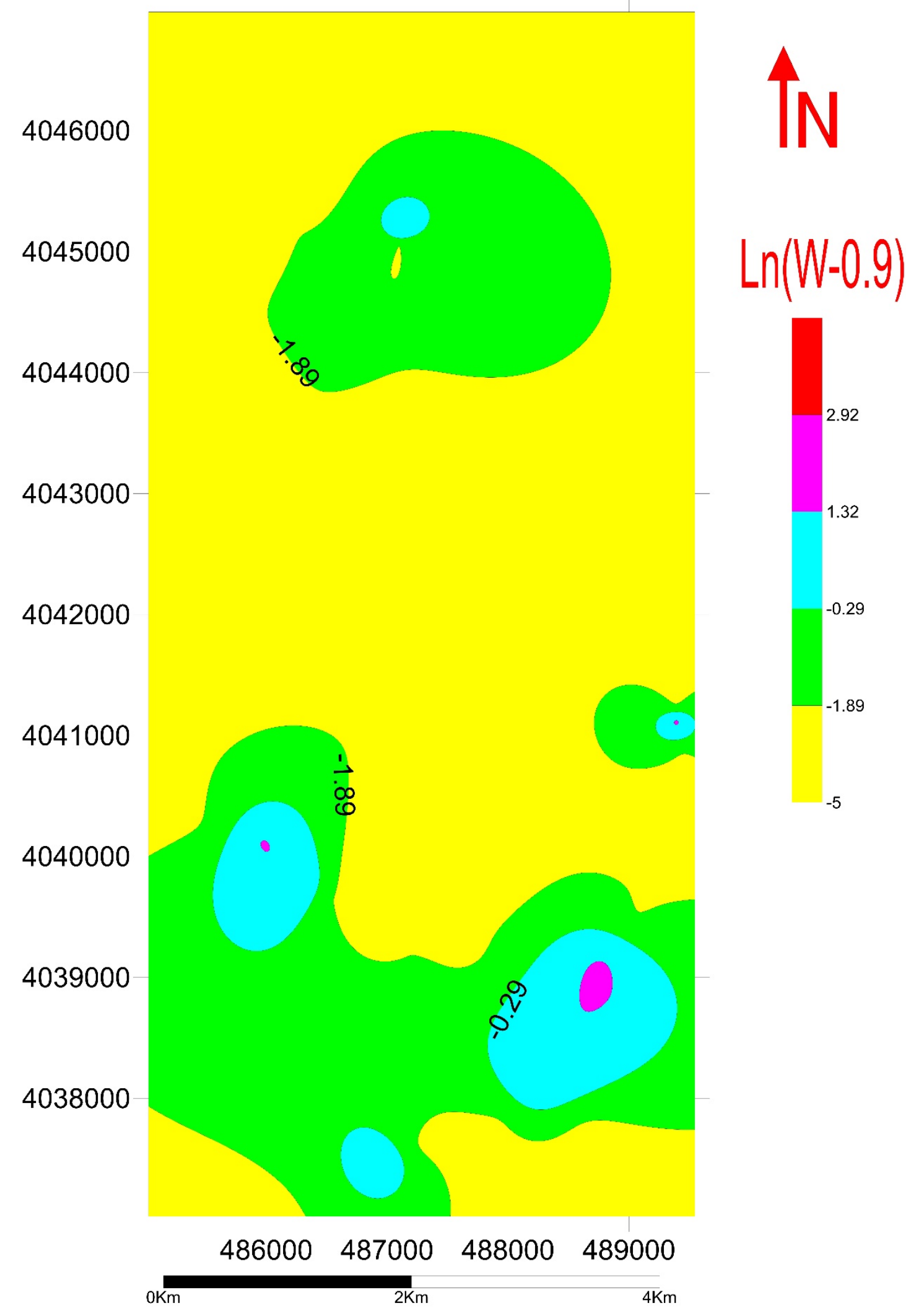

Fig. $31 \mathrm{~W}$ geochemical population distribution map based on threshold method. 


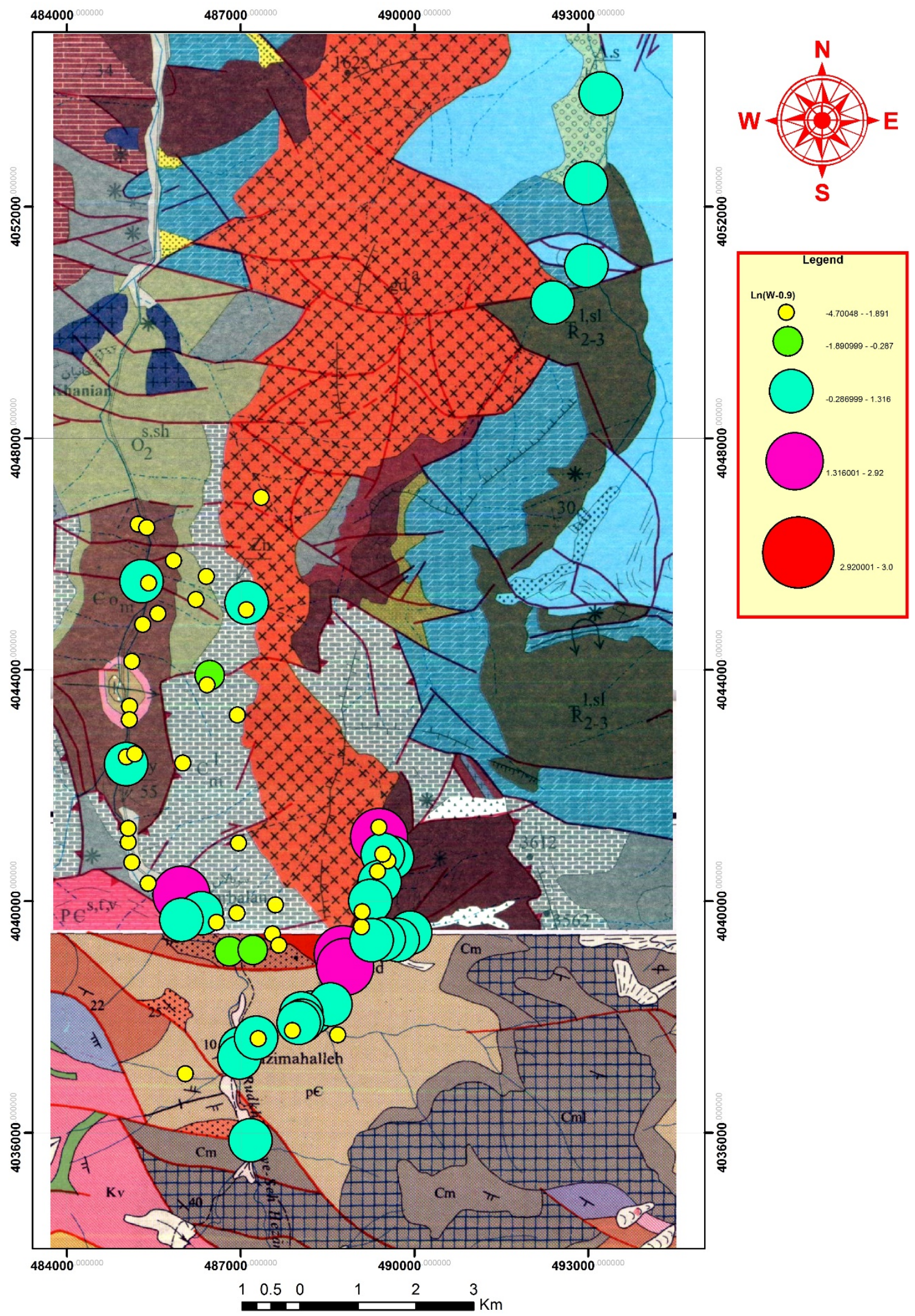

Fig. $32 \mathrm{~W}$ geochemical grade symbolic map based on threshold method. 
Table 1 Results of the anomaly samples by threshold limit and P.N methods.

\begin{tabular}{|c|c|c|c|}
\hline elements & $\begin{array}{c}\text { Anomalous sample } \\
\text { number }\end{array}$ & P.N method & $\begin{array}{l}\text { Raw amount of elements } \\
\text { (PPm (only Au: PPb)) }\end{array}$ \\
\hline \multirow{5}{*}{$\mathrm{Au}$} & SH-019-G & Confirmed & 30 \\
\hline & SH-037-G & Confirmed & 26 \\
\hline & SH-040-G & Confirmed & 133 \\
\hline & $\mathrm{SH}-042-\mathrm{G}$ & Confirmed & 47 \\
\hline & SH-044-G & Confirmed & 729 \\
\hline $\mathrm{Ag}$ & SH-044-G & Confirmed & 2.8 \\
\hline \multirow{2}{*}{ As } & $\mathrm{SH}-025-\mathrm{G}$ & Confirmed & 56.3 \\
\hline & SH-047-G & Confirmed & 77.6 \\
\hline $\mathrm{Ba}$ & SH-042-R & Confirmed & 379 \\
\hline $\mathrm{Cd}$ & SH-025-G & Confirmed & 2.3 \\
\hline \multirow{2}{*}{ Co } & SH-020-G & Confirmed & 33 \\
\hline & SH-037-G & Confirmed & 34 \\
\hline \multirow{3}{*}{$\mathrm{Cu}$} & $\mathrm{SH}-002-\mathrm{G}$ & & 59 \\
\hline & SH-020-G & Confirmed & 69 \\
\hline & SH-046-G & Confirmed & 61 \\
\hline \multirow{2}{*}{$\mathrm{Sb}$} & SH-014-G & Confirmed & 1.35 \\
\hline & $\mathrm{SH}-025-\mathrm{G}$ & Confirmed & 1.36 \\
\hline $\mathrm{Fe}$ & SH-037-G & Confirmed & 81944 \\
\hline $\mathrm{Mn}$ & SH-020-G & Confirmed & 2110 \\
\hline
\end{tabular}




\begin{tabular}{|c|c|c|c|}
\hline elements & $\begin{array}{c}\text { Anomalous sample } \\
\text { number }\end{array}$ & P.N method & $\begin{array}{l}\text { Raw amount of elements } \\
\text { (PPm (only Au: PPb)) }\end{array}$ \\
\hline \multirow{2}{*}{ Mo } & SH-036-G & Confirmed & 1.75 \\
\hline & SH-041-G & Confirmed & 1.9 \\
\hline \multirow{2}{*}{$\mathrm{Ni}$} & $\mathrm{SH}-019-\mathrm{G}$ & Confirmed & 91 \\
\hline & SH-020-G & Confirmed & 96 \\
\hline \multirow{2}{*}{$\mathrm{Pb}$} & SH-045-G & Confirmed & 142 \\
\hline & SH-046-G & Confirmed & 184 \\
\hline \multirow{2}{*}{ S } & SH-039-G & Confirmed & 1937 \\
\hline & SH-041-G & Confirmed & 2266 \\
\hline \multirow{3}{*}{ Th } & SH-010-G & Confirmed & 76.6 \\
\hline & SH-011-G & Confirmed & 36.1 \\
\hline & $\mathrm{SH}-032-\mathrm{G}$ & Confirmed & 57.4 \\
\hline
\end{tabular}


Table 2 Results of the Kolmogorov-Smirnov non-parametric test.

\begin{tabular}{|c|c|c|}
\hline Asymp. Sig. (2-tailed) & Kolmogorov-Smirnov Z & \\
\hline 0.09 & 1.529 & $\operatorname{Ln}(\mathrm{Au})$ \\
\hline 0.08 & 1.269 & $\mathrm{Ln}(\mathrm{Cu}+1.9)$ \\
\hline 0.584 & 0.776 & $\mathrm{Ln}(\mathrm{Fe})$ \\
\hline 0.303 & 0.971 & $\mathrm{Ln}(\mathrm{W}-0.9)$ \\
\hline 0.429 & 0.868 & $\mathrm{Sb}$ \\
\hline 0.267 & 1.003 & $\mathrm{Ln}(\mathrm{As}-0.25)$ \\
\hline 0.162 & 1.121 & $\mathrm{Ln}(\mathrm{Ag}-0.58)$ \\
\hline 0.195 & 1.079 & $\mathrm{Ni}$ \\
\hline 0.220 & 1.050 & $\mathrm{~Pb}$ \\
\hline 0.480 & 0.840 & $\mathrm{Zn}$ \\
\hline
\end{tabular}

Table $3 \mathrm{KMO}$ and Bartlett's test.

\begin{tabular}{|c|c|c|}
\hline \multicolumn{3}{|c|}{ KMO and Bartlett's Test } \\
\hline Kaiser-Meyer-Olkin Measure of Sampling Adequacy. & .784 \\
\hline & $\begin{array}{c}\text { Approx. Chi- } \\
\text { Bartlett's Test of Sphericity }\end{array}$ & 3070.556 \\
\hline
\end{tabular}

Table 4 Factor analysis results that indicated 6 factors. 


\begin{tabular}{|c|c|c|c|c|c|c|}
\hline & \multicolumn{6}{|c|}{ Component } \\
\hline & 1 & 2 & 3 & 4 & 5 & 6 \\
\hline $\mathrm{Al}$ & .283 & -.240 & .839 & . 164 & .243 & .047 \\
\hline $\mathrm{Ni}$ & .580 & .527 & 190 & -.222 & -.213 & -.152 \\
\hline $\mathrm{Pb}$ & .104 & .844 & -.020 & -.121 & .031 & .249 \\
\hline Sc & .465 & -.092 & .773 & -.041 & -.268 & -.001 \\
\hline$Y$ & .700 & .492 & -.046 & -.123 & .123 & .074 \\
\hline $\mathrm{Zn}$ & 290 & .779 & .160 & -.008 & .001 & .326 \\
\hline $\mathrm{Zr}$ & .516 & .641 & .192 & -.248 & .150 & -.116 \\
\hline $\operatorname{Ln}(\mathrm{Au})$ & 179 & -.020 & .140 & -.037 & -.118 & .800 \\
\hline $\operatorname{Ln}(\mathrm{Cr})$ & .802 & .239 & .346 & -.128 & .016 & -.114 \\
\hline $\operatorname{Ln}(\mathrm{Ca})$ & -.269 & -.086 & -.848 & .204 & -.275 & .008 \\
\hline $\operatorname{Ln}(\mathrm{Ce})$ & .906 & -.091 & .178 & -.012 & .252 & .207 \\
\hline $\operatorname{Ln}(\mathrm{Co})$ & .835 & .349 & .157 & -.198 & -.080 & -.066 \\
\hline $\operatorname{Ln}(\mathrm{Fe})$ & .893 & .065 & .361 & -.055 & .069 & .071 \\
\hline $\operatorname{Ln}(\mathrm{La})$ & .866 & -.034 & .136 & -.060 & .418 & .111 \\
\hline Ln(Mn) & .524 & .211 & .626 & -.096 & -.148 & .280 \\
\hline $\mathrm{Ln}(\mathrm{Na})$ & .502 & -.303 & .459 & .142 & .470 & .190 \\
\hline $\operatorname{Ln}(S)$ & -.179 & -.214 & -.194 & .791 & -.112 & -.142 \\
\hline $\operatorname{Ln}(\mathrm{Ti})$ & .909 & .102 & .296 & -.128 & .112 & .051 \\
\hline $\operatorname{Ln}(V)$ & .895 & .127 & .302 & -.145 & .109 & .003 \\
\hline $\operatorname{Ln}(\mathrm{Ag}-0.58)$ & -.637 & -.356 & .198 & .466 & -.247 & .195 \\
\hline $\operatorname{Ln}(A s-0.25)$ & -.052 & .535 & -.165 & .422 & .100 & -.044 \\
\hline $\operatorname{Ln}(\mathrm{Be}-0.14)$ & .336 & .191 & .351 & -.265 & .756 & -.035 \\
\hline $\operatorname{Ln}(\mathrm{Bi}-0.65)$ & -.200 & -.794 & .296 & .204 & -.047 & .177 \\
\hline $\operatorname{Ln}(\mathrm{Cd}-0.65)$ & -.051 & .761 & -.237 & .116 & -.132 & -.118 \\
\hline $\operatorname{Ln}(\mathrm{Cu}+1.9)$ & .407 & .699 & .216 & -.336 & -.008 & -.089 \\
\hline $\operatorname{Ln}(K+2)$ & .070 & -.238 & .823 & .093 & .414 & .135 \\
\hline $\operatorname{Ln}(\mathrm{Mg}-0.35)$ & -.231 & -.021 & -.162 & -.266 & -.702 & .369 \\
\hline $\operatorname{Ln}(\mathrm{Mo}-0.7)$ & -.279 & -.194 & .276 & .728 & .212 & .038 \\
\hline $\operatorname{Ln}(\mathrm{P}-0.19)$ & .854 & 222 & .005 & -.101 & .067 & .208 \\
\hline $\operatorname{Ln}(\mathrm{Sr}-0.31)$ & -.100 & -.794 & .096 & .453 & -.054 & .133 \\
\hline
\end{tabular}




\section{Appendices}

\subsection{Figure and table captions}

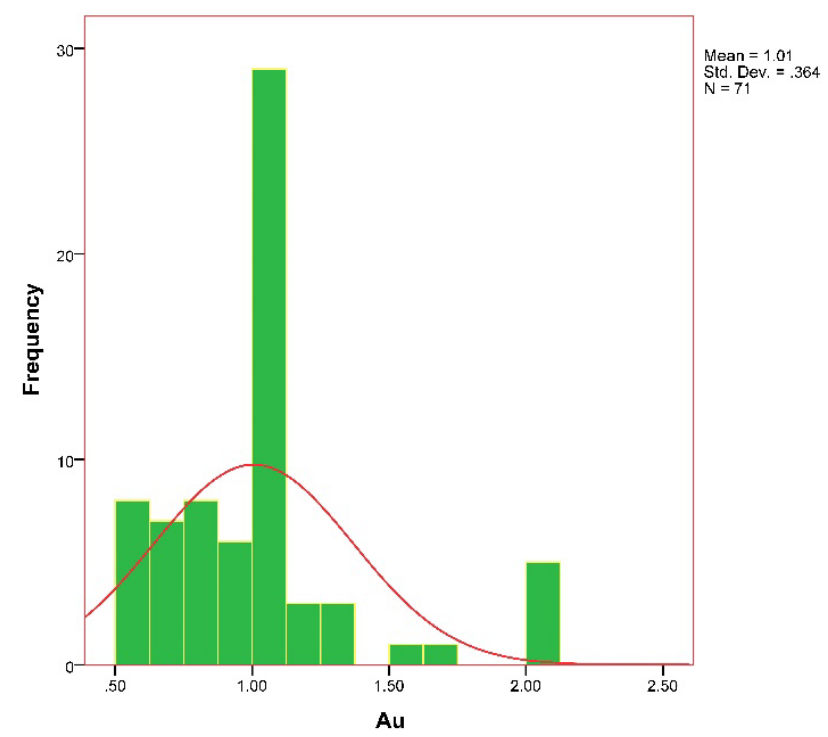

Fig. A. 1 Histogram of Au for raw data.

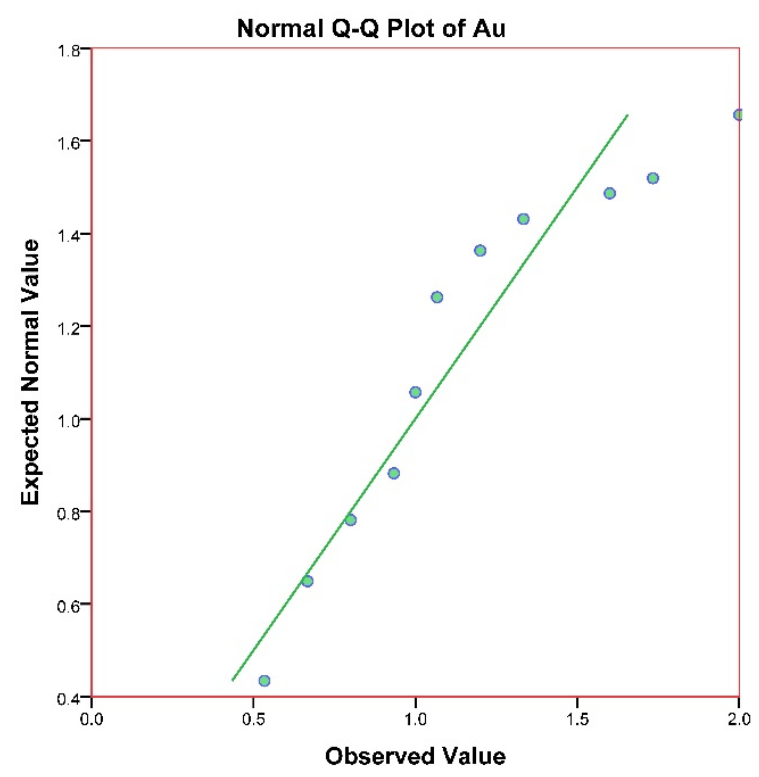

Fig. A. 2 Q-Q Plot of Au for raw data. 


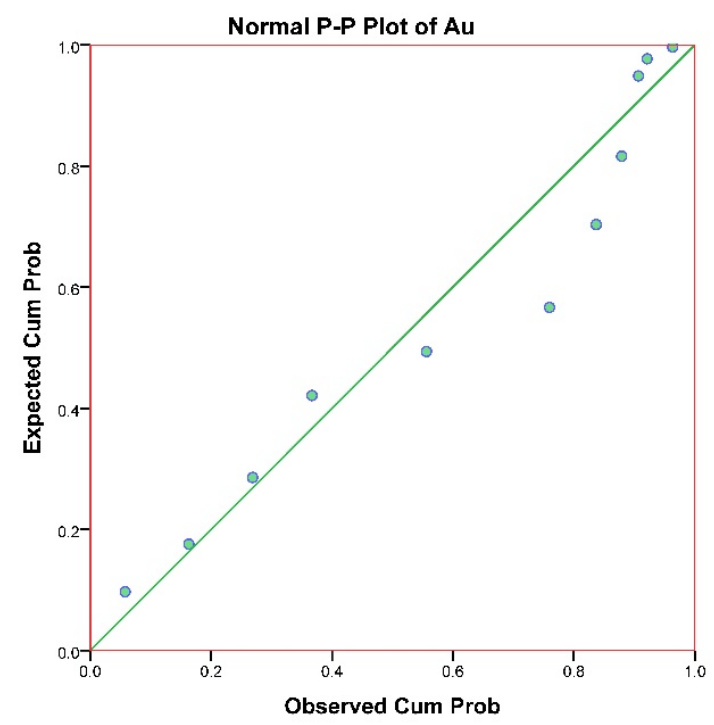

Fig. A. 3 P-P Plot of Au for raw data.

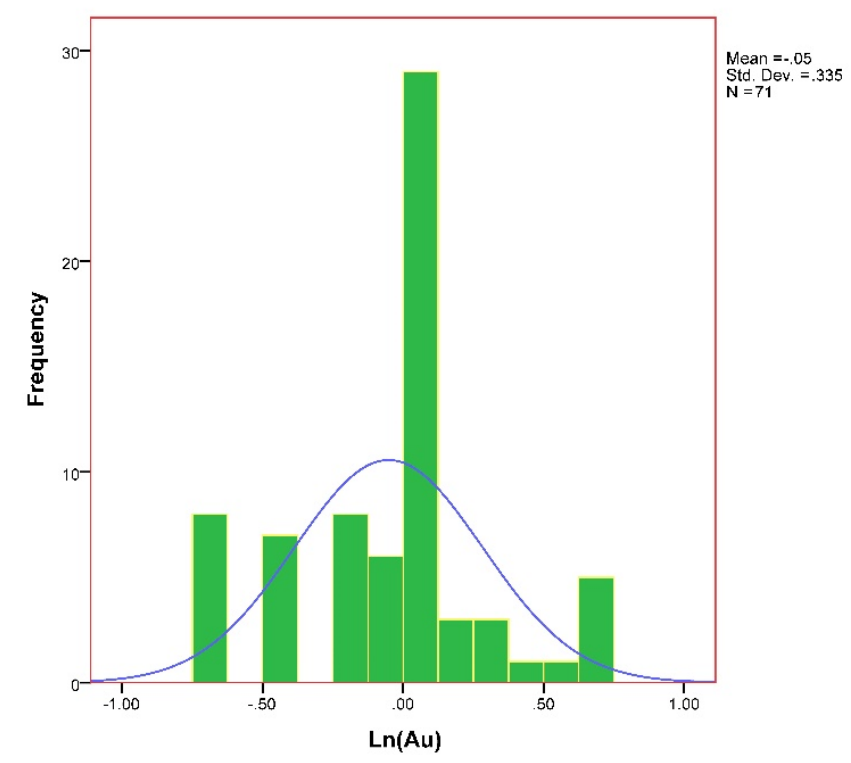

Fig. A. 4 Histogram of Au for normalized data. 


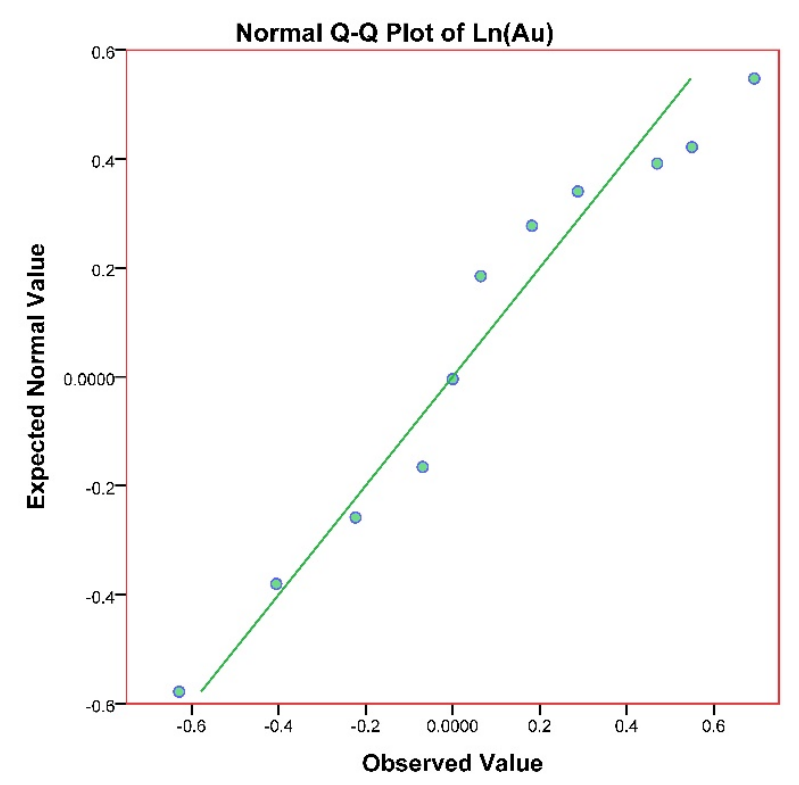

Fig. A. 5 Q-Q Plot of Au for normalized data.

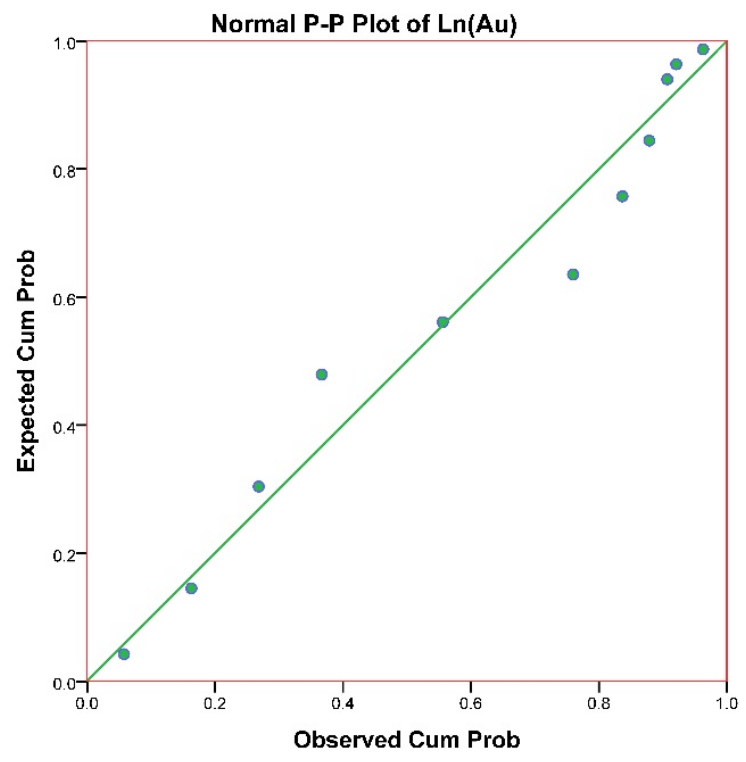

Fig. A. 6 P-P Plot of Au for normalized data. 


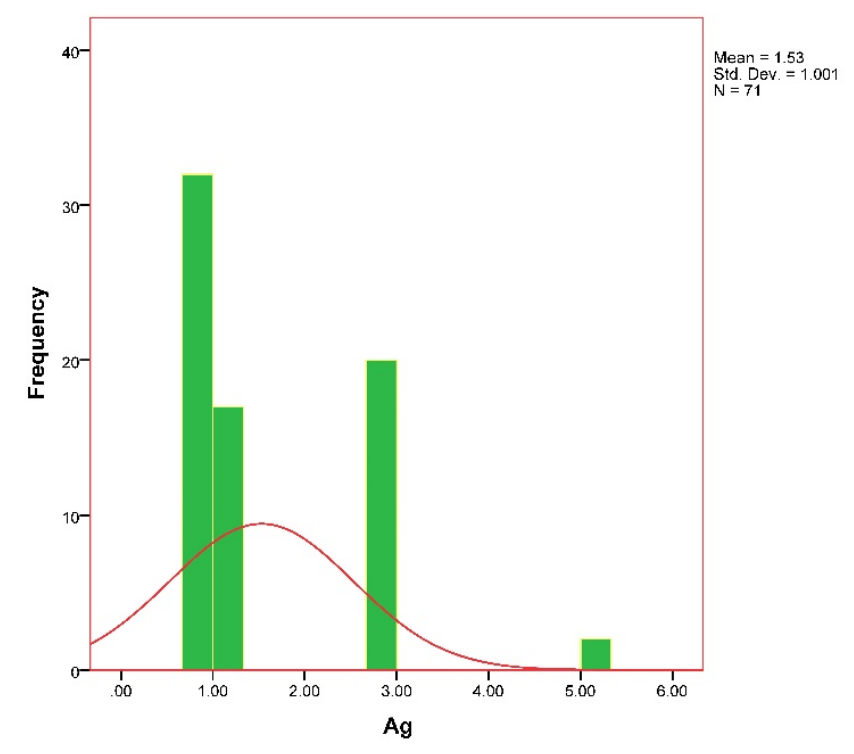

Fig. A. 7 Histogram of Ag for raw data.

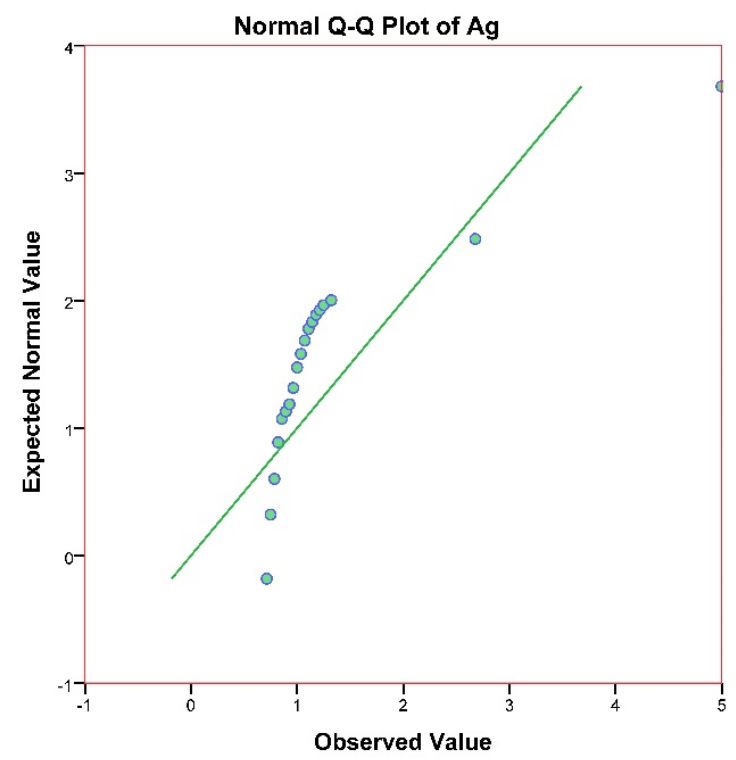

Fig. A. 8 Q-Q Plot of Ag for raw data. 


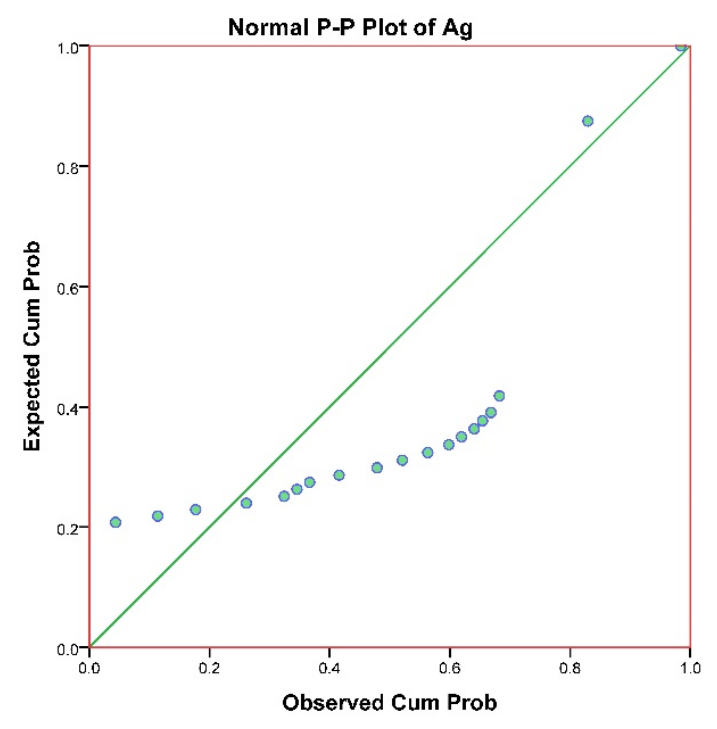

Fig. A. 9 P-P Plot of Ag for raw data.

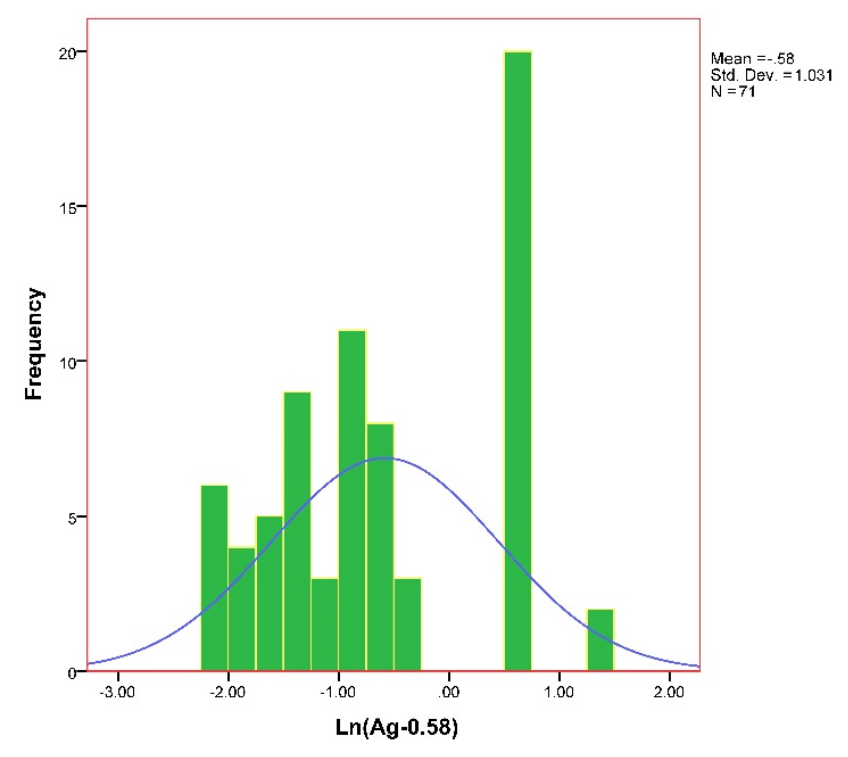

Fig. A. 10 Histogram of Ag for normalized data. 


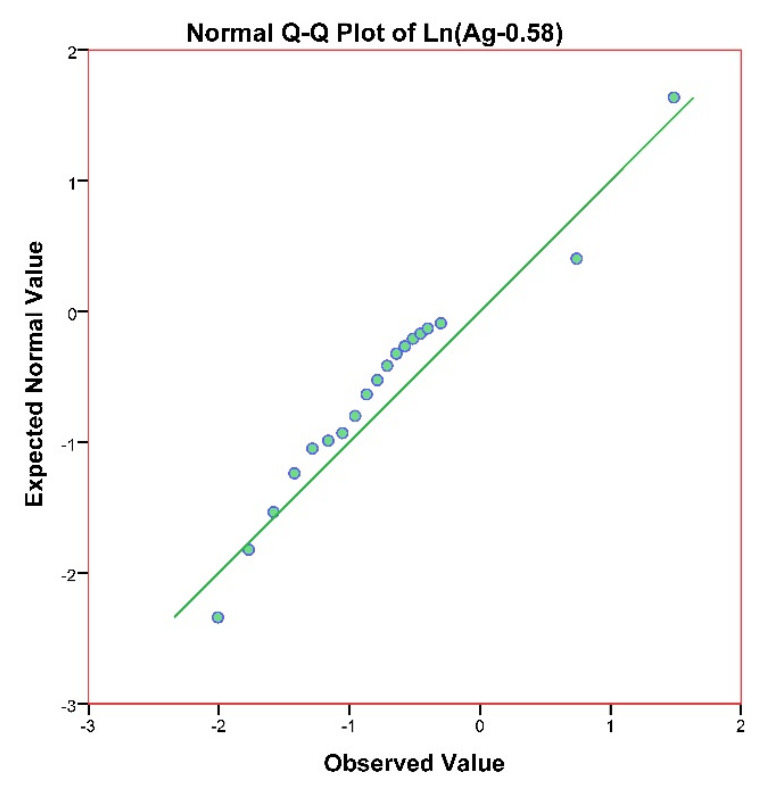

Fig. A. 11 Q-Q Plot of Ag for normalized data.

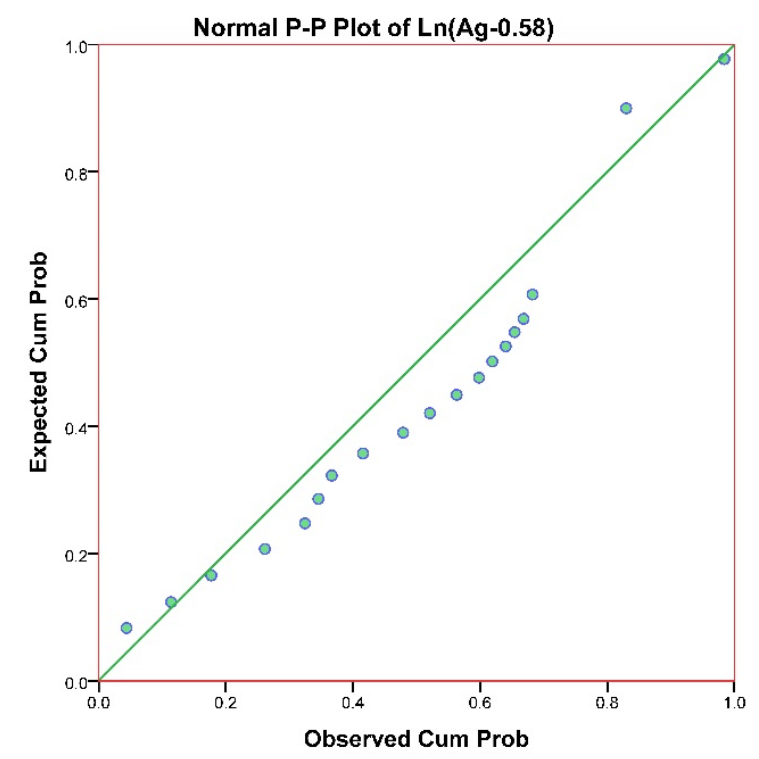

Fig. A. 12 P-P Plot of Ag for normalized data. 


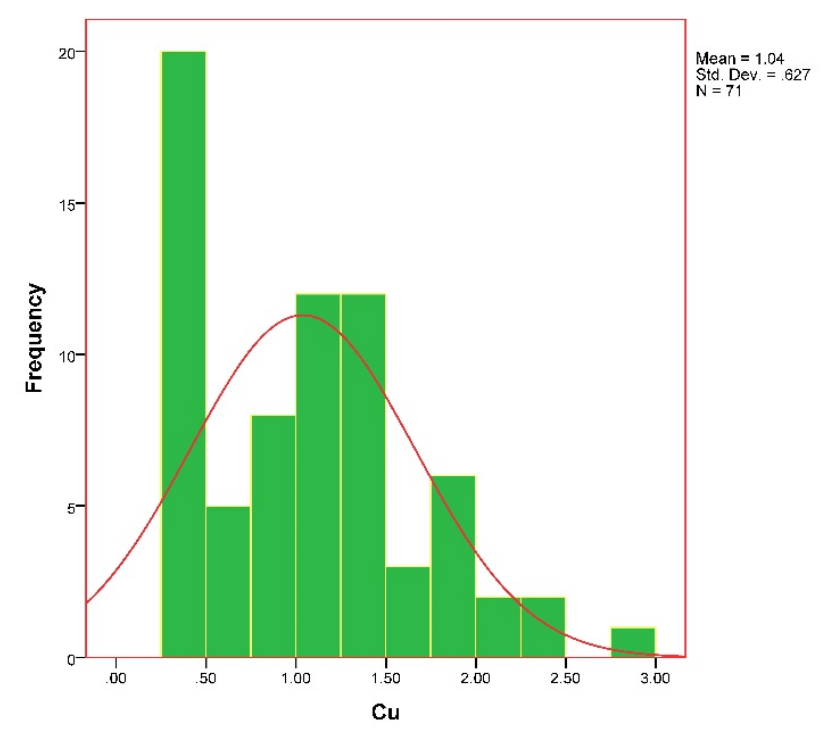

Fig. A. 13 Histogram of Cu for raw data.

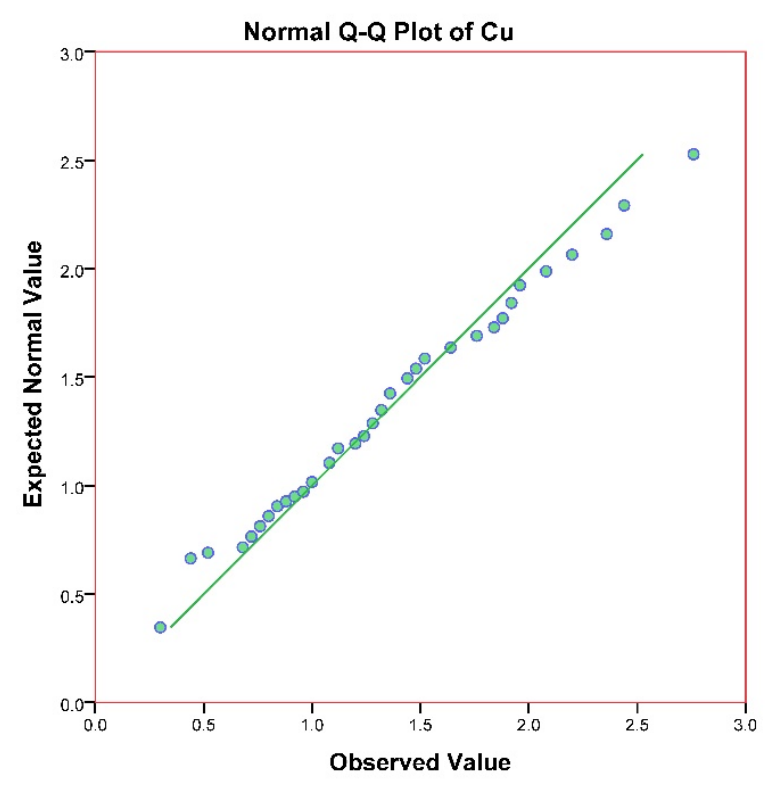

Fig. A. 14 Q-Q Plot of Cu for raw data. 


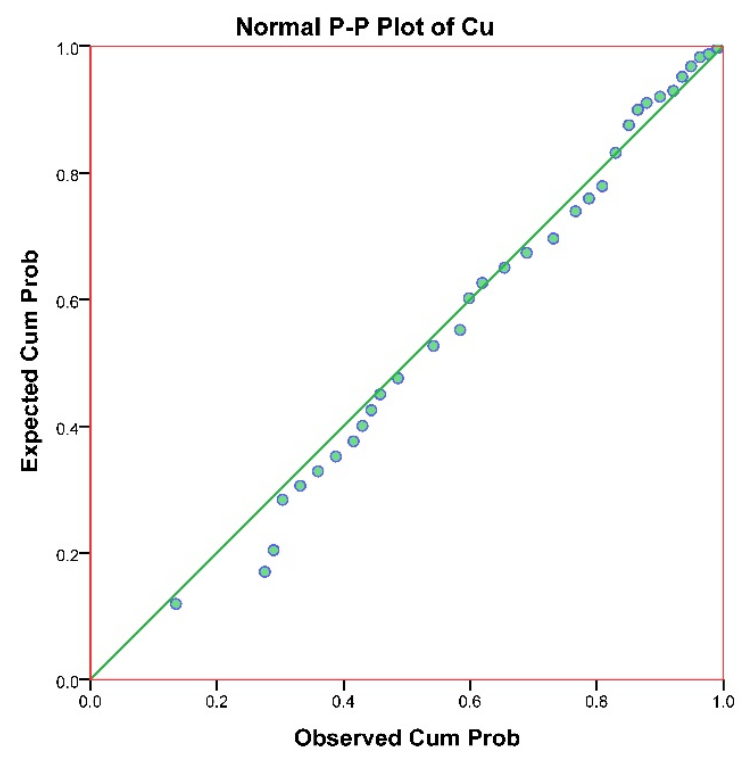

Fig. A. 15 P-P Plot of Cu for raw data.

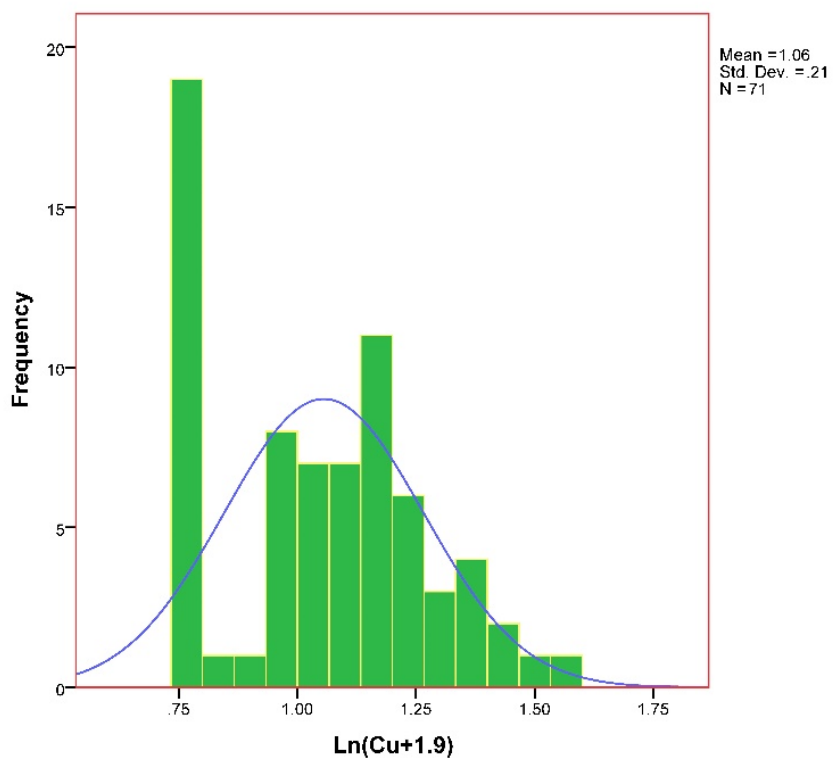

Fig. A. 16 Histogram of Cu for normalized data. 


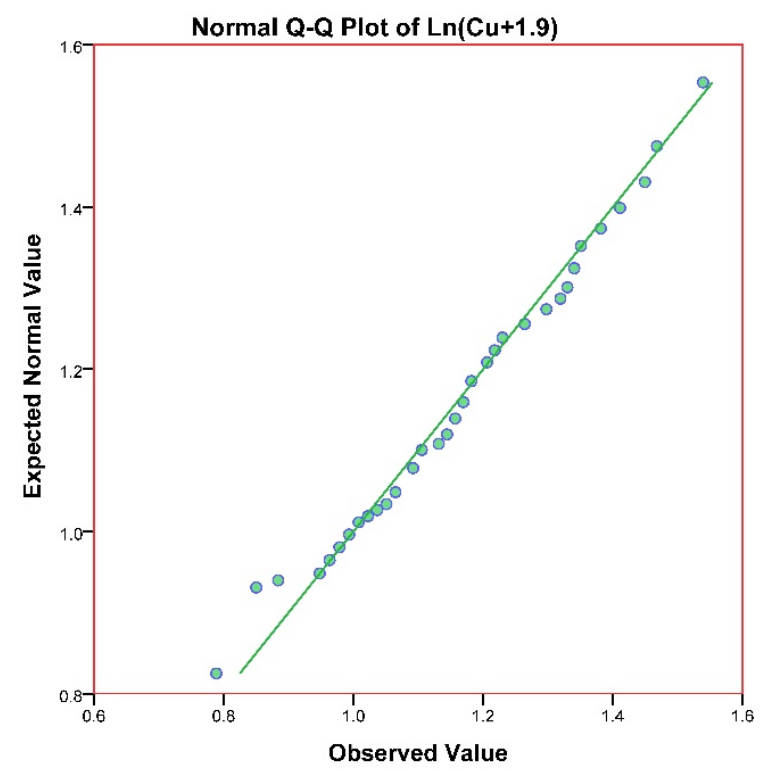

Fig. A. 17 Q-Q Plot of Cu for normalized data.

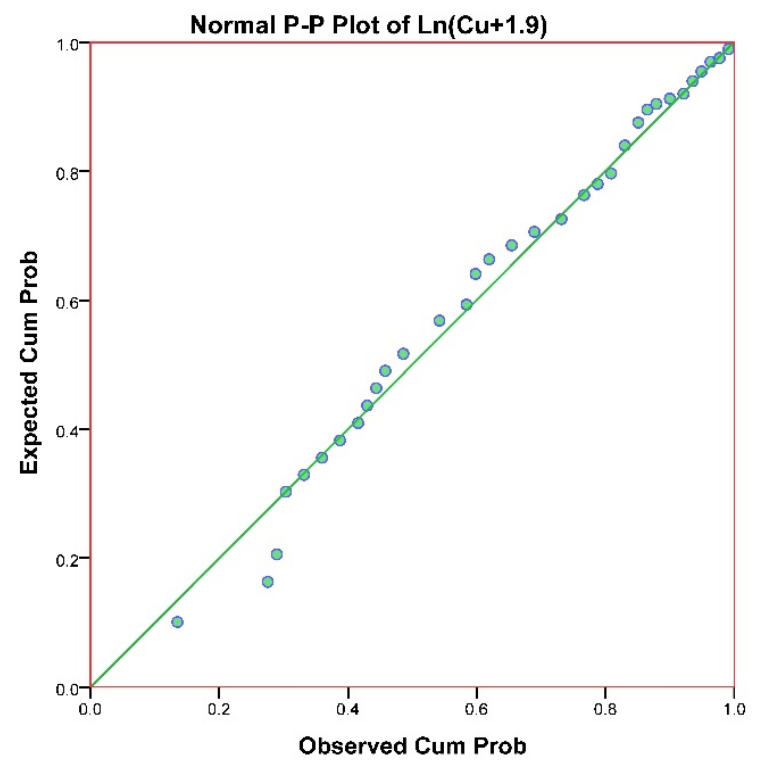

Fig. A. 18 P-P Plot of Cu for normalized data. 


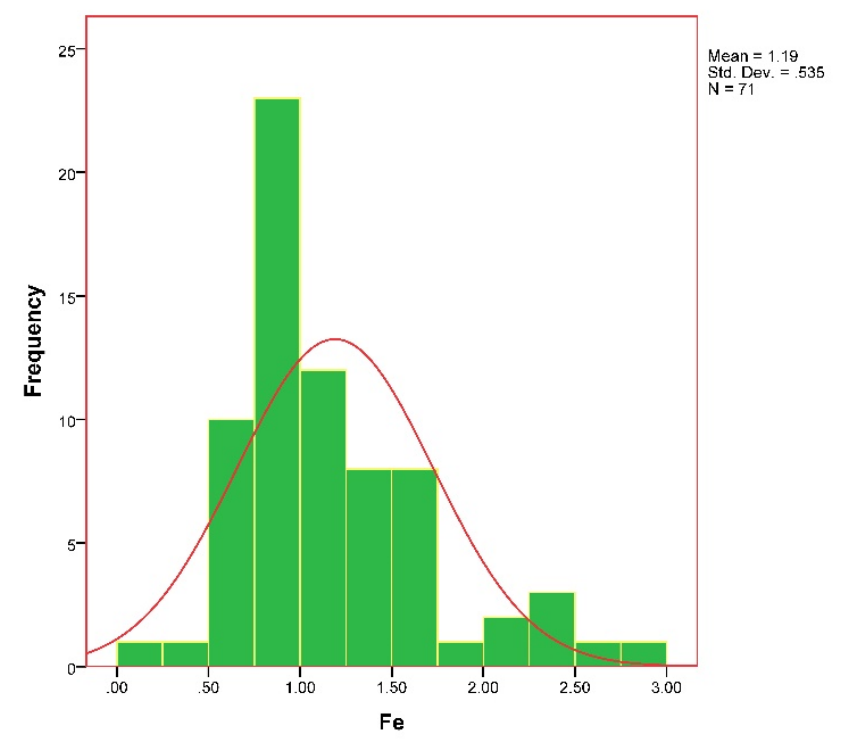

Fig. A. 19 Histogram of Fe for raw data.

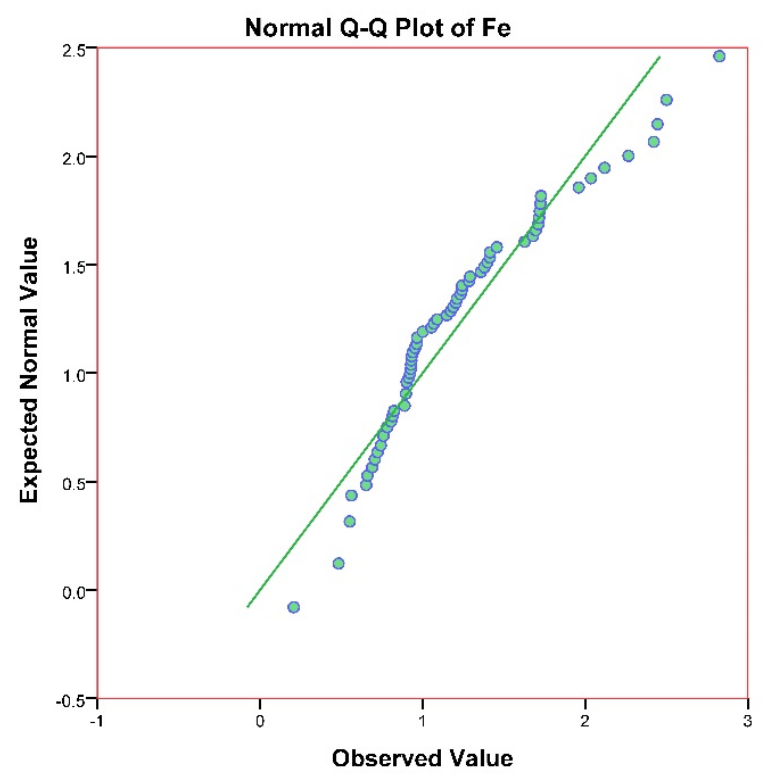

Fig. A. 20 Q-Q Plot of Fe for raw data. 


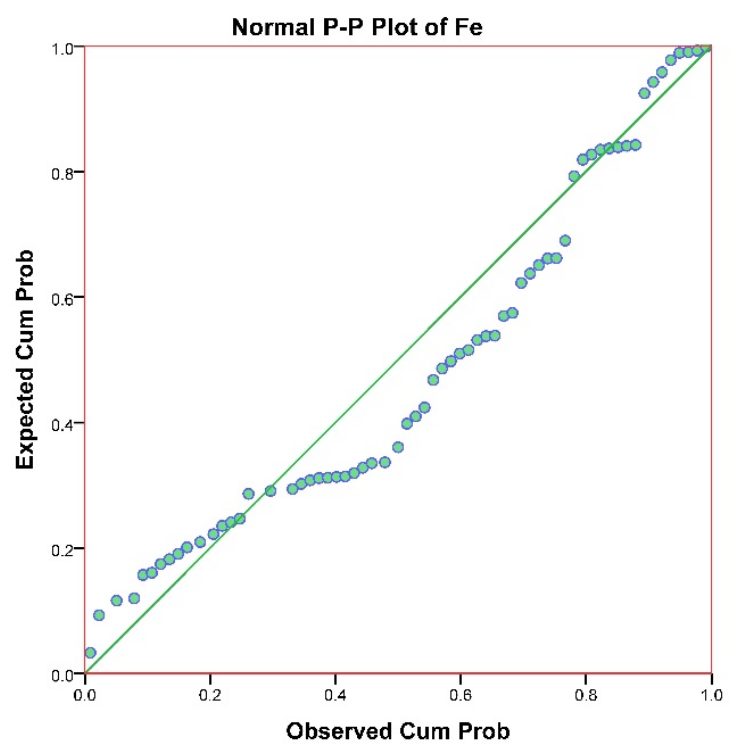

Fig. A. 21 P-P Plot of Fe for raw data.

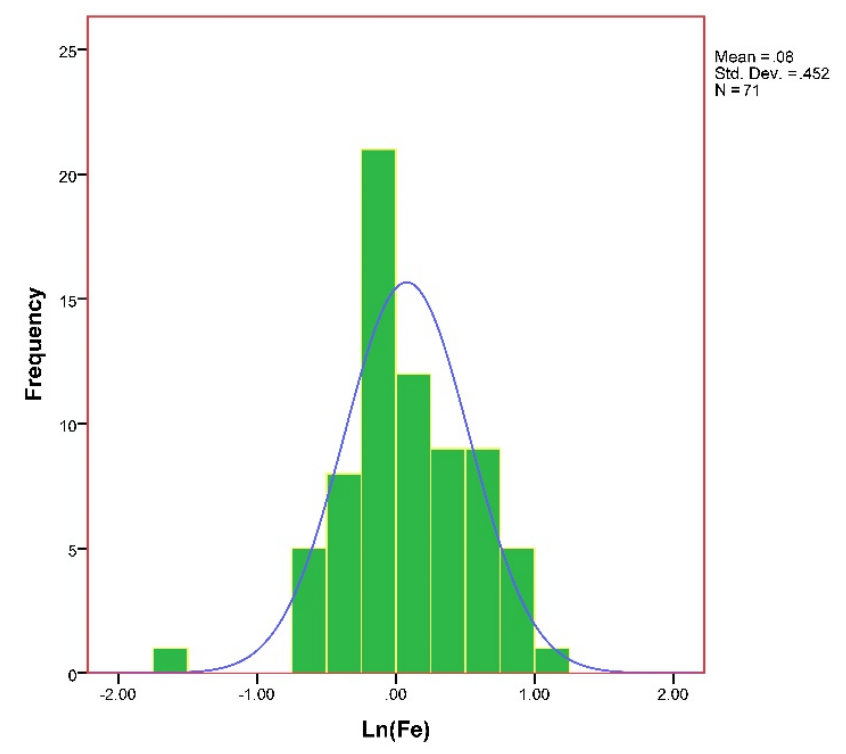

Fig. A. 22 Histogram of Fe for normalized data. 


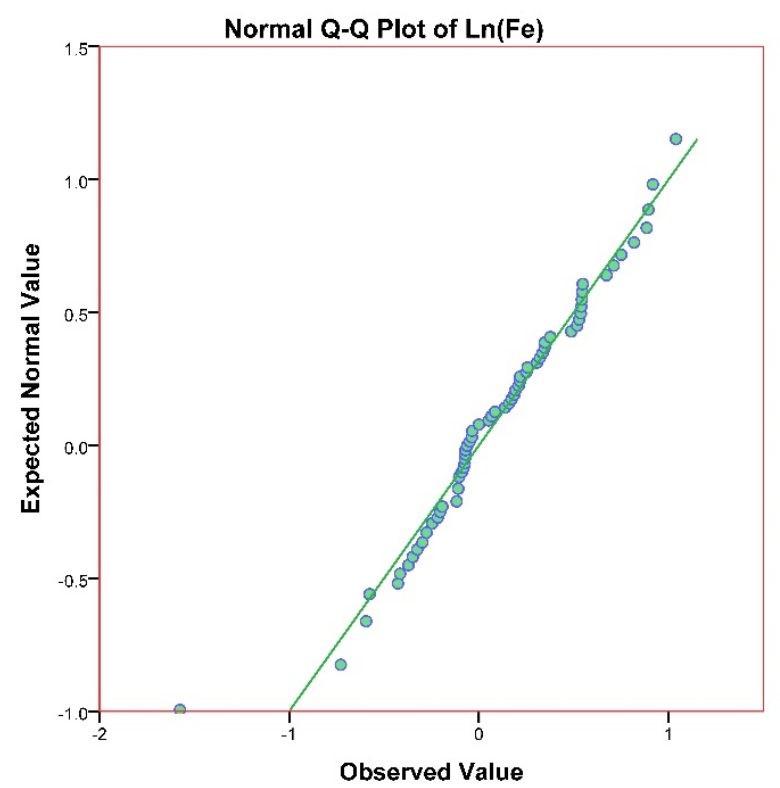

Fig. A. 23 Q-Q Plot of Fe for normalized data.

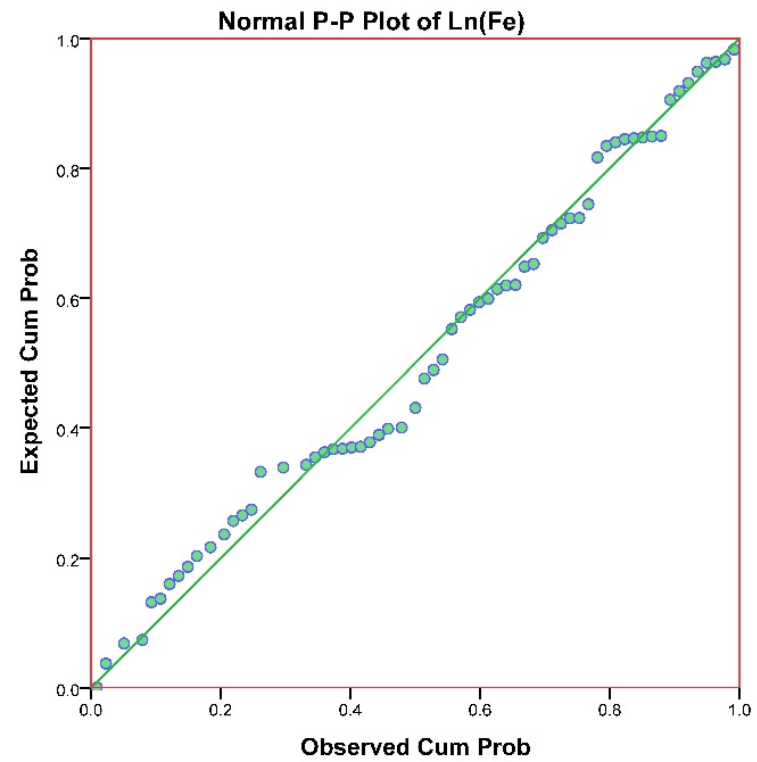

Fig. A. 24 P-P Plot of Fe for normalized data. 


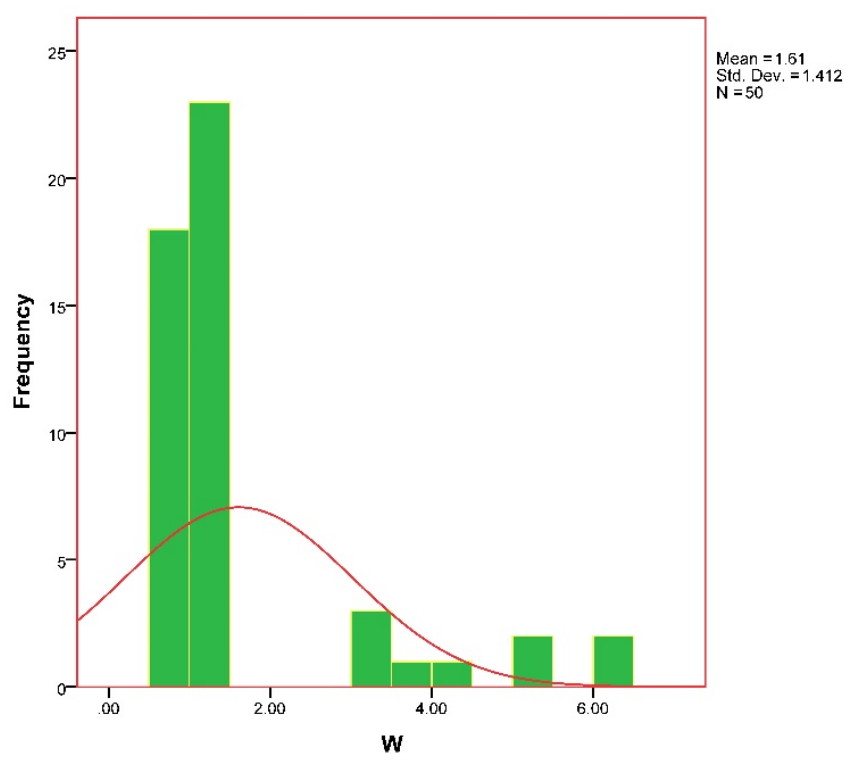

Fig. A. 25 Histogram of $W$ for raw data.

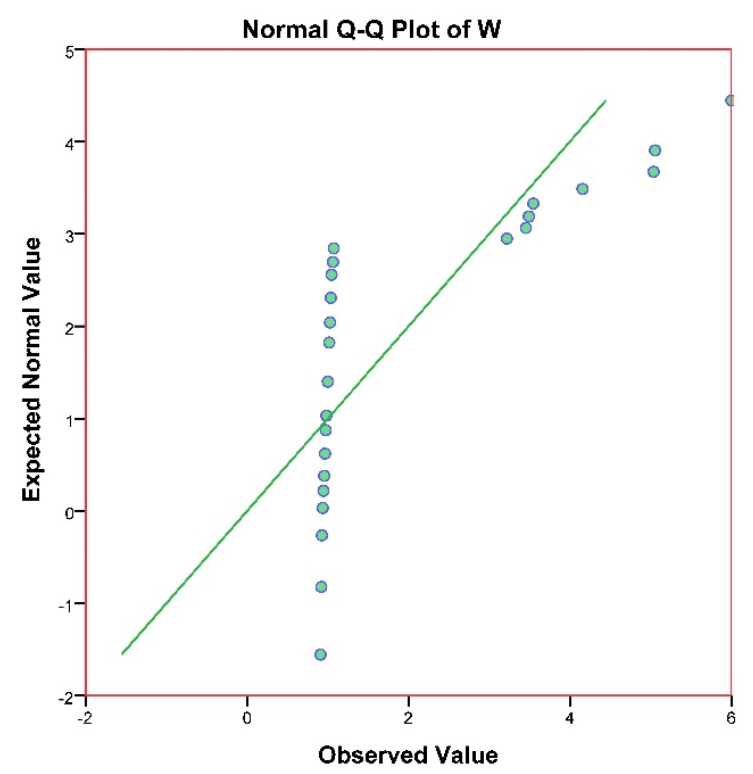

Fig. A. 26 Q-Q Plot of W for raw data. 


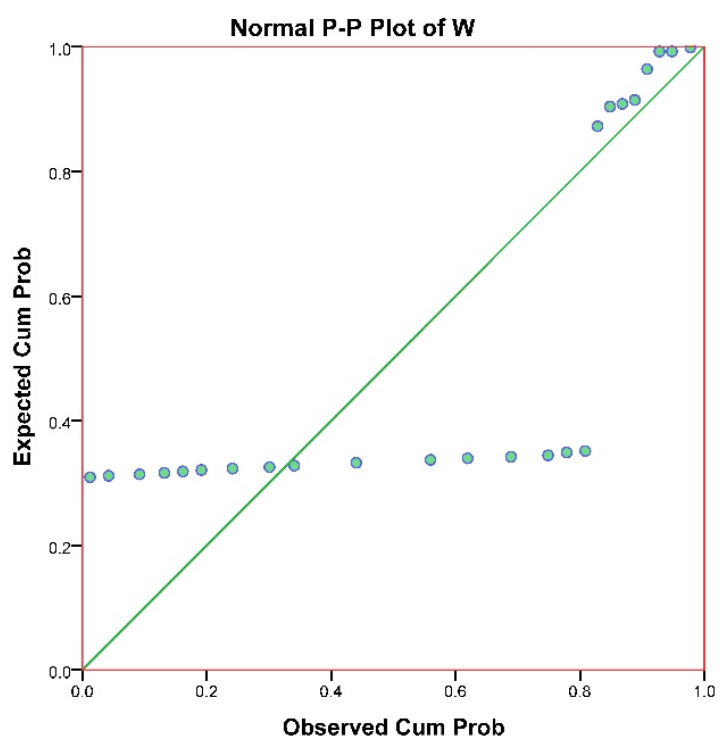

Fig. A. 27 P-P Plot of $W$ for raw data.

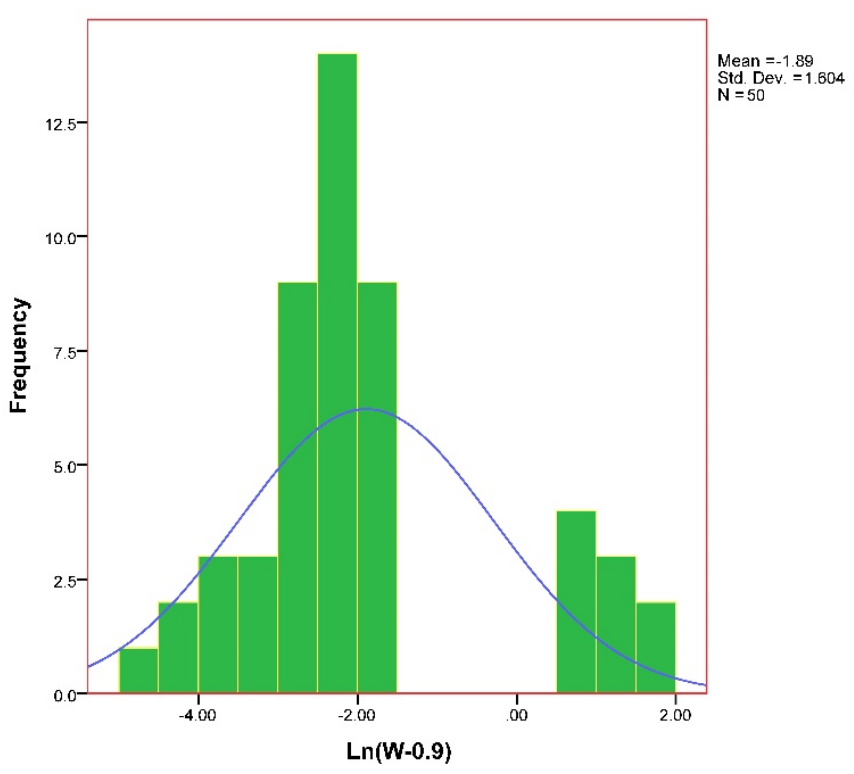

Fig. A. 28 Histogram of $W$ for normalized data. 


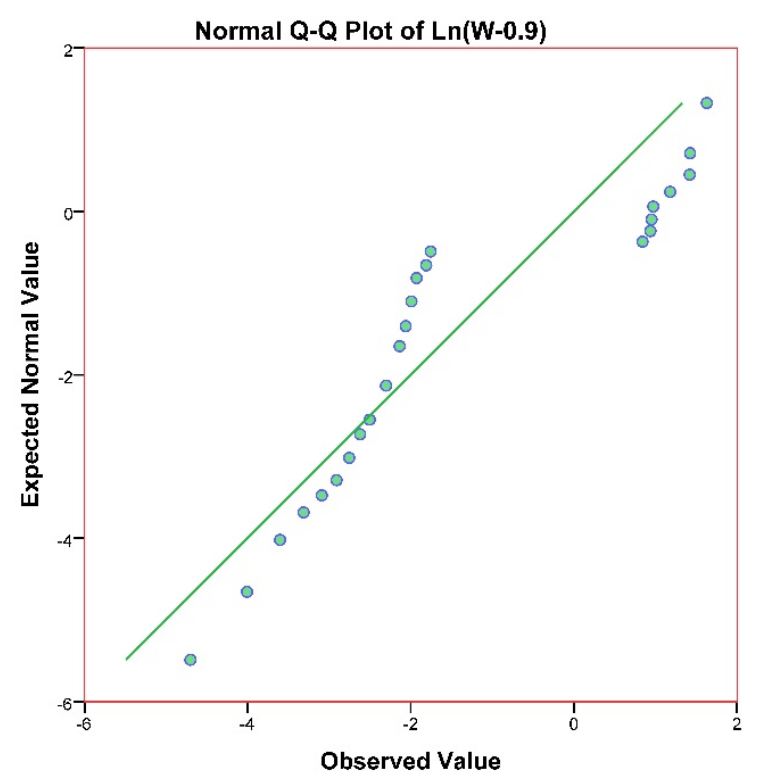

Fig. A. 29 Q-Q Plot of $W$ for normalized data.

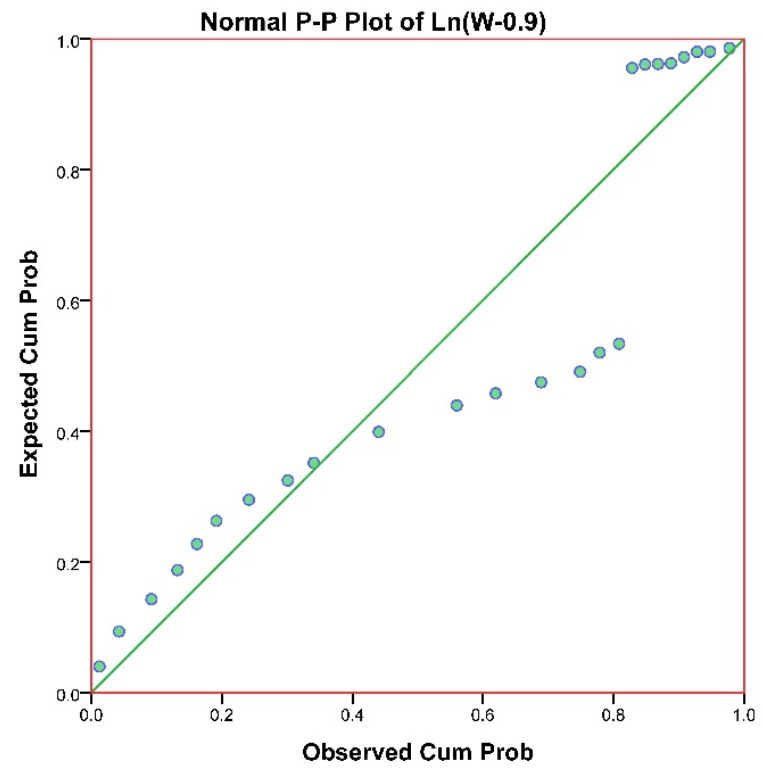

Fig. A. 30 P-P Plot of $W$ for normalized data. 
reprints (wWw.preprints.org) | NOT PEER-REVIEWED | Posted: 20 October $2019 \quad$ doi:10.20944/preprints201910.0237.v1

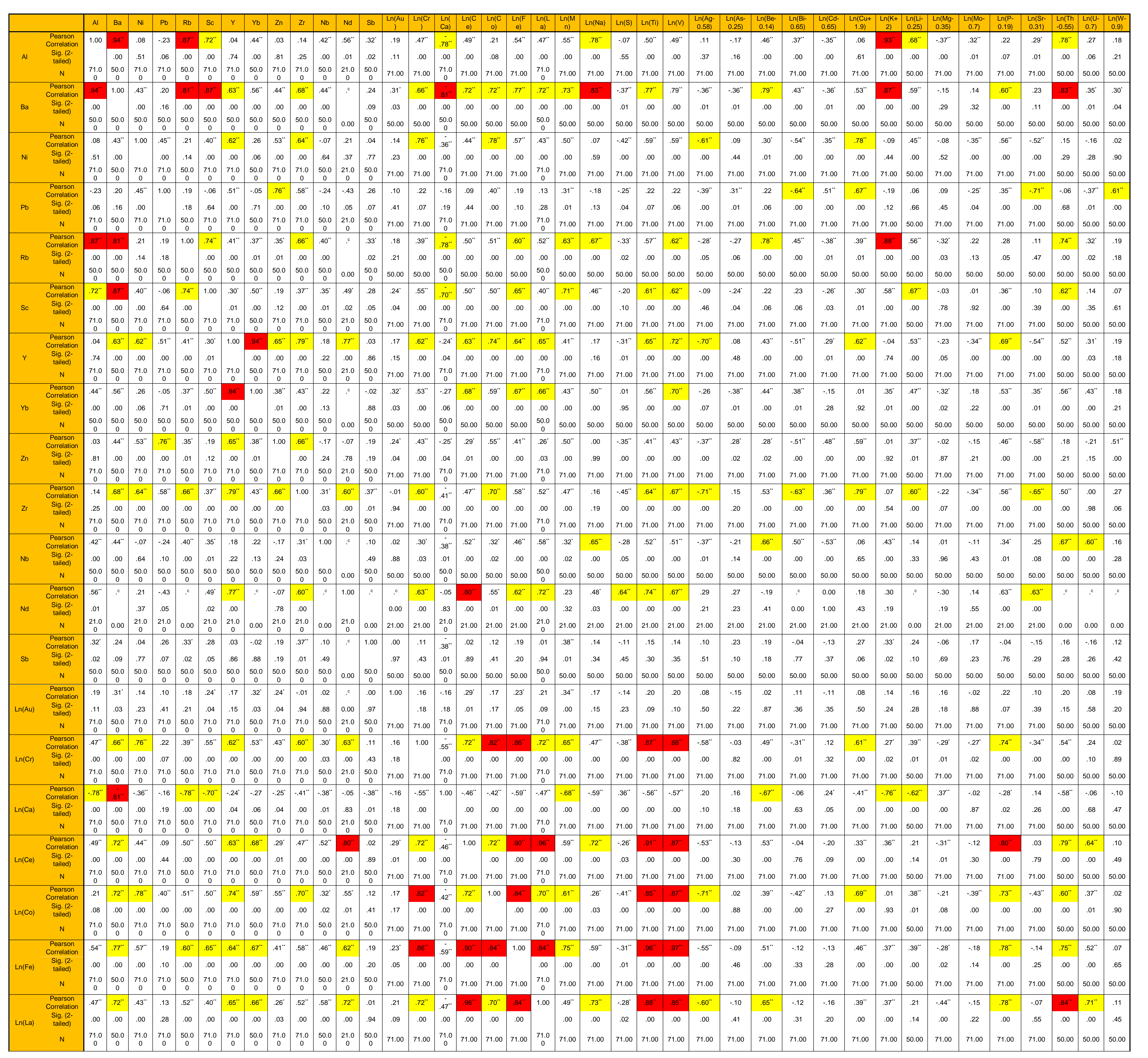




\begin{tabular}{|c|c|c|c|c|c|c|c|c|c|c|c|c|c|c|c|c|c|c|c|c|c|c|c|c|c|c|c|c|c|c|c|c|c|c|c|c|c|}
\hline & & $\mathrm{Al}$ & \begin{tabular}{|l|} 
Ba \\
\end{tabular} & $\mathrm{Ni}$ & $\mathrm{Pb}$ & Rb & Sc & r & $\mathrm{Yb}$ & $\mathrm{zn}$ & $\mathrm{zr}$ & Nb & Nd & sb & $\mid \begin{array}{c}\operatorname{Ln}(\mathrm{AU}) \\
\mathrm{f}\end{array}$ & $\mid \begin{array}{c}\operatorname{Ln}(\mathrm{Cl} r \\
1\end{array}$ & \begin{tabular}{|l|}
\begin{tabular}{ll|} 
Lnd \\
ca)
\end{tabular} \\
\end{tabular} & \begin{tabular}{l|}
$\operatorname{Ln}(C)$ \\
e)
\end{tabular} & \begin{tabular}{|l|}
$\operatorname{Ln}(C)$ \\
0
\end{tabular} & \begin{tabular}{|l|}
$\operatorname{Ln}(F)$ \\
e
\end{tabular} & \begin{tabular}{|l|}
$\operatorname{Ln}(\mathrm{L})$ \\
a)
\end{tabular} & $\mid$\begin{tabular}{|l|}
$\operatorname{Ln}(M)$ \\
$n)$
\end{tabular} & $\operatorname{Ln}(\mathrm{Na})$ & $\operatorname{Ln}(s)$ & $\mid \operatorname{Ln}(\mathrm{T})$ & $\operatorname{Ln}(v)$ & $\begin{array}{l}\ln (\mathrm{AQQ}- \\
0.58\end{array}$ & $\begin{array}{l}\text { Ln(AS.) } \\
0.25\end{array}$ & 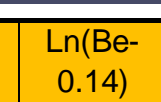 & \begin{tabular}{|l}
$\ln (8) \cdot(1)$ \\
$0.65)$
\end{tabular} & $\begin{array}{l}\text { Lnc(Cd- } \\
0.65)\end{array}$ & $\begin{array}{l}\text { In(Cut) } \\
1.9)\end{array}$ & $\begin{array}{c}\frac{\ln (K)+}{2} \\
2)\end{array}$ & $\mid$ & 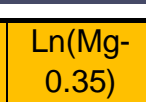 & $\begin{array}{l}\operatorname{Ln}(\mathrm{M} M O- \\
0,7)\end{array}$ & $\begin{array}{l}\ln (P-P) \\
0.19)\end{array}$ \\
\hline & $\begin{array}{l}\text { arsanon } \\
\text { relataion }\end{array}$ & \begin{tabular}{|l}
$.55^{\prime \prime}$ \\
\end{tabular} & $\frac{73^{\prime \prime}}{}$ & $.50^{\prime \prime}$ & .31" & $.63^{\prime \prime}$ & $\begin{array}{l}.71 \\
\end{array}$ & $.41^{\circ 1}$ & $.43^{\prime \prime}$ & $.50^{\prime \prime}$ & $.47^{\prime \prime}$ & $.32^{\circ}$ & .23 & $.38^{\prime \prime}$ & $.34^{\prime \prime}$ & $.65^{\prime \prime}$ & $.60^{\prime \prime}$ & $.59^{\prime \prime}$ & \begin{tabular}{|l|l}
$.61^{\prime \prime}$ \\
\end{tabular} & $.75^{\prime \prime}$ & . $49^{\prime \prime \prime}$ & $\begin{array}{ll}1.00 \\
\end{array}$ & $.47^{\prime \prime}$ & $-.35^{\prime \prime}$ & $70^{\circ}$ & $.66^{\prime \prime}$ & $.26^{\prime}$ & .00 & $.36^{\prime \prime}$ & .05 & .10 & $.49^{\prime \prime}$ & $.45^{\prime \prime}$ & $.48^{\prime \prime}$ & .02 & .15 & $.58^{\prime \prime}$ \\
\hline $\operatorname{Ln}(M n)$ & $\begin{array}{l}\text { sig, (2- } \\
\text { taled) }\end{array}$ & $\mid .00$ & .00 & .00 & 01 & .00 & \begin{tabular}{|l|}
.00 \\
\end{tabular} & .00 & .00 & .00 & .00 & .02 & .32 & .01 & .00 & .00 & \begin{tabular}{|l|}
.00 \\
\end{tabular} & .00 & .00 & .00 & .00 & & .00 & .00 & .00 & .00 & .03 & .98 & .00 & .70 & .42 & .00 & .00 & .00 & .87 & .22 & .00 \\
\hline & N & \begin{tabular}{|c|}
71.0 \\
0
\end{tabular} & $\begin{array}{c}50.0 \\
0\end{array}$ & $\begin{array}{c}71.0 \\
0\end{array}$ & $\begin{array}{c}71.0 \\
0\end{array}$ & \begin{tabular}{|c|c|}
50.0 \\
0
\end{tabular} & $\mid \begin{array}{c}71.0 \\
0\end{array}$ & \begin{tabular}{|c|}
71.0 \\
0
\end{tabular} \mid & \begin{tabular}{|c|}
50.0 \\
0
\end{tabular} & $\begin{array}{c}71.0 \\
0\end{array}$ & \begin{tabular}{|c|}
71.0 \\
0
\end{tabular} & \begin{tabular}{|l|}
50.0 \\
0
\end{tabular} & $\mid \begin{array}{c}21.0 \\
0\end{array}$ & $\begin{array}{l}50.0 \\
0\end{array}$ & 71.00 & 71.00 & $\mid \begin{array}{c}71.0 \\
0\end{array}$ & \begin{tabular}{|l|l|} 
\\
71.00
\end{tabular} & 71.00 & 71.00 & \begin{tabular}{|c|c|c|}
11.0 \\
0
\end{tabular} & 71.00 & 71.00 & 71.00 & 71.00 & \begin{tabular}{|l|l|} 
& 71.00 \\
\end{tabular} & 71.00 & 71.00 & 71.00 & 71.00 & 71.00 & 71.00 & 71.00 & 50.00 & 71.00 & 71.00 & 71.00 \\
\hline & $\begin{array}{l}\text { 位arson } \\
\text { Corretation }\end{array}$ & \begin{tabular}{|l|l|}
$.78^{\prime \prime}$ \\
\end{tabular} & & .07 & -.18 & $.67^{\prime \prime}$ & $.46^{\prime \prime}$ & $\begin{array}{l}.17 \\
\end{array}$ & $.50^{\circ}$ & \begin{tabular}{|l|}
.00 \\
\end{tabular} & \begin{tabular}{|l|}
.16 \\
\end{tabular} & $.65^{\prime \prime}$ & $\begin{array}{l}.48^{\circ} \\
\end{array}$ & .14 & .17 & .47" & \begin{tabular}{|c|}
$.59^{\prime \prime}$ \\
\end{tabular} & $.72^{\prime \prime}$ & $.26^{\circ}$ & .59" & \begin{tabular}{|l}
$.73^{\prime \prime}$ \\
\end{tabular} & $.47^{\prime \prime}$ & \begin{tabular}{|l|l|}
1.00 \\
\end{tabular} & \begin{tabular}{|l|}
.10 \\
\end{tabular} & $.62^{\prime \prime}$ & \begin{tabular}{|l|l|}
$.53^{\prime \prime}$ \\
\end{tabular} & -.13 & .09 & $.56^{\prime \prime}$ & $.28^{\circ}$ & $-37^{\prime \prime}$ & .06 & $.74^{\prime \prime}$ & $.32^{\circ}$ & $-.37^{\prime \prime}$ & .19 & $.50^{\circ}$ \\
\hline $\operatorname{Ln}(\mathrm{Na})$ & 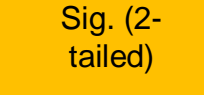 & $\mid .00$ & .00 & .59 & .13 & .00 & \begin{tabular}{|l|} 
\\
\end{tabular} & .16 & .00 & 99 & .19 & .00 & .03 & .34 & .15 & .00 & \begin{tabular}{|l|}
.00 \\
\end{tabular} & .00 & .03 & .00 & .00 & .00 & & .42 & .00 & .00 & .30 & .48 & .00 & .02 & .00 & .64 & .00 & .02 & .00 & .12 & .00 \\
\hline & $\mathrm{N}$ & $\mid \begin{array}{c}71.0 \\
0\end{array}$ & $\begin{array}{c}50.0 \\
0\end{array}$ & 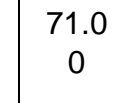 & $\begin{array}{c}71.0 \\
0\end{array}$ & $\begin{array}{c}50.0 \\
0\end{array}$ & $\begin{array}{c}71.0 \\
0\end{array}$ & $\begin{array}{c}77.0 \\
0\end{array}$ & $\begin{array}{c}50.0 \\
0\end{array}$ & $\begin{array}{c}71.0 \\
0\end{array}$ & $\begin{array}{c}71.0 \\
0\end{array}$ & \begin{tabular}{|l}
50.0 \\
0
\end{tabular} & $\begin{array}{c}21.0 \\
0\end{array}$ & $\begin{array}{l}50.0 \\
0\end{array}$ & 71.00 & 71.00 & $\begin{array}{c}71.0 \\
0\end{array}$ & \begin{tabular}{|l|}
71.00 \\
\end{tabular} & \begin{tabular}{|l|} 
\\
\end{tabular} & 71.00 & $\begin{array}{c}71.0 \\
0\end{array}$ & \begin{tabular}{|l|} 
\\
\end{tabular} & \begin{tabular}{|l|l|} 
& 71.00 \\
\end{tabular} & 71.00 & 71.00 & 71.00 & \begin{tabular}{|l|l|l} 
& 71.00 \\
\end{tabular} & 71.00 & 71.00 & 71.00 & 71.00 & 71.00 & 71.00 & 50.00 & 71.00 & 71.00 & 71.00 \\
\hline & $\begin{array}{c}\text { Pearson } \\
\text { Corretalion }\end{array}$ & \begin{tabular}{|l|}
.07 \\
\end{tabular} & .37 & $2^{\prime \prime}$ & $-25^{\circ}$ & $.33^{3}$ & \begin{tabular}{|l|}
-.20 \\
\end{tabular} & . $.31^{\prime \prime}$ & .01 & $-.35^{\prime \prime}$ & $-.45^{\prime \prime}$ & .28 & $.64^{\prime \prime}$ & -.11 & -.14 & $-.38^{\prime \prime}$ & $.36^{\prime \prime}$ & $-26^{\circ}$ & \begin{tabular}{|l|}
$-41^{\prime \prime}$ \\
\end{tabular} & \begin{tabular}{|l|}
$-31^{\prime \prime}$ \\
\end{tabular} & \begin{tabular}{|l|}
$.28^{\circ}$ \\
\end{tabular} & \begin{tabular}{|l|l|}
$.35^{\prime \prime}$ \\
\end{tabular} & -.10 & \begin{tabular}{|l|}
1.00 \\
\end{tabular} & $.38^{\prime \prime}$ & $-37^{\prime \prime}$ & $.50^{\circ "}$ & .12 & $-.43^{\prime \prime}$ & $.27^{\circ}$ & .03 & - $.48^{\prime \prime \prime}$ &. .12 & .09 & -.12 & $.53^{\prime \prime}$ & $-31^{\prime \prime}$ \\
\hline $\operatorname{Ln}(s)$ & $\begin{array}{l}\text { sig. (2.2- } \\
\text { talace) }\end{array}$ & .55 & .01 & .00 & .04 & .02 & .10 & .01 & .95 & .00 & .00 & .05 & .00 & .45 & .23 & .00 & \begin{tabular}{|l|}
.00 \\
\end{tabular} & .03 & .00 & .01 & .02 & .00 & .42 & & .00 & .00 & .00 & .31 & .00 & .02 & .81 & .00 & .32 & .55 & .34 & .00 & .01 \\
\hline & . & $\begin{array}{l}71.0 \\
0\end{array}$ & $\begin{array}{c}50.0 \\
0\end{array}$ & $\begin{array}{c}71.0 \\
0\end{array}$ & $\begin{array}{c}71.0 \\
0\end{array}$ & \begin{tabular}{|c|c|}
50.0 \\
0
\end{tabular} & $\left|\begin{array}{c}71.0 \\
0\end{array}\right|$ & \begin{tabular}{|c|}
71.0 \\
0
\end{tabular} & $\begin{array}{c}50.0 \\
0\end{array}$ & $\left|\begin{array}{c}71.0 \\
0\end{array}\right|$ & $\left|\begin{array}{c}71.0 \\
0\end{array}\right|$ & \begin{tabular}{|l|}
50.0 \\
0
\end{tabular} & \begin{tabular}{|c|}
21.0 \\
0
\end{tabular} & $\begin{array}{c}50.0 \\
0\end{array}$ & 71.00 & 71.00 & $\left|\begin{array}{c}71.0 \\
0\end{array}\right|$ & 71.00 & 71.00 & 71.00 & \begin{tabular}{c|c|}
71.0 \\
0
\end{tabular} & 71.00 & \begin{tabular}{|l|}
71.00 \\
\end{tabular} & 71.00 & 71.00 & \begin{tabular}{|l|l|} 
& 71.00 \\
\end{tabular} & 71.00 & 71.00 & \begin{tabular}{|l}
1.00 \\
\end{tabular} & 71.00 & 71.00 & 71.00 & 71.00 & 50.00 & 71.00 & \begin{tabular}{|l}
71.00 \\
\end{tabular} & 71.00 \\
\hline & $\begin{array}{l}\text { Pearsonon } \\
\text { Correlatio }\end{array}$ & $.50^{\prime \prime}$ & $\mid .77^{\prime \prime}$ & $.59^{\prime \prime}$ & .22 & $.57^{\prime \prime}$ & $.61^{\circ}$ & $.65^{\prime \prime}$ & $.56^{\circ}$ & $.41^{\prime \prime}$ & $.64^{\circ}$ & $.52^{\prime \prime}$ & $.74^{\prime \prime}$ & .15 & .20 & & $.56^{\prime \prime}$ & & & & $88^{8}$ & $.70^{\circ}$ & $.62^{2}$ & $-.38^{\prime \prime}$ & 1.00 & & $-.63^{*}$ & -.04 & $.53^{\prime \prime}$ & .21 & -.07 & $.53^{\prime \prime}$ & $.33^{\prime \prime}$ & $.29^{\circ}$ & $-.26^{\circ}$ & $-28^{\circ}$ & \\
\hline $\operatorname{Ln}(T)$ & 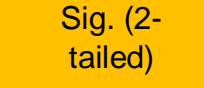 & $\mid .00$ & .00 & .00 & .07 & .00 & \begin{tabular}{|l|}
.00 \\
\end{tabular} & .00 & 00 & .00 & \begin{tabular}{|l|}
.00 \\
\end{tabular} & .00 & .00 & .30 & .09 & .00 & \begin{tabular}{|l|}
.00 \\
\end{tabular} & \begin{tabular}{|l|}
.00 \\
\end{tabular} & . 00 & $\mid .00$ & .00 & |.00 & .00 & .00 & & \begin{tabular}{|l|}
.00 \\
\end{tabular} & .00 & .74 & .00 & .08 & .58 & .00 & .00 & .04 & .03 & .02 & .00 \\
\hline & $\mathrm{N}$ & $\begin{array}{l}71.0 \\
0\end{array}$ & $\begin{array}{c}50.0 \\
0\end{array}$ & $\begin{array}{c}71.0 \\
0\end{array}$ & $\begin{array}{c}71.0 \\
0\end{array}$ & \begin{tabular}{|c|c|}
50.0 \\
0
\end{tabular} & $\left|\begin{array}{c}71.0 \\
0\end{array}\right|$ & \begin{tabular}{|c|}
71.0 \\
0
\end{tabular} & $\begin{array}{c}50.0 \\
0\end{array}$ & $\left|\begin{array}{c}71.0 \\
0\end{array}\right|$ & $\left|\begin{array}{c}71.0 \\
0\end{array}\right|$ & \begin{tabular}{|l|}
50.0 \\
0
\end{tabular} & \begin{tabular}{c|c}
21.0 \\
0
\end{tabular} & $\begin{array}{c}50.0 \\
0\end{array}$ & 71.00 & 71.00 & $\left|\begin{array}{c}71.0 \\
0\end{array}\right|$ & 71.00 & 71.00 & 71.00 & \begin{tabular}{c|c}
71.0 \\
0
\end{tabular} & 71.00 & \begin{tabular}{|l|}
71.00 \\
\end{tabular} & 71.00 & 71.00 & \begin{tabular}{|l|l|} 
& 71.00 \\
\end{tabular} & 71.00 & 71.00 & 71.00 & 71.00 & 71.00 & 71.00 & 71.00 & 50.00 & 71.00 & \begin{tabular}{|l}
1.00 \\
\end{tabular} & 71.00 \\
\hline & $\begin{array}{l}\text { Pearason } \\
\text { corretation }\end{array}$ & \begin{tabular}{|l|l|}
$.49^{\prime \prime}$ \\
\end{tabular} & \begin{tabular}{|l|l|}
$.79^{\prime \prime}$ \\
\end{tabular} & $.59^{\prime \prime}$ & .22 & $.62^{n}$ & $\mid .62^{\prime \prime}$ & $.72^{\prime \prime}$ & $.70^{\circ}$ & $.43^{\prime \prime}$ & $\mid .67^{\prime \prime}$ & $.51^{\prime \prime}$ & \begin{tabular}{|l|}
$.67^{\prime \prime}$ \\
\end{tabular} & .14 & .20 & 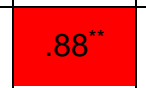 & \begin{tabular}{|l|l|}
$.57^{\prime}$ \\
\end{tabular} & $\mid .87^{\prime \prime}$ & $.87^{\prime \prime}$ & $.97^{\prime \prime}$ & .85 & $.66^{\prime \prime}$ & \begin{tabular}{|l|l}
$.53^{\prime \prime}$ \\
\end{tabular} & \begin{tabular}{|l|l|}
$-37^{\prime \prime}$ \\
\end{tabular} & $.96^{\prime \prime}$ & \begin{tabular}{|l|l|}
1.00 \\
\end{tabular} & $-.64^{4}$ & -.08 & $.55^{\prime \prime}$ & .21 & -.06 & $.53^{\prime \prime}$ & $.31^{\prime \prime}$ & . $41^{\prime \prime}$ & $-30^{\circ}$ & -27 & \\
\hline $\operatorname{Ln}(M)$ & $\begin{array}{l}\text { Sig. (2.2. } \\
\text { taliecer) }\end{array}$ & \begin{tabular}{|l|}
.00 \\
\end{tabular} & .00 & .00 & .06 & .00 & \begin{tabular}{|l|}
.00 \\
\end{tabular} & .00 & .00 & .00 & \begin{tabular}{|l|}
.00 \\
\end{tabular} & .00 & .00 & .35 & .10 & .00 & \begin{tabular}{|l|}
.00 \\
\end{tabular} & .00 & .00 & .00 & .00 & .00 & .00 & .00 & .00 & & 0 & .48 & .00 & .08 & 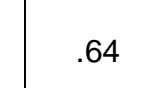 & & .01 & .00 & .01 & .02 & .00 \\
\hline & $\mathrm{N}$ & \begin{tabular}{|c|}
71.0 \\
0
\end{tabular} & $\begin{array}{c}50.0 \\
0\end{array}$ & $\begin{array}{c}71.0 \\
0\end{array}$ & $\begin{array}{c}71.0 \\
0\end{array}$ & \begin{tabular}{|c|c|}
50.0 \\
0
\end{tabular} & $\left|\begin{array}{c}71.0 \\
0\end{array}\right|$ & \begin{tabular}{|c|}
71.0 \\
0
\end{tabular} & $\begin{array}{c}50.0 \\
0\end{array}$ & $\left|\begin{array}{c}71.0 \\
0\end{array}\right|$ & $\left|\begin{array}{c}71.0 \\
0\end{array}\right|$ & \begin{tabular}{|c|}
50.0 \\
0
\end{tabular} & $\begin{array}{c}21.0 \\
0\end{array}$ & $\begin{array}{c}50.0 \\
0\end{array}$ & 71.00 & 71.00 & $\left|\begin{array}{c}71.0 \\
0\end{array}\right|$ & 71.00 & 71.00 & 71.00 & $\left|\begin{array}{c|c}71.0 \\
0\end{array}\right|$ & 71.00 & \begin{tabular}{|l|}
71.00 \\
\end{tabular} & 71.00 & 71.00 & \begin{tabular}{|l|l|} 
& 71.00
\end{tabular} & 71.00 & 71.00 & 71.00 & 71.00 & 71.00 & 71.00 & 71.00 & 50.00 & 71.00 & 71.00 & 71.00 \\
\hline & $\begin{array}{l}\text { 位arson } \\
\text { correlation }\end{array}$ & \begin{tabular}{|l|}
.11 \\
\end{tabular} & $.36^{\prime \prime}$ & $.61^{\prime \prime}$ & $-39^{\prime \prime}$ & $.28^{\circ}$ & \begin{tabular}{|l|}
-.09 \\
\end{tabular} & $.70^{\circ \prime}$ & .26 & $\mid-37^{\prime \prime}$ & \begin{tabular}{|l|}
$-71^{\prime \prime}$ \\
\end{tabular} & $-37^{\prime \prime}$ & .29 & .10 & .08 & $-.58^{\prime \prime}$ & \begin{tabular}{|l|}
.20 \\
\end{tabular} & \begin{tabular}{|c|}
$-.53^{\prime \prime}$ \\
\end{tabular} & $\mid-71^{\prime \prime}$ & $\mid-.55^{\prime \prime}$ & $-60^{\prime \prime}$ & $-26^{\circ}$ & -.13 & $.50^{\circ \prime}$ & .63" & \begin{tabular}{|l|}
$-.64^{\prime \prime}$ \\
\end{tabular} & \begin{tabular}{|l|}
1.00 \\
\end{tabular} & $\begin{array}{l}.07 \\
\end{array}$ & $\begin{array}{l}.53^{\prime \prime} \\
\end{array}$ & $.59^{\prime \prime}$ & . .16 & -64" & $\begin{array}{l}.17 \\
\end{array}$ & . .17 & .22 & $.55^{\prime \prime}$ & .64" \\
\hline $\begin{array}{l}\text { Ln(Ag- } \\
0.588\end{array}$ & $\begin{array}{c}\text { sig. (2. } \\
\text { taliece) }\end{array}$ & 37 & \begin{tabular}{|l}
.01 \\
\end{tabular} & .00 & .00 & .05 & \begin{tabular}{|l|}
.46 \\
\end{tabular} & .00 & . 07 & .00 & \begin{tabular}{|l|}
.00 \\
\end{tabular} & .01 & .21 & .51 & .50 & .00 & \begin{tabular}{|l|}
.10 \\
\end{tabular} & .00 & .00 & .00 & .00 & .03 & .30 & .00 & .00 & .00 & & .55 & .00 & .00 & .19 & .00 & .15 & .24 & .06 & .00 & .00 \\
\hline & $\mathrm{N}$ & $\begin{array}{c}71.0 \\
0\end{array}$ & $\begin{array}{c}50.0 \\
0\end{array}$ & $\begin{array}{c}71.0 \\
0\end{array}$ & $\begin{array}{c}71.0 \\
0\end{array}$ & \begin{tabular}{|c|c|}
50.0 \\
0
\end{tabular} & $\left|\begin{array}{c}71.0 \\
0\end{array}\right|$ & \begin{tabular}{|c|}
71.0 \\
0
\end{tabular} & $\begin{array}{c}50.0 \\
0\end{array}$ & $\left|\begin{array}{c}71.0 \\
0\end{array}\right|$ & $\left|\begin{array}{c}71.0 \\
0\end{array}\right|$ & \begin{tabular}{|c|}
50.0 \\
0
\end{tabular} & $\begin{array}{c}21.0 \\
0\end{array}$ & $\begin{array}{c}50.0 \\
0\end{array}$ & 71.00 & 71.00 & $\left|\begin{array}{c}71.0 \\
0\end{array}\right|$ & 71.00 & 71.00 & 71.00 & $\mid$\begin{tabular}{c|c}
71.0 \\
0
\end{tabular} & 71.00 & 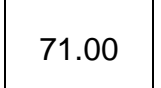 & 71.00 & 71.00 & $\begin{array}{l}71.00 \\
\end{array}$ & 71.00 & 71.00 & 71.00 & 71.00 & 71.00 & 71.00 & 71.00 & 50.00 & 71.00 & 71.00 & 71.00 \\
\hline & $\begin{array}{c}\text { Pearson } \\
\text { Correlation }\end{array}$ & \begin{tabular}{|l|}
-.17 \\
\end{tabular} & $.36^{\prime \prime}$ & .09 & $.31^{\prime \prime}$ & .27 & \begin{tabular}{|l|l|}
$-24^{\prime}$ \\
\end{tabular} & .08 & $.38^{\prime \prime}$ & $.28^{\circ}$ & \begin{tabular}{|l|}
.15 \\
\end{tabular} & .21 & .27 & .23 & -.15 & \begin{tabular}{|c|}
.03 \\
\end{tabular} & \begin{tabular}{|l|}
.16 \\
\end{tabular} & \begin{tabular}{|c|c|}
.13 \\
\end{tabular} & .02 & \begin{tabular}{l|}
-.09 \\
\end{tabular} & -.10 & .00 & .09 & .12 & .04 & . .08 & .07 & 1.00 & -.02 & $.37^{\prime \prime}$ & $.37^{\prime \prime}$ & .15 & . .19 & .04 & $\begin{array}{l}-.08 \\
\end{array}$ & .06 & .06 \\
\hline $\begin{array}{l}\text { Ln(AS- } \\
0.25-\end{array}$ & $\begin{array}{l}\text { Sigig (2-) } \\
\text { tailda) }\end{array}$ & .16 & \begin{tabular}{|l}
.01 \\
\end{tabular} & .44 & .01 & .06 & \begin{tabular}{|l|}
.04 \\
\end{tabular} & .48 & .01 & .02 & .20 & .14 & .23 & .10 & .22 & .82 & \begin{tabular}{|l|}
.18 \\
\end{tabular} & .30 & .88 & .46 & .41 & .98 & .48 & 31 & .74 & .48 & .55 & & .84 & .00 & .00 & .22 & .11 & .80 & .48 & .61 & .60 \\
\hline & $\mathrm{N}$ & \begin{tabular}{|c|}
71.0 \\
0
\end{tabular} & $\begin{array}{c}50.0 \\
0\end{array}$ & $\begin{array}{c}71.0 \\
0\end{array}$ & $\begin{array}{c}71.0 \\
0\end{array}$ & \begin{tabular}{|c|}
50.0 \\
0
\end{tabular} & $\left|\begin{array}{c}71.0 \\
0\end{array}\right|$ & \begin{tabular}{|c|}
71.0 \\
0
\end{tabular} & $\begin{array}{c}50.0 \\
0\end{array}$ & $\begin{array}{c}71.0 \\
0\end{array}$ & $\mid \begin{array}{c}71.0 \\
0\end{array}$ & \begin{tabular}{|l|}
50.0 \\
0
\end{tabular} & $\begin{array}{c}21.0 \\
0\end{array}$ & $\begin{array}{l}50.0 \\
0\end{array}$ & 71.00 & 71.00 & $\left|\begin{array}{c}71.0 \\
0\end{array}\right|$ & 71.00 & 71.00 & 71.00 & \begin{tabular}{|c|c|c|}
11.0 \\
0
\end{tabular} & 71.00 & \begin{tabular}{|l|l|} 
& 71.00 \\
\end{tabular} & 71.00 & 71.00 & \begin{tabular}{|l|l|} 
& 71.00
\end{tabular} & 71.00 & 71.00 & 71.00 & 71.00 & 71.00 & 71.00 & 71.00 & 50.00 & 71.00 & 71.00 & 71.00 \\
\hline & $\begin{array}{l}\text { Peararon } \\
\text { Correlation }\end{array}$ & \begin{tabular}{|l|l}
$.46^{\prime \prime}$ \\
\end{tabular} & \begin{tabular}{|l}
$.79^{\prime \prime}$ \\
\end{tabular} & $.30^{\circ}$ & .22 & $.78^{\prime \prime}$ & \begin{tabular}{|l|}
.22 \\
\end{tabular} & . $43^{\prime \prime}$ & $.44^{\prime \prime}$ & \begin{tabular}{|l|l|}
$8^{\circ}$ \\
\end{tabular} & $.53^{\prime \prime}$ & $.66^{\prime \prime}$ & \begin{tabular}{l|}
-.19 \\
\end{tabular} & .19 & .02 & . $49^{\prime \prime}$ & $.67^{\prime \prime}$ & \begin{tabular}{|l|l}
$.53^{\prime \prime}$ \\
\end{tabular} & \begin{tabular}{|l|}
$.39^{\prime \prime}$ \\
\end{tabular} & \begin{tabular}{|l|}
$.51^{\prime \prime}$ \\
\end{tabular} & \begin{tabular}{|l|l}
$.65 "$ \\
\end{tabular} & $.36 "$ & $.56^{\prime \prime}$ & $-.43^{\prime \prime}$ & $.53^{\prime \prime}$ & $\mid .55^{\prime \prime}$ & $-.53^{\prime \prime}$ & -.02 & 1.00 & .20 & .06 & $.44^{\prime \prime}$ & $.53^{\prime \prime}$ & $.51^{\prime \prime}$ & $.60^{\prime \prime}$ & .05 & $.40^{\prime \prime}$ \\
\hline $\begin{array}{l}\operatorname{Ln}(B e-) \\
0.144)\end{array}$ & $\begin{array}{l}\text { Sig., (2- } \\
\text { talied) }\end{array}$ & $\mid .00$ & .00 & .01 & .06 & .00 & \begin{tabular}{|l|}
.06 \\
\end{tabular} & .00 & .00 & .02 & .00 & .00 & .41 & .18 & .87 & .00 & \begin{tabular}{|l|}
.00 \\
\end{tabular} & .00 & .00 & .00 & .00 & .00 & .00 & .00 & .00 & .00 & .00 & .84 & & .10 & .62 & .00 & .00 & .00 & .00 & .70 & .00 \\
\hline & N & $\begin{array}{c}71.0 \\
0\end{array}$ & $\begin{array}{c}50.0 \\
0\end{array}$ & $\begin{array}{c}71.0 \\
0\end{array}$ & $\begin{array}{c}71.0 \\
0\end{array}$ & 50.0 & $\mid \begin{array}{c}71.0 \\
0\end{array}$ & $\begin{array}{c}71.0 \\
0\end{array}$ & $\begin{array}{c}50.0 \\
0\end{array}$ & $\begin{array}{c}71.0 \\
0\end{array}$ & $\mid \begin{array}{c}71.0 \\
0\end{array}$ & \begin{tabular}{|l|}
50.0 \\
0
\end{tabular} & $\begin{array}{c}21.0 \\
0\end{array}$ & $\begin{array}{l}50.0 \\
0\end{array}$ & 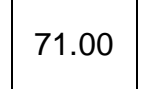 & 71.00 & $\mid \begin{array}{c}71.0 \\
0\end{array}$ & \begin{tabular}{|l|}
71.00 \\
\end{tabular} & 71.00 & 71.00 & \begin{tabular}{|c|c|}
71.0 \\
0
\end{tabular} & \begin{tabular}{|l|} 
\\
11.00
\end{tabular} & \begin{tabular}{|l|l|}
71.00 \\
\end{tabular} & \begin{tabular}{|l|l|} 
& 71.00
\end{tabular} & 71.00 & 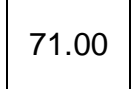 & \begin{tabular}{|l} 
\\
\end{tabular} & 71.00 & 71.00 & 71.00 & 71.00 & 71.00 & 71.00 & 50.00 & 71.00 & \begin{tabular}{|l|l} 
& 71.00 \\
\end{tabular} & 71.00 \\
\hline & Pearson & $.37^{\prime \prime}$ & \begin{tabular}{|l|l|}
$3^{\prime \prime}$ & \\
\end{tabular} & 54" & $.64^{\prime \prime}$ & $.45^{\prime \prime}$ & \begin{tabular}{|l|}
.23 \\
\end{tabular} & $.51^{\prime \prime}$ & $.38^{\prime \prime}$ & . $.51^{\prime \prime}$ & $-.63^{\prime \prime}$ & $.50^{\prime \prime}$ & & \begin{tabular}{|l|}
.04 \\
\end{tabular} & .11 & $.31^{\prime \prime}$ & \begin{tabular}{|l|}
-06 \\
\end{tabular} & -0 & - $-42^{\prime \prime}$ &. .12 & -.12 & -.05 & .28 & $.27^{\circ}$ & -.21 & .21 & $.59^{\prime \prime}$ & $.37^{*}$ & .20 & 1.00 & $.70^{\prime \prime}$ & $66^{6}$ & $.42^{\prime \prime}$ & .15 & .04 & $46^{\prime \prime}$ & $.36^{\prime \prime}$ \\
\hline 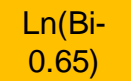 & $\begin{array}{c}\text { Sig., (2.2- } \\
\text { tateles) }\end{array}$ & $\mid .00$ & \begin{tabular}{|l|}
.00 \\
\end{tabular} & .00 & .00 & .00 & \begin{tabular}{|l|}
.06 \\
\end{tabular} & .00 & .01 & .00 & \begin{tabular}{|l|}
.00 \\
\end{tabular} & .00 & \begin{tabular}{|l|l|} 
& 0.00 \\
\end{tabular} & .77 & .36 & .01 & \begin{tabular}{|l|}
.63 \\
\end{tabular} & .76 & .00 & .33 & .31 & .70 & .02 & .02 & .08 & .08 & .00 & .00 & .10 & & .00 & .00 & .00 & .30 & .73 & .00 & .00 \\
\hline & $\mathrm{N}$ & $\begin{array}{c}71.0 \\
0\end{array}$ & $\begin{array}{c}50.0 \\
0\end{array}$ & $\begin{array}{c}71.0 \\
0\end{array}$ & $\begin{array}{c}71.0 \\
0\end{array}$ & \begin{tabular}{|c|c|}
50.0 \\
0
\end{tabular} & $\begin{array}{c}71.0 \\
0\end{array}$ & \begin{tabular}{|c|}
771.0 \\
0
\end{tabular} & $\begin{array}{c}50.0 \\
0\end{array}$ & $\begin{array}{c}71.0 \\
0\end{array}$ & $\begin{array}{c}71.0 \\
0\end{array}$ & \begin{tabular}{|c|}
50.0 \\
0
\end{tabular} & $\begin{array}{c}21.0 \\
0\end{array}$ & $\begin{array}{c}50.0 \\
0\end{array}$ & 71.00 & 71.00 & $\mid \begin{array}{c}71.0 \\
0\end{array}$ & \begin{tabular}{|l|} 
\\
71.00
\end{tabular} & 71.00 & 71.00 & $\left|\begin{array}{c|}71.0 \\
0\end{array}\right|$ & 71.00 & 71.00 & 71.00 & 71.00 & \begin{tabular}{|l|l|} 
& 71.00 \\
\end{tabular} & 71.00 & $\begin{array}{l}71.00 \\
\end{array}$ & 71.00 & 71.00 & 1.00 & 71.00 & 71.00 & 50.00 & 71.00 & 71.00 & 71.00 \\
\hline & $\begin{array}{c}\text { Pearson } \\
\text { Corretation }\end{array}$ & \begin{tabular}{|l|}
$-.35^{\prime \prime}$ \\
\end{tabular} & $-36^{\circ}$ & $.35^{\prime \prime}$ & $.51^{\prime \prime}$ & $-38^{\prime \prime}$ & \begin{tabular}{|l|l|}
$6^{\circ}$ \\
\end{tabular} & $.29^{\circ}$ & .15 & $.48^{\prime \prime}$ & $.36^{\prime \prime}$ & $.53^{\prime \prime}$ & \begin{tabular}{|l|}
0.00 \\
\end{tabular} & \begin{tabular}{|l|l|}
.13 \\
\end{tabular} & .11 & .12 & \begin{tabular}{|l|l|}
$4^{\circ}$ \\
\end{tabular} & .20 & .13 & \begin{tabular}{l|}
-.13 \\
\end{tabular} & -.16 & .10 & - $.37^{\prime \prime}$ & \begin{tabular}{|c|}
.03 \\
\end{tabular} & 07 & .06 & .16 & $.37^{\prime \prime}$ & .06 & - .70" & 1.00 & $41^{\prime \prime}$ & $.40^{\prime \prime}$ & .10 & .08 & .20 & .11 \\
\hline $\begin{array}{l}\text { Ln(c)- } \\
0.65)\end{array}$ & 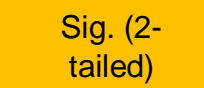 & $\mid .00$ & \begin{tabular}{|l|}
.01 \\
\end{tabular} & .00 & .00 & .01 & \begin{tabular}{|l|}
.03 \\
\end{tabular} & .01 & .28 & .00 & .00 & .00 & 1.00 & .37 & .35 & .32 & \begin{tabular}{|l|}
.05 \\
\end{tabular} & .09 & .27 & .28 & .20 & .42 & .00 & .81 & .58 & .64 & .19 & .00 & .62 & .00 & & ח0. & .00 & .48 & .53 & .09 & .37 \\
\hline & N & $\begin{array}{c}71.0 \\
0\end{array}$ & $\begin{array}{c}50.0 \\
0\end{array}$ & $\begin{array}{c}71.0 \\
0\end{array}$ & $\begin{array}{c}71.0 \\
0\end{array}$ & \begin{tabular}{|c|c|}
50.0 \\
0
\end{tabular} & $\left|\begin{array}{c}71.0 \\
0\end{array}\right|$ & $\begin{array}{c}71.0 \\
0\end{array}$ & $\begin{array}{c}50.0 \\
0\end{array}$ & $\left|\begin{array}{c}71.0 \\
0\end{array}\right|$ & $\left|\begin{array}{c}71.0 \\
0\end{array}\right|$ & \begin{tabular}{|l|}
50.0 \\
0
\end{tabular} & \begin{tabular}{|c|}
21.0 \\
0
\end{tabular} & $\begin{array}{c}50.0 \\
0\end{array}$ & 71.00 & 71.00 & $\left|\begin{array}{c}71.0 \\
0\end{array}\right|$ & 71.00 & 71.00 & 71.00 & $\left|\begin{array}{c|c}71.0 \\
0\end{array}\right|$ & 71.00 & 71.00 & 71.00 & 71.00 & 71.00 & \begin{tabular}{|l|l} 
\\
\end{tabular} & 71.00 & 71.00 & 71.00 & 71.00 & 71.00 & 71.00 & 50.00 & 71.00 & 71.00 & 71.00 \\
\hline & 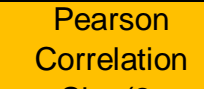 & \begin{tabular}{|l|}
.06 \\
\end{tabular} & $.53^{\prime \prime}$ & $.78^{\prime \prime}$ & $.67^{\prime \prime}$ & $.39^{\prime \prime}$ & $.30^{\circ}$ & $.62^{\prime \prime}$ & .01 & $.59^{*}$ & $.79^{\circ}$ & .06 & .18 & .27 & .08 & $.61^{\prime \prime}$ & $.44^{\prime \prime}$ & $.33^{\prime \prime}$ & \begin{tabular}{|l|}
$.69 "$ \\
\end{tabular} & \begin{tabular}{|l|}
$.46^{\prime \prime}$ \\
\end{tabular} & $.39 "$ & .49" & .06 & - $-48^{\prime \prime}$ & $.53^{*}$ & \begin{tabular}{|l|l|}
$.53^{\prime \prime}$ \\
\end{tabular} & $-.64^{\prime \prime}$ & .15 & $.44^{\prime \prime}$ & $.66^{\prime \prime}$ & $.41^{\prime \prime}$ & 1.00 & .03 & $.52^{\prime \prime}$ & -.09 & $-.40^{\prime \prime}$ & $.54^{\prime \prime}$ \\
\hline $\begin{array}{l}\text { Lnc(C)t } \\
1.9)\end{array}$ & 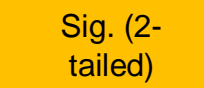 & .61 & \begin{tabular}{|l|}
.00 \\
\end{tabular} & .00 & .00 & .01 & \begin{tabular}{|l|}
.01 \\
\end{tabular} & .00 & .92 & .00 & \begin{tabular}{|l|}
.00 \\
\end{tabular} & .65 & .43 & .06 & .50 & .00 & \begin{tabular}{|l|}
.00 \\
\end{tabular} & .00 & .00 & .00 & .00 & .00 & .64 & .00 & .00 & .00 & .00 & .22 & .00 & .00 & .00 & & .80 & .00 & 46 & .00 & .00 \\
\hline & $\mathrm{N}$ & \begin{tabular}{|c|}
711.0 \\
0
\end{tabular} & $\begin{array}{c}50.0 \\
0\end{array}$ & $\begin{array}{c}71.0 \\
0\end{array}$ & $\begin{array}{c}1.00 \\
0\end{array}$ & \begin{tabular}{|c|c|}
50.0 \\
0
\end{tabular} & $\left|\begin{array}{c}71.0 \\
0\end{array}\right|$ & $\begin{array}{c}71.0 \\
0\end{array}$ & $\begin{array}{c}50.0 \\
0\end{array}$ & $\left|\begin{array}{c}71.0 \\
0\end{array}\right|$ & $\left|\begin{array}{c}71.0 \\
0\end{array}\right|$ & \begin{tabular}{|c|}
50.0 \\
0
\end{tabular} & \begin{tabular}{c|c}
21.0 \\
0
\end{tabular} & $\begin{array}{c}50.0 \\
0\end{array}$ & 71.00 & 71.00 & $\left|\begin{array}{c}71.0 \\
0\end{array}\right|$ & 71.00 & 71.00 & 71.00 & $\mid$\begin{tabular}{c|}
71.0 \\
0
\end{tabular} & 71.00 & \begin{tabular}{|l|}
71.00 \\
\end{tabular} & 71.00 & 71.00 & \begin{tabular}{|l|l|} 
& 71.00
\end{tabular} & 71.00 & 71.00 & 71.00 & .00 & 1.00 & 71.00 & 71.00 & 50.00 & 71.00 & 71.00 & 71.00 \\
\hline & $\begin{array}{l}\text { Peararon } \\
\text { correlation }\end{array}$ & & & -.09 & .19 & | & $.58^{\prime \prime}$ & .04 & $.35^{\circ}$ & . 01 & \begin{tabular}{|l|}
.07 \\
\end{tabular} & . $43^{\prime \prime}$ & .30 & $.33^{*}$ & .14 & $.27^{\circ}$ & $.7^{\prime \prime}$ & $.36^{\prime \prime}$ & .01 & \begin{tabular}{|l|}
$.37^{\prime \prime}$ \\
\end{tabular} & $.37^{\prime \prime}$ & $.45^{\prime \prime}$ & $.74^{\prime \prime}$ & \begin{tabular}{|l|}
.12 \\
\end{tabular} & $.33^{\prime \prime}$ & \begin{tabular}{|l|l|}
$.31^{\prime \prime}$ \\
\end{tabular} & .17 & . .19 & $.53^{\prime \prime \prime}$ & $.42^{\prime \prime}$ & $-40^{\prime \prime}$ & -.03 & 1.00 & $.58^{\prime \prime}$ & $.36^{\prime \prime}$ & $.39^{\prime \prime}$ & .11 \\
\hline $\operatorname{Ln}(K+2)$ & $\begin{array}{l}\text { sig, (2- } \\
\text { talede) }\end{array}$ & \begin{tabular}{|l|}
.00 \\
\end{tabular} & $\mid .00$ & .44 & .12 & .00 & .00 & .74 & .01 & .92 & \begin{tabular}{|l|}
.54 \\
\end{tabular} & .00 & .19 & .02 & .24 & .02 & \begin{tabular}{|l|}
.00 \\
\end{tabular} & . 00 & .93 & .00 & .00 & . 00 & .00 & .32 & .00 & .01 & .15 & .11 & .00 & .00 & .00 & .80 & & .00 & .00 & .00 & .37 \\
\hline & N & \begin{tabular}{|c|}
71.0 \\
0
\end{tabular} & $\begin{array}{c}50.0 \\
0\end{array}$ & $\begin{array}{c}71.0 \\
0\end{array}$ & $\begin{array}{c}71.0 \\
0\end{array}$ & \begin{tabular}{|c|c|}
50.0 \\
0
\end{tabular} & $\left|\begin{array}{c}71.0 \\
0\end{array}\right|$ & \begin{tabular}{|c|}
71.0 \\
0
\end{tabular} & $\begin{array}{c}50.0 \\
0\end{array}$ & $\left|\begin{array}{c}71.0 \\
0\end{array}\right|$ & $\left|\begin{array}{c}71.0 \\
0\end{array}\right|$ & \begin{tabular}{|c|}
50.0 \\
0
\end{tabular} & $\begin{array}{c}21.0 \\
0\end{array}$ & $\begin{array}{c}50.0 \\
0\end{array}$ & 71.00 & 71.00 & $\left|\begin{array}{c}71.0 \\
0\end{array}\right|$ & 71.00 & 71.00 & 71.00 & $\left|\begin{array}{c|c}71.0 \\
0\end{array}\right|$ & 71.00 & \begin{tabular}{|l|}
71.00 \\
\end{tabular} & 71.00 & 71.00 & \begin{tabular}{|l|l|} 
& 71.00
\end{tabular} & $\begin{array}{l}1.00 \\
\end{array}$ & 71.00 & 71.00 & 71.00 & 71.00 & 71.00 & 71.00 & 50.00 & 71.00 & \begin{tabular}{|l}
1.00 \\
\end{tabular} & 71.00 \\
\hline & $\begin{array}{l}\text { Peararon } \\
\text { Correlation }\end{array}$ & \begin{tabular}{|l|l|}
$.68^{\prime \prime}$ \\
\end{tabular} & $.59^{\prime \prime}$ & $.45^{\prime \prime}$ & .06 & $.56^{\prime \prime}$ & $\mid .67^{\prime \prime}$ & $.53^{\prime \prime}$ & . $47^{\prime \prime}$ & $.37^{\prime \prime}$ & $\mid .60^{\circ}$ & .14 & $\therefore$ & .24 & .16 & .39" & $.62^{*}$ & .21 & $.38^{\prime \prime}$ & $.39^{\prime \prime}$ & .21 & \begin{tabular}{|l|}
$.48^{\prime \prime}$ \\
\end{tabular} & \begin{tabular}{|l|}
$.32^{\circ}$ \\
\end{tabular} & \begin{tabular}{l|l|}
.09 \\
\end{tabular} & $.29^{\circ}$ & \begin{tabular}{|l|l|}
$.41^{\prime \prime}$ \\
\end{tabular} &. .17 & .04 & $51^{\prime \prime}$ & .15 & \begin{tabular}{|c|}
.10 \\
\end{tabular} & $.52^{\prime \prime}$ & $.58 "$ & 1.00 & $.39^{\prime \prime}$ & $.30^{\circ}$ & .10 \\
\hline $\begin{array}{l}\frac{L}{2 n(L(L)} \\
0.25)\end{array}$ & 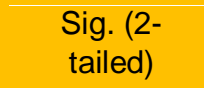 & $\mid .00$ & \begin{tabular}{|l|l} 
\\
\end{tabular} & .00 & .66 & .00 & \begin{tabular}{|l|}
.00 \\
\end{tabular} & .00 & .00 & .01 & \begin{tabular}{|l|}
.00 \\
\end{tabular} & .33 & & .10 & .28 & .01 & \begin{tabular}{|l|}
.00 \\
\end{tabular} & .14 & .01 & .00 & .14 & . .00 & .02 & .55 & .04 & .00 & .24 & .80 & .00 & .30 & .48 & .00 & .00 & & .01 & 03 & .49 \\
\hline & $\mathrm{N}$ & $\begin{array}{c}50.0 \\
0\end{array}$ & $\begin{array}{c}50.0 \\
0\end{array}$ & $\begin{array}{c}50.0 \\
0\end{array}$ & $\begin{array}{c}50.0 \\
0\end{array}$ & $\begin{array}{c}50.0 \\
0\end{array}$ & $\mid \begin{array}{c}50.0 \\
0\end{array}$ & \begin{tabular}{|l|l}
50.0 \\
0
\end{tabular} & $\begin{array}{c}50.0 \\
0\end{array}$ & $\begin{array}{c}50.0 \\
0\end{array}$ & $\mid \begin{array}{c}50.0 \\
0\end{array}$ & \begin{tabular}{|l|l|}
50.0 \\
0
\end{tabular} & 0.00 & $\begin{array}{c}50.0 \\
0\end{array}$ & 50.00 & 50.00 & $\mid \begin{array}{c}50.0 \\
0\end{array}$ & 50.00 & 50.00 & 50.00 & $\mid \begin{array}{c}50.0 \\
0\end{array}$ & 50.00 & \begin{tabular}{|l|l|} 
\\
\end{tabular} & 50.00 & 50.00 & 50.00 & 50.00 & 50.00 & 50.00 & \begin{tabular}{|l|l}
50.00 \\
\end{tabular} & 50.00 & 50.00 & 50.00 & 50.00 & 50.00 & 50.00 & 50.00 \\
\hline & tition & $-37^{\prime \prime}$ & -.15 & .08 & .09 & $\mid-32{ }^{-}$ & $\mid-03$ & .23 & $.32^{\prime}$ & -.02 & $\mid-.22$ & \begin{tabular}{|l|}
.01 \\
\end{tabular} & \begin{tabular}{|c|}
-.30 \\
\end{tabular} & .06 & .16 & \begin{tabular}{|l|}
$9^{\circ}$ \\
\end{tabular} & $.37^{\prime \prime}$ & $.31^{\prime \prime}$ & .21 & $.28^{\circ}$ & - $-44^{\prime \prime}$ & $\mid .02$ & $-37^{\prime \prime}$ & -.12 & $.26^{\circ}$ & $-30^{\circ}$ & .2 & .08 & $-.60^{-1}$ & \begin{tabular}{|l|l}
.04 \\
\end{tabular} & .08 & \begin{tabular}{|c|}
.09 \\
\end{tabular} & $-36^{\prime \prime}$ & $39^{\prime \prime}$ & .00 & $-30^{\circ}$ & .06 \\
\hline $\begin{array}{l}\text { Ln(MGG- } \\
0.35 \text { ) }\end{array}$ & 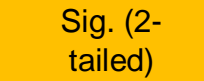 & $\mid .00$ & .29 & .52 & .45 & .03 & .78 & .05 & .02 & .87 & \begin{tabular}{|l|} 
\\
\end{tabular} & .96 & .19 & .69 & .18 & .01 & \begin{tabular}{|l|}
.00 \\
\end{tabular} & .01 & .08 & .02 & .00 & .87 & .00 & .34 & .03 & .01 & .06 & .48 & s & 73 & ร2 & & 00 & . 01 & & 01 & .64 \\
\hline & 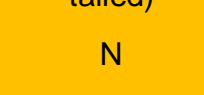 & $\begin{array}{c}71.0 \\
0\end{array}$ & $\begin{array}{c}50.0 \\
0\end{array}$ & $\begin{array}{c}71.0 \\
0\end{array}$ & $\begin{array}{c}71.0 \\
0\end{array}$ & \begin{tabular}{|c|c|c|}
50.0 \\
0
\end{tabular} & $\begin{array}{c}71.0 \\
0\end{array}$ & \begin{tabular}{|c|c|c|}
71.0 \\
0
\end{tabular} & $\begin{array}{c}50.0 \\
0\end{array}$ & $\begin{array}{c}71.0 \\
0\end{array}$ & $\begin{array}{c}71.0 \\
0\end{array}$ & $\begin{array}{l}50.0 \\
0\end{array}$ & $\begin{array}{c}21.0 \\
0\end{array}$ & $\begin{array}{c}50.0 \\
0\end{array}$ & 71.00 & 71.00 & $\mid \begin{array}{c}71.0 \\
0\end{array}$ & 71.00 & 71.00 & 71.00 & \begin{tabular}{|c|}
71.0 \\
0
\end{tabular} & 71.00 & 71.00 & 71.00 & 71.00 & \begin{tabular}{|l|l|}
71.00 \\
\end{tabular} & 71.00 & 71.00 & 71.00 & 71.00 & 71.00 & 71.00 & 71.00 & 50.00 & 71.00 & 71.00 & 71.00 \\
\hline & $\begin{array}{l}\text { Cearson } \\
\text { Corretation }\end{array}$ & \begin{tabular}{|l|}
$.32^{\prime \prime}$ \\
\end{tabular} & \begin{tabular}{|l|}
.14 \\
\end{tabular} & $-35^{\circ}$ & $.25^{\circ}$ & .22 & \begin{tabular}{|l|}
.01 \\
\end{tabular} & $-34^{\prime \prime}$ & \begin{tabular}{l|l|}
.18 \\
\end{tabular} & . .15 & $-.34^{\prime \prime}$ & .11 & $\begin{array}{l}.14 \\
\end{array}$ & .17 & .02 & $-.27^{\prime}$ & \begin{tabular}{|l|}
-02 \\
\end{tabular} & -.12 & -39" & \begin{tabular}{l|}
.18 \\
\end{tabular} & -.15 & -.15 & .18 & $.53^{\prime \prime}$ & $.28^{\circ}$ & .27 & $.55^{\circ}$ & .06 & .05 & $.46^{\prime \prime}$ & 20 & $.40^{\prime \prime}$ & $.39^{\prime \prime}$ & $.30^{\circ}$ & $-30^{\circ}$ & 1.00 & $-36^{\prime \prime}$ \\
\hline $\begin{array}{l}\text { Ln(MOT- } \\
0.7)\end{array}$ & $\begin{array}{c}\text { sig. } \\
\text { taleder) }\end{array}$ & $\mid .01$ & .32 & .00 & .04 & .13 & \begin{tabular}{|l|}
.92 \\
\end{tabular} & .00 & .22 & .21 & \begin{tabular}{|l|} 
\\
\end{tabular} & .43 & .55 & .23 & .88 & .02 & \begin{tabular}{|l|}
.87 \\
\end{tabular} & .30 & .00 & .14 & .22 & .22 & .12 & .00 & .02 & .02 & .00 & .61 & .70 & .00 & .09 & .00 & .00 & .03 & 01 & & .00 \\
\hline & & $\begin{array}{c}71.0 \\
0\end{array}$ & $\begin{array}{c}50.0 \\
0\end{array}$ & $\begin{array}{c}71.0 \\
0\end{array}$ & $\begin{array}{c}71.0 \\
0 \\
0\end{array}$ & $\begin{array}{c}50.0 \\
0\end{array}$ & $\mid \begin{array}{c}71.0 \\
0\end{array}$ & $\begin{array}{c}71.0 \\
0\end{array}$ & $\begin{array}{c}50.0 \\
0\end{array}$ & $\begin{array}{c}71.0 \\
0\end{array}$ & $\begin{array}{c}71.0 \\
0\end{array}$ & \begin{tabular}{|c|c|}
50.0 \\
0
\end{tabular} & $\begin{array}{c}21.0 \\
0\end{array}$ & $\begin{array}{c}50.0 \\
0\end{array}$ & 71.00 & 71.00 & $\mid \begin{array}{c}71.0 \\
0\end{array}$ & 71.00 & 71.00 & 71.00 & $\mid \begin{array}{c}71.0 \\
0\end{array}$ & 71.00 & \begin{tabular}{|l|l|} 
\\
\end{tabular} & 71.00 & 71.00 & \begin{tabular}{|l|l|}
71.00 \\
\end{tabular} & 71.00 & 71.00 & 71.00 & 71.00 & 71.00 & 1.00 & 71.00 & 50.00 & 71.00 & 71.00 & 71.00 \\
\hline & $\begin{array}{l}\text { Pearson } \\
\text { Correlation }\end{array}$ & .22 & . $60^{\circ}$ & $.56^{\prime \prime}$ & $.35^{\prime \prime}$ & .28 & $.36^{\prime \prime}$ & $.69^{\prime \prime}$ & $.53^{\prime \prime}$ & $.46^{\prime \prime}$ & $.56^{\circ}$ & $.34^{\circ}$ & $.63^{\prime \prime}$ & -04 & .22 & .74" & $-.28^{\circ}$ & & $.73^{\prime \prime}$ & $.78^{\prime \prime}$ & $.78^{\prime \prime}$ & \begin{tabular}{|l|l}
$.58^{\prime \prime}$ \\
\end{tabular} & $.50^{\circ}$ & $-31^{\prime \prime}$ & & 800 & .6.64" & .06 & & $-36^{\prime \prime}$ & & $.54^{\prime \prime}$ & .11 & .10 & -.06 & $.36^{\prime \prime}$ & 1.00 \\
\hline 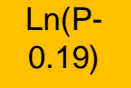 & $\begin{array}{l}\text { Sig., } \\
\text { tailed }\end{array}$ & $\mid .07$ & .00 & .00 & .00 & .05 & \begin{tabular}{|l|}
.00 \\
\end{tabular} & .00 & \begin{tabular}{|l|}
.00 \\
\end{tabular} & .00 & .00 & .01 & .00 & .76 & .07 & .00 & \begin{tabular}{|l|}
.02 \\
\end{tabular} & .00 & .00 & .00 & .00 & .00 & .00 & .01 & .00 & .00 & .00 & .60 & .00 & 00 & .37 & .00 & .37 & .49 & .64 & .00 & \\
\hline & $\mathrm{N}$ & \begin{tabular}{|c|c}
71.0 & \\
0
\end{tabular} & $\begin{array}{l}50.0 \\
0\end{array}$ & $\begin{array}{c}71.0 \\
0 \\
\end{array}$ & $\begin{array}{c}71.0 \\
0\end{array}$ & $\begin{array}{c}50.0 \\
0 \\
0\end{array}$ & $\begin{array}{c}71.0 \\
0\end{array}$ & \begin{tabular}{|c|c}
71.0 \\
0
\end{tabular} & \begin{tabular}{|c|}
50.0 \\
0
\end{tabular} & \begin{tabular}{|l|}
71.0 \\
0
\end{tabular} & $\begin{array}{c}71.0 \\
0\end{array}$ & $\begin{array}{l}50.0 \\
0\end{array}$ & $\begin{array}{c}21.0 \\
0\end{array}$ & \begin{tabular}{|l}
50.0 \\
\end{tabular} & 71.00 & 71.00 & $\begin{array}{c}71.0 \\
0\end{array}$ & 71.00 & 71.00 & 71.00 & $\begin{array}{c}71.0 \\
0\end{array}$ & \begin{tabular}{|l|}
71.00 \\
\end{tabular} & 71.00 & 71.00 & 71.00 & $\begin{array}{l}71.00 \\
\end{array}$ & 71.00 & 71.00 & 71.00 & \begin{tabular}{|l|l} 
& 71.00
\end{tabular} & 71.00 & 71.00 & 71.00 & 50.00 & 71.00 & 71.00 & 71.00 \\
\hline & $\begin{array}{c}\text { Pearlon } \\
\text { Correlation }\end{array}$ & \begin{tabular}{|l|}
$9^{\circ}$ \\
\end{tabular} & .23 & $.52^{\prime \prime}$ & $.71^{\prime \prime}$ & .11 & \begin{tabular}{|l|}
.10 \\
\end{tabular} & $.54^{\prime \prime}$ & $35^{\circ}$ & $-.58^{\prime \prime}$ & $-.65^{\prime \prime}$ & .25 & $.63^{*}$ & \begin{tabular}{|l|l}
.15 \\
\end{tabular} & 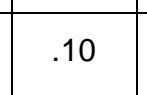 & $-34^{\prime \prime}$ & \begin{tabular}{|l|}
.14 \\
\end{tabular} & .03 & 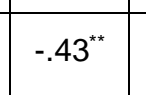 & -.14 & -.07 &.-16 & 31" & $.45^{\prime \prime}$ & -20 & \begin{tabular}{|l|l|}
$-26^{\circ}$ \\
\end{tabular} & 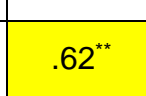 & $.28^{\circ}$ & $-30^{\circ}$ & $7^{\circ " \pi}$ & $-.53^{\prime \prime}$ & $7^{\prime \prime \prime}$ & $.28^{\circ}$ & .07 & .02 & $.56^{\prime \prime}$ & $-31^{\prime \prime}$ \\
\hline 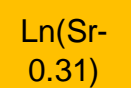 & $\begin{array}{l}\text { Sig. } \\
\text { taled }\end{array}$ & $\mid .01$ & .11 & .00 & .00 & .47 & .39 & .00 & .01 & .00 & \begin{tabular}{|l|}
.00 \\
\end{tabular} & .08 & .00 & .29 & .39 & .00 & .26 & .79 & .00 & .25 & .55 & .1 & .01 & .00 & .09 & .03 & .00 & .02 & .01 & 00 & .00 & 0 & .02 & .64 & .84 & .00 & .01 \\
\hline & N & $\begin{array}{c}71.0 \\
0\end{array}$ & $\begin{array}{c}50.0 \\
0\end{array}$ & $\begin{array}{c}71.0 \\
0\end{array}$ & \begin{tabular}{|c|c|}
71.0 \\
0
\end{tabular} & \begin{tabular}{|c|c|}
50.0 \\
0
\end{tabular} & $\mid \begin{array}{c}71.0 \\
0\end{array}$ & \begin{tabular}{|c|c|c|}
71.0 \\
0
\end{tabular} & $\begin{array}{c}50.0 \\
0\end{array}$ & $\begin{array}{c}71.0 \\
0\end{array}$ & $\mid \begin{array}{c}71.0 \\
0\end{array}$ & \begin{tabular}{|l|l|}
50.0 \\
0
\end{tabular} & $\begin{array}{c}21.0 \\
0\end{array}$ & $\begin{array}{c}50.0 \\
0\end{array}$ & 71.00 & 71.00 & $\left|\begin{array}{c}71.0 \\
0\end{array}\right|$ & 71.00 & 71.00 & 71.00 & $\begin{array}{c}71.0 \\
0\end{array}$ & 71.00 & 71.00 & 71.00 & 71.00 & \begin{tabular}{|l|l|}
71.00 \\
\end{tabular} & 71.00 & 71.00 & 71.00 & \begin{tabular}{|l}
71.00 \\
\end{tabular} & 71.00 & 71.00 & 71.00 & 50.00 & 71.00 & 71.00 & 71.00 \\
\hline & $\begin{array}{l}\text { Pearson } \\
\text { corretation }\end{array}$ & $.78^{\prime \prime}$ & & .15 & .06 & $.74^{\prime \prime}$ & $.62^{\prime \prime}$ & $.52^{\prime \prime}$ & $.56^{\prime \prime}$ & \begin{tabular}{|l|}
.18 \\
\end{tabular} & \begin{tabular}{|l|l}
$0^{\circ}$ \\
\end{tabular} & $.67^{\prime \prime}$ & ${ }^{\circ}$ & .16 & 20 & $.54^{\prime \prime}$ & \begin{tabular}{|l|l|}
$5^{\circ}$ \\
\end{tabular} & $.79^{\prime \prime}$ & \begin{tabular}{|l|l}
$.60^{\prime \prime}$ \\
\end{tabular} & $.75^{\prime \prime}$ & $.84^{\prime \prime}$ & $.53^{\prime \prime}$ & .94 & $-.38^{\prime \prime}$ & $.75^{\prime \prime}$ & . $.79^{\prime \prime}$ & $-.48^{\prime \prime \prime}$ & $-.41^{*}$ & $.94^{\prime \prime}$ & $.70^{\prime \prime}$ & $-.57^{\prime \prime}$ & .25 & $.78^{\prime \prime}$ & $.40^{\prime \prime}$ & -.25 & .21 & $.60^{\prime \prime}$ \\
\hline $\begin{array}{l}\text { Ln(Th- } \\
0.555\end{array}$ & $\begin{array}{l}\text { Sig. } \\
\text { tailed }\end{array}$ & $\mid .00$ & \begin{tabular}{|l|}
.00 \\
\end{tabular} & .29 & .68 & .00 & \begin{tabular}{|l|}
.00 \\
\end{tabular} & .00 & .00 & .21 & .00 & .00 & & .28 & .15 & .00 & \begin{tabular}{|l|}
.00 \\
\end{tabular} & .00 & .0 & & .00 & 00 & .00 & & & .00 & .00 & & & & & & & .00 & & & \\
\hline & & $\begin{array}{c}50.0 \\
0\end{array}$ & $\begin{array}{c}50.0 \\
0\end{array}$ & $\begin{array}{c}50.0 \\
0\end{array}$ & $\begin{array}{c}50.0 \\
0\end{array}$ & \begin{tabular}{|c|}
50.0 \\
0
\end{tabular} & $\left|\begin{array}{c}50.0 \\
0\end{array}\right|$ & \begin{tabular}{|l|}
50.0 \\
0
\end{tabular} & $\begin{array}{c}50.0 \\
0\end{array}$ & \begin{tabular}{|c|}
50.0 \\
0
\end{tabular} & $\left|\begin{array}{c}50.0 \\
0\end{array}\right|$ & \begin{tabular}{|c|}
50.0 \\
0
\end{tabular} & \begin{tabular}{|l|l|} 
& 0.00 \\
\end{tabular} & $\begin{array}{c}50.0 \\
0\end{array}$ & 50.00 & 50.00 & $\left|\begin{array}{c}50.0 \\
0\end{array}\right|$ & 50.00 & 50 & $50 \mid$ & $\mid$\begin{tabular}{c|c}
50.0 \\
0
\end{tabular} & 50.00 & \begin{tabular}{|l|}
50.00 \\
\end{tabular} & 50.00 & 50.00 & $\begin{array}{l}50.00 \\
\end{array}$ & 50.00 & 50.00 & 50.00 & 50.00 & 50.00 & 50.00 & 50.00 & 50.00 & $\begin{array}{l}50.00 \\
\end{array}$ & 50.00 & 50.00 \\
\hline & $\begin{array}{c}\text { Pearson } \\
\text { Corretation }\end{array}$ & \begin{tabular}{|l|}
.27 \\
\end{tabular} & $.35^{\circ}$ & -.16 & $-37^{\prime \prime}$ & $\begin{array}{ll}32^{\circ} \\
\end{array}$ & \begin{tabular}{|l|}
.14 \\
\end{tabular} & $.31^{\circ}$ & $.43^{\prime \prime}$ & \begin{tabular}{|l|}
.21 \\
\end{tabular} & \begin{tabular}{|l|}
.00 \\
\end{tabular} & $.60^{\prime \prime}$ & & \begin{tabular}{|l|l|}
.16 \\
\end{tabular} & .08 & .24 & \begin{tabular}{|l|}
-.06 \\
\end{tabular} & $.64^{\prime \prime}$ & $.37^{\prime \prime}$ & \begin{tabular}{|l|l}
$.52^{\prime \prime}$ \\
\end{tabular} & $.71^{\prime \prime}$ & .07 & $.64^{\prime \prime}$ & \begin{tabular}{|c|}
.12 \\
\end{tabular} & . $47^{\prime \prime}$ & \begin{tabular}{|l|l|}
$4^{\prime \prime}$ \\
\end{tabular} & . $49^{\prime \prime}$ & $.38^{\prime \prime}$ & .63 & $.68^{\circ "}$ & . $49^{\prime \prime}$ & .20 & .31' & .00 & $-.29^{\circ}$ & .15 & $43^{\prime \prime}$ \\
\hline 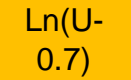 & $\begin{array}{l}\text { Sig. (2-1) } \\
\text { tatele) }\end{array}$ & \begin{tabular}{|l|}
.06 \\
\end{tabular} & .01 & .28 & .01 & .02 & \begin{tabular}{|l|}
35 \\
\end{tabular} & .03 & .00 & .15 & \begin{tabular}{|l|}
.98 \\
\end{tabular} & .00 & & .26 & .58 & .10 & \begin{tabular}{|l|}
.68 \\
\end{tabular} & .00 & .01 & .00 & 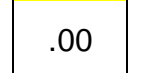 & .63 & .00 & .41 & .00 & .00 & 00 & & & & .00 & 16 & .03 & .98 & 04 & 29 & .00 \\
\hline & N & \begin{tabular}{|l|}
50.0 \\
0
\end{tabular} & $\begin{array}{c}50.0 \\
0\end{array}$ & $\begin{array}{c}50.0 \\
0\end{array}$ & $\begin{array}{c}50.0 \\
0\end{array}$ & $\begin{array}{c}50.0 \\
0\end{array}$ & $\mid \begin{array}{c}50.0 \\
0\end{array}$ & $\begin{array}{c}50.0 \\
0\end{array}$ & $\begin{array}{c}50.0 \\
0\end{array}$ & \begin{tabular}{|c|}
50.0 \\
0
\end{tabular} & $\mid \begin{array}{c}50.0 \\
0\end{array}$ & $\begin{array}{c}50.0 \\
0\end{array}$ & 0.00 & $\begin{array}{c}50.0 \\
0\end{array}$ & 50.00 & 50.00 & $\begin{array}{c}50.0 \\
0\end{array}$ & 50.00 & 50.00 & 50.00 & $\mid \begin{array}{c}50.0 \\
0\end{array}$ & 50.00 & \begin{tabular}{|l|}
50.00 \\
\end{tabular} & 50.00 & 50.00 & $\begin{array}{l}50.00 \\
\end{array}$ & 50.00 & 50.00 & 50.00 & \begin{tabular}{|l}
50.00 \\
\end{tabular} & 50.00 & 50.00 & 50.00 & 50.00 & 50.00 & \begin{tabular}{|l|l} 
& 50.00 \\
\end{tabular} & 50.00 \\
\hline & $\begin{array}{l}\text { arson } \\
\text { elatioion }\end{array}$ & \begin{tabular}{|l|}
.18 \\
\end{tabular} & $.30^{\circ}$ & .02 & $.61^{\prime \prime}$ & .19 & \begin{tabular}{|l|}
.07 \\
\end{tabular} & .19 & \begin{tabular}{l|l|}
.18 \\
\end{tabular} & $.51^{\prime \prime}$ & \begin{tabular}{|l|}
.27 \\
\end{tabular} & \begin{tabular}{l|l|}
.16 \\
\end{tabular} & & .12 & .19 & .02 & \begin{tabular}{|l|}
-.10 \\
\end{tabular} & .10 & .02 & .07 & .11 & .16 & .12 & .19 & \begin{tabular}{|l|}
.02 \\
\end{tabular} & 0.02 & $.37^{\prime \prime}$ & .09 & .2 & .01 & .18 & .27 & .23 & .18 & .00 & . $49^{\prime \prime}$ & \\
\hline $\begin{array}{l}\text { Lntw } \\
0.9)\end{array}$ & $\begin{array}{l}\text { Sig., (2-) } \\
\text { tailed) }\end{array}$ & .21 & .04 & .90 & .00 & .18 & \begin{tabular}{|l|}
.61 \\
\end{tabular} & .18 & .21 & \begin{tabular}{|l|}
.00 \\
\end{tabular} & \begin{tabular}{|l|}
.06 \\
\end{tabular} & .28 & & .42 & .20 & .89 & \begin{tabular}{|l|}
.47 \\
\end{tabular} & .49 & .90 & .65 & $\mid .45$ & .26 & .40 & .18 & .86 & .87 & .01 & .53 & .09 & .94 & 21 & .06 & .11 & .22 & .99 & .00 & .61 \\
\hline & $\mathrm{N}$ & \begin{tabular}{|l|l|}
50.0 \\
0
\end{tabular} & 50.0 & $\begin{array}{c}50.0 \\
0\end{array}$ & 50.0 & 50.0 & \begin{tabular}{|c|}
50.0 \\
0
\end{tabular} & 50.0 & 50.0 & $\begin{array}{c}50.0 \\
0\end{array}$ & \begin{tabular}{|c|}
50.0 \\
0
\end{tabular} & \begin{tabular}{|l|}
50.0 \\
\end{tabular} & 0.00 & $\begin{array}{l}50.0 \\
0\end{array}$ & 50.00 & \begin{tabular}{|l|l|} 
& 50.00 \\
\end{tabular} & \begin{tabular}{|c|}
50.0 \\
0
\end{tabular} & 50.00 & 50.00 & 50.00 & \begin{tabular}{|l|}
50.0 \\
0
\end{tabular} & 50.00 & \begin{tabular}{|l|}
50.00 \\
\end{tabular} & \begin{tabular}{|l|l|} 
& 50.00 \\
\end{tabular} & 50.00 & 50.00 & | 50.00 & 50.00 & 50.00 & 50.00 & 50.00 & 50.00 & 50.00 & 50.00 & | 50.00 & 50.00 & 50.00 \\
\hline
\end{tabular}

